Márcio Marques da Silva

\title{
PROTÓTIPO DE UMA PLATAFORMA PARA SOFTWARE DE CÁLCULOS PARA OTIMIZAÇÃO DA TRAJETÓRIA DE FIBRAS EM REVESTIMENTO DE MATERIAIS COMPÓSITOS.
}

\begin{abstract}
Dissertação apresentada à Escola de Engenharia de São Carlos da Universidade de São Paulo, como parte dos requisitos para a obtenção do Título de Mestre em Engenharia Mecânica.
\end{abstract}

Orientador: prof. Dr. Jonas de Carvalho

São Carlos 


\section{DEDICATÓRIA}

Dedico este trabalho a Deus em primeiro lugar pelo qual nada seria possível, ao meu orientador Prof. Dr. Jonas de Carvalho, sem o qual não teria conseguido êxito e à minha família que tem me incentivado e dado força nas horas mais difíceis. 


\section{AGRADECIMENTOS}

Ao Prof. Dr. Jonas de Carvalho, orientador, meu respeito e admiração, pela oportunidade, incentivo e por um ambiente de estudo formidável.

Aos meus amigos de laboratório e disciplinas que contribuíram e incentivaram para que fosse possível esta conquista.

Aos amigos e colegas envolvidos direta e indiretamente neste trabalho, Geraldo, Romeu, Amauri, Canto, Volnei e Márcio.

E, principalmente, a Deus pelo seu eterno Amor e dom da Vida. 


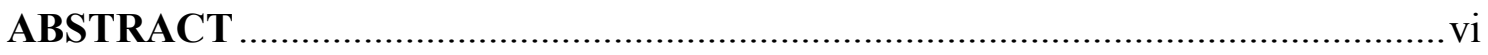

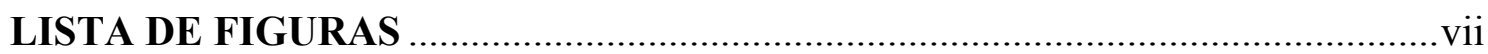

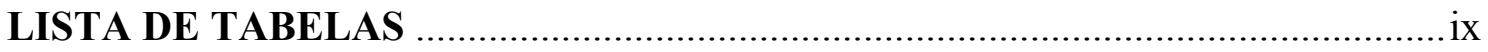

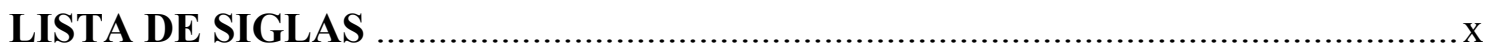

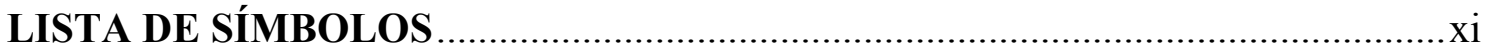

CAPÍTULO 1

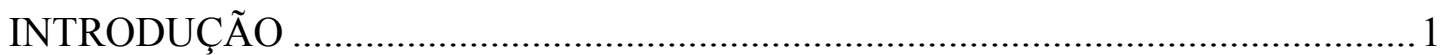

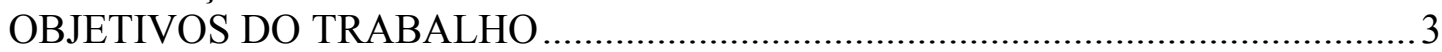

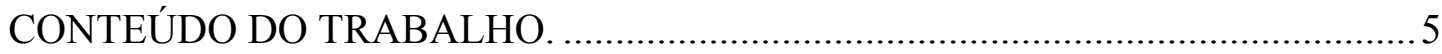

2.1 EVOLUÇÃO DOS MATERIAIS REFORÇADOS POR FIBRAS .......................6

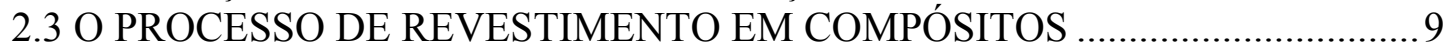

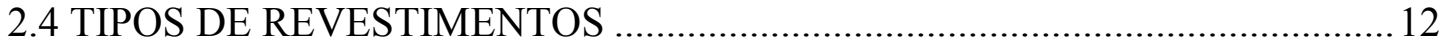

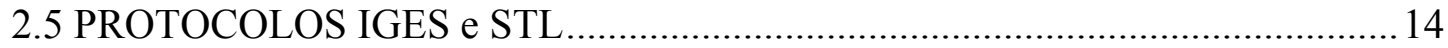

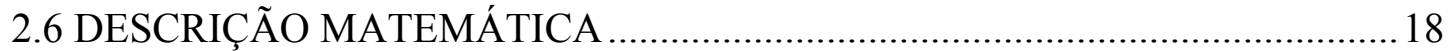

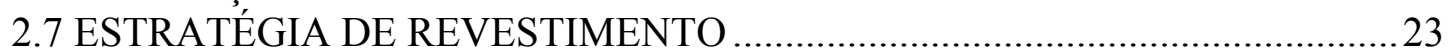

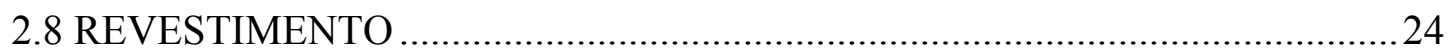

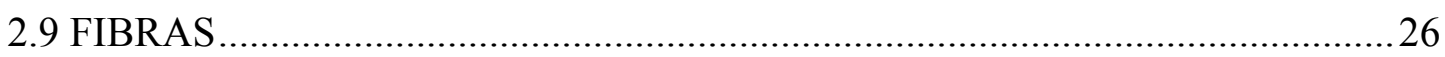

2.10 INTERFACE ENTRE A FIBRA E A MATRIZ …....................................... 28

3.3 CÁLCULO DA TRAJETÓRIA DA FIBRA …................................................56

3.3.1 CÁLCULO DO PRIMEIRO QUADRANTE .........................................................58

3.3.2 CÁLCULO DA TRAJETÓRIA DA FIBRA ATÉ O COMPRIMENTO DO

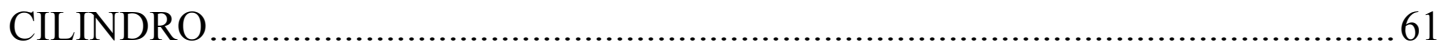

3.3.3 CÁLCULO DA TRAJETÓRIA APÓS O GIRO DE 180 GRAUS ....................63

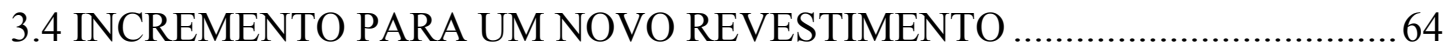

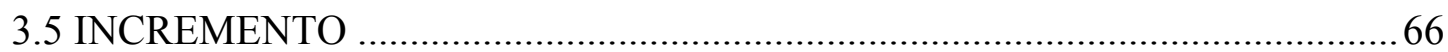

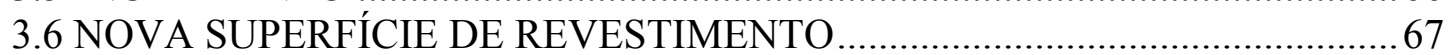

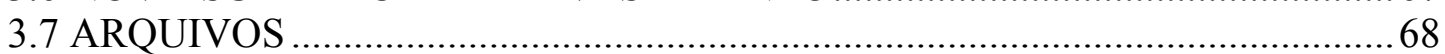

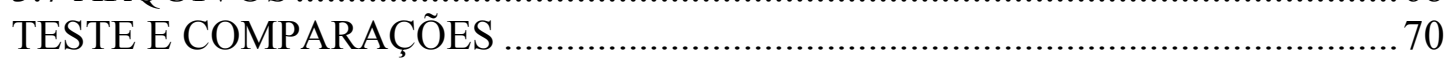

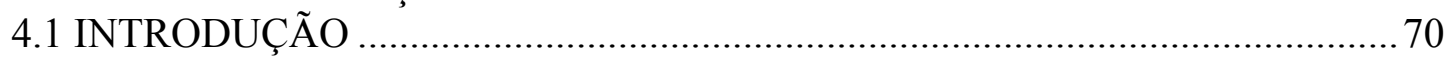

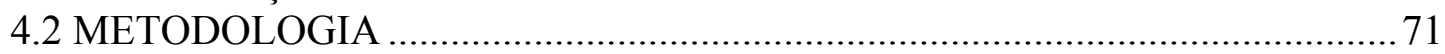

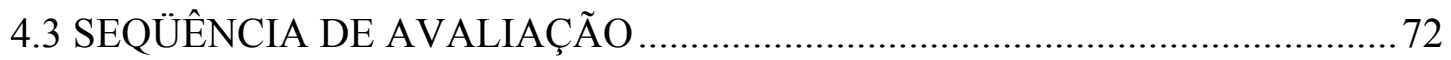

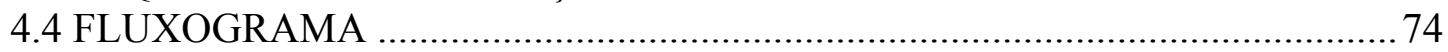

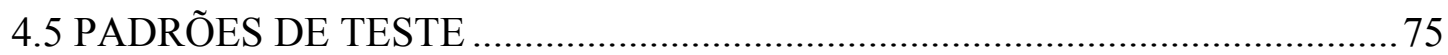

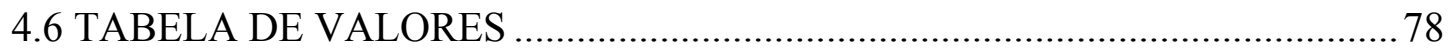

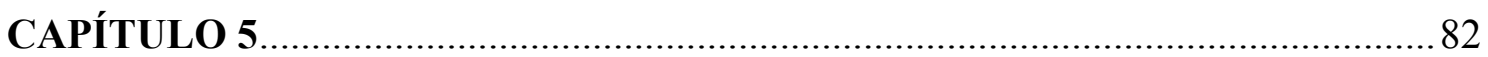




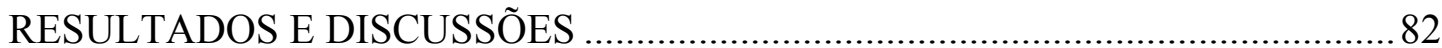

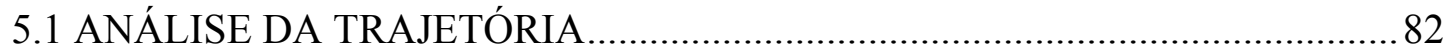

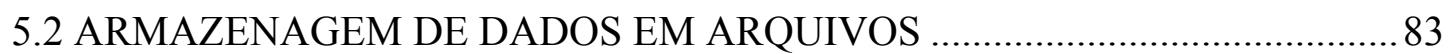

5.3 ANÁLISE DOS VALORES DOS DADOS …............................................... 84

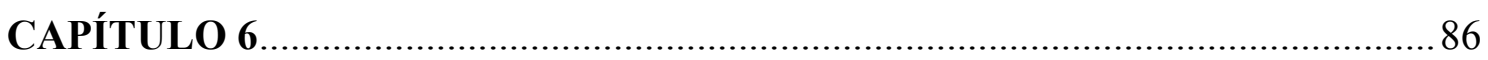

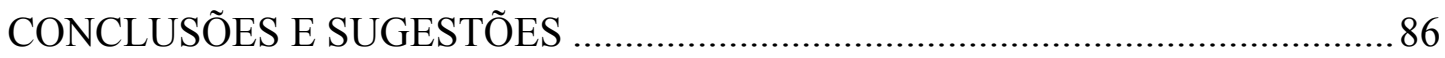

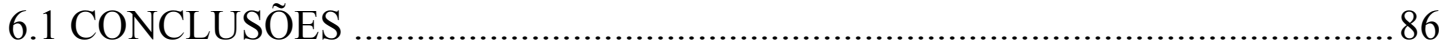

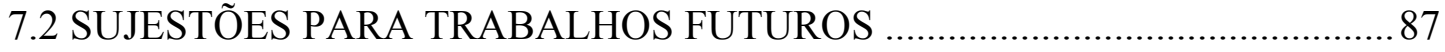

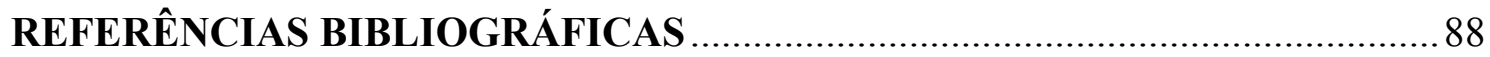




\section{RESUMO}

SILVA, M. M. (2004) Protótipo de uma plataforma para software de cálculos para otimização da trajetória de fibras em revestimento de materiais compósitos. Dissertação (Mestrado) - Escola de Engenharia de São Carlos, Universidade de São Paulo, São Carlos, 2005.

Na busca de novos materiais que possuam boa resistência mecânica, baixo peso e de fácil manufatura, surgem os compósitos e os compósitos reforçados direcionando a uma ampla área de aplicações e estudos em desenvolvimento. Os materiais compósitos têm um vasto campo de aplicação, porém quando sujeitos a maiores esforços, não apresentam grande resistência e bom desempenho frente aos materiais metálicos. Os materiais compósitos quando reforçados com fibras multiplicam sua resistência consideravelmente, tornando-se um excelente substituto de materiais que possuem boa resistência mecânica como os metais, sendo um material resistente à oxidação. Em muitos casos os compósitos reforçados substituem os metais com um desempenho superior, como exemplo a aplicação de materiais reforçados com fibra de carbono. Este trabalho tem como objetivo criar uma plataforma para o desenvolvimento de um software para o cálculo otimizado das trajetórias das fibras em materiais compósitos, com fibras que venham a reforçar o mesmo e que venham a ser utilizados pela comunidade em diversas áreas como mecânica, medicina, elétrica, entre várias outras.

Palavras-chave: Compósito; fibras; revestimento; linguagem C++; otimização. 


\section{ABSTRACT}

SILVA, M. M. (2004) Prototype of a platform to software of calculation to optimization of path of fibers in covering in compound materials. M. Sc. Dissertation Escola de Engenharia de São Carlos, Universidade de São Paulo, São Carlos, 2005.

In the search of new materials, which have good mechanic strength, low weight and easy manufacturing, appear the composites and reinforced composites leading to an ample area of applications and studies in development. The composites materials have a vast field of application, however when subjected to a bigger effort, they do not show a great strength and a good development when compared to metallic materials. The composites materials when reinforced with fibers multiply their strength considerably, becoming an excellent substitute of materials, which have mechanic strength like metals, which in a strong material to corrosion. In many cases, the reinforced composites substitute the metals with a higher development, for example, like applications of reinforced materials with carbon fiber. This production has to objective, to create a platform to development of a software to a calculation optimization of course the fibers in a composite material, using fibers that come to reinforce it and are able to used by the community in many areas like mechanic, medicine, electric and among others.

KEYWORDS: Composites; fibers; covering; language $\mathrm{C}++$; optimization. 


\section{LISTA DE FIGURAS}

Figura 1 - Exemplo de carbono encontrado em grafite e diamante............................... 8

Figura 2- Estrutura molecular do nanotubo de carbono................................................. 9

Figura 3 Exemplo de Revestimento com Fibra (SCHOLLIERS, 1992)....................... 10

Figura 4 Exemplo de tipos de revestimento (CARVALHO, 1996).............................. 14

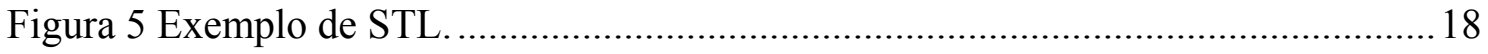

Figura 6 Vetores das forças que atuam na superfície da peça durante o processo de revestimento.

Figura 7 Estratégia de revestimento (CARVALHO, 1996) .........................................24

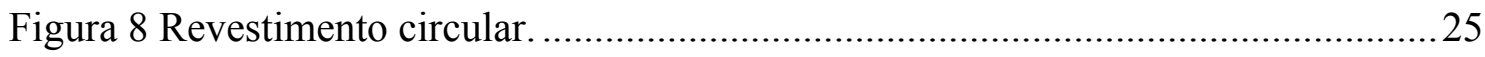

Figura 9 Efeito da deformação ao redor da fibra na matriz sob tensão: (a) fibra contínua; (b) fibra descontínua (MATHEUWS \& RAWLINGS, 1994). ..............................27

Figura 10 Exemplo de revestimento umedecido por resina (wet filament). ..................29

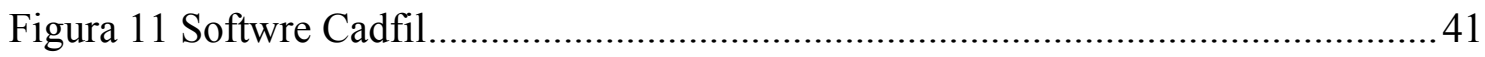

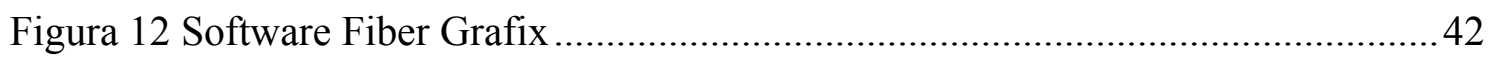

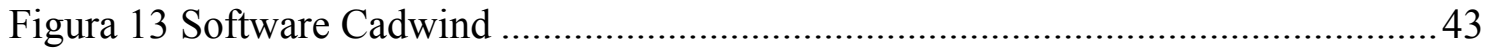

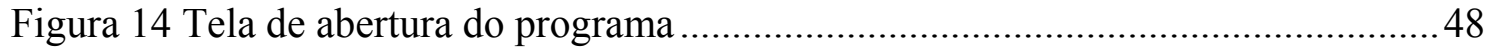

Figura 15 Menu do evento para escolha da fibra...................................................... 49

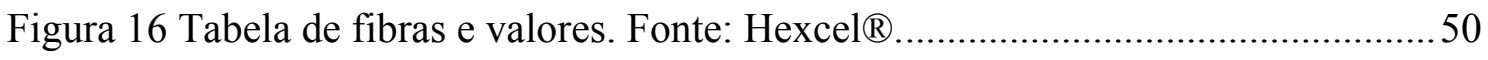

Figura 17 Menu para escolha do revestimento de um cilindro. ...................................51

Figura 18 Tela dos valores do cilindro e dos resultados dos cálculos. .........................52

Figura 19 Ilustração um exemplo de erro quando o usuário fornece um valor para passo ou ângulo que ultrapasse o limite de comprimento ou esteja fora da janela de zero a 90 graus. 53

Figura 20 Botão Primeiro Quadrante habilitado. 54 
Figura 21 Valores do primeiro quadrante e valor para passo ou ângulo Alfa. 55

Figura 22Valores dos demais quadrantes para todo o revestimento. 55

Figura 23 Pontos calculados que formarão uma trajetória para a fibra. .57

Figura 24 Referência e sentido adotado para os cálculos do programa. 58

Figura 25 Divisões dos pontos do eixo Y. 59

Figura 26 Valor do ponto $\mathrm{Z}$ tendo como base o ponto $\mathrm{Y}$ e o raio. 60

Figura 27 Ilustração de um cilindro com a opção de pinos e com a opção de aumentar o comprimento do cilindro.

Figura 28 Estratégia do uso de pinos e do aumento do comprimento útil do cilindro....63

Figura 29 Desenho ilustrativo de uma fita contendo fios e filamentos. 65

Figura 30 Incremento formado pela largura da fita. 67

Figura 31 Cilindro revestido com várias camadas de fibra 68

Figura 32 Trajetória da fibra ao longo do cilindro. 79

Figura 33 Volta de 180 graus no final do cilindro. 80

Figura 34 Trajetória da fibra de volta ao topo inicial...... 80

Figura 35 Giro de 180 graus no topo inicial mais incremento. .81 


\section{LISTA DE TABELAS}

Tabela 1 Ilustração do histórico das fibras com o passar dos anos..................................

Tabela 2 Valor das indicações fornecidas pela entidade 126 e o formato das “Splines". 17

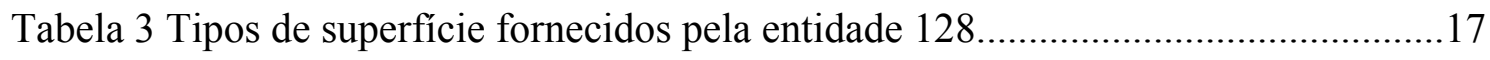

Tabela 4 Disposição dos valores para a planilha.......................................................69 


\section{LISTA DE SIGLAS}

$\begin{array}{ll}\text { ABNT } & \text { Associação Brasileira de Normas Técnicas } \\ \text { EESC } & \text { Escola de Engenharia de São Carlos } \\ \text { USP } & \text { Universidade de São Paulo } \\ \text { MCRF } & \text { Materiais Compósitos Reforçados por Fibras } \\ \text { CAD } & \text { Computer Aided Desing (Projeto Auxiliado por } \\ & \text { Computador) } \\ \text { IGES } & \text { Initial Graphics Exchanges Specification (Especificação } \\ \text { Inicial de Intercâmbio de Gráficos) } \\ \text { Standard Triagulation Language (Linguagem Padrão de } \\ \text { Triangularização). } \\ \text { Orientado a Objetos. } \\ \text { DOS } & \text { Disk Operating System (Sistema Operacional rodando em } \\ & \text { Disco). } \\ & \text { Linguagem de Modelagem Unificada }\end{array}$




\section{LISTA DE SÍMBOLOS}

\begin{tabular}{|c|c|}
\hline$\Gamma(s)$ & Trajetória da fibra na superfície da peça \\
\hline$\vec{n}$ & Direção do força normal \\
\hline$\vec{f}_{b}$ & Força transversal \\
\hline$p$ & Trajetória da fibra \\
\hline$\vec{f}_{t}$ & Tensão da fibra \\
\hline$\vec{f}_{n}$ & Força normal \\
\hline $\overrightarrow{f_{r}}$ & Força de revestimento \\
\hline$\vec{t}$ & Tangente \\
\hline$\vec{c}$ & Curvatura do vetor \\
\hline$\vec{b}$ & Binormal \\
\hline$S(u, v)$ & Superfície da peça \\
\hline Q & Valor para a curva Spline \\
\hline $\mathrm{R}$ & Raio da peça a ser revestida \\
\hline$\alpha$ & $\begin{array}{l}\text { Ângulo formado entre a trajetória da fibra e o eixo de } \\
\text { simetria da peça revestida }\end{array}$ \\
\hline$\beta$ & $\begin{array}{l}\text { Ângulo formado pelos pontos no eixo } \mathrm{Y} \text { e } \mathrm{Z} \text { durante o } \\
\text { processo de revestimento }\end{array}$ \\
\hline$\lambda$ & Tendência ao deslizamento \\
\hline $\mathrm{N}$ & Número de revoluções do revestimento \\
\hline
\end{tabular}


Comprimento da seção transversal da circunferência

w

$l_{c}$

$\sigma_{f}$

$\tau_{f}$

d

$d c$

$\mathrm{V}$

$\mathrm{m}$

$\mathrm{D}$

h

S

nfil

dfil

nY

pr

$\mathrm{P}$

Passo
Largura da fita ou diâmetro do fio

Comprimento crítico da fibra

Resistência à tração na ruptura da fibra

Menor resistência ao cisalhamento da matriz ou da interface

Diâmetro da secção transversal do fio da fibra

Diâmetro do cilindro após revestimento

Volume

Massa

Densidade

Comprimento da fibra

Área equivalente do fio da fibra

Número de filamentos

Diâmetro do filamento

Número de divisões do eixo Y

Precisão fornecida pelo programa

Perímetro da circunferência

Distância entre dois pontos numa volta de 360 graus na trajetória da fibra 


\section{CAPÍTULO 1}

\section{INTRODUÇÃO}

O Revestimento de materiais compósitos ("Filament Winding”) ou processo de bobinagem (vide página 7) consiste no processo de fabricação de materiais compósitos reforçados por fibras (vidro, aramida, carbono) impregnadas com resinas, com uma trajetória definida sobre uma superfície de um compósito tendo como objetivo aumentar a resistência, rigidez e resistência à corrosão do compósito.

Os materiais compósitos de matriz polimérica surgiram em meados do século XX. Os desafios permanentes que estes materiais colocam à imaginação levam a estudos e esforços concentrados em sua aplicação e desempenho obtidos cada vez mais exigentes.

Materiais compósitos podem ser definidos como a união química ou mecânica de dois ou mais materiais com diferentes propriedades de maneira a gerar um produto final com características físico-químicas superiores às iniciais individuais (CARVALHO, 1996). 
Segundo Carvalho (1996), o desempenho superior, a resistência à corrosão e a baixa densidade são umas das características marcantes dos compósitos já testados e aprovados pela engenharia.

Materiais compósitos são conhecidos pela excelente combinação de alta resistência mecânica e baixo peso (CARVALHO, 1996).

Os avanços tecnológicos dos últimos anos e os estudos na direção da substituição de peças e estruturas metálicas por materiais compósitos têm viabilizado seu uso crescente e têm causado impactos positivos na comunidade. A previsão para os materiais compósitos é que sua aplicação não seja limitada apenas em áreas como a aviação, aeroespacial e militar, mas em outras áreas mais próximas à comunidade como engenharia civil, medicina, automotiva, etc.

O processo tradicional de manufatura de materiais compósitos revestidos tem se aperfeiçoado ao longo dos anos. A necessidade de novas geometrias, otimização de trajetórias para as fibras, projetos mais exigentes e o crescente uso de materiais compósitos nas mais variadas áreas de aplicação, tem tornado obrigatório um estudo para otimizar o revestimento em materiais compósitos para a obtenção das mais variadas formas com alta resistência mecânica e com menor custo de manufatura.

A tecnologia de manufatura tem sido expandida para incluir uma completa gama de novos processos, com todos os aspectos correlatos envolvidos como parâmetros de processo, inspeção de materiais e controle de qualidade (CARVALHO, 1996). 
Algumas máquinas foram desenvolvidas para a manufatura de materiais compósitos revestidos como, máquinas $\mathrm{CNC}$, tornos convencionais e outras dedicadas. Segundo Carvalho (1996) uma boa máquina de revestimento de materiais compósitos deve ser capaz de revestir um compósito dentro de um programa que otimize as trajetórias de seus componentes de forma que haja o mínimo desvio entre a trajetória calculada e a trajetória real executada pela máquina.

Dentro deste contexto, é apresentado o Software Cawar, desenvolvido por Schillers (1992) e aprimorado por Carvalho (1996), escrito em C e sendo executado em DOS, é uma ferramenta para o cálculo da trajetória das fibras durante o revestimento dos materiais compósitos com o objetivo de otimizar todo o processo de manufatura. Neste trabalho, será iniciado uma plataforma para a programação de um novo software similar ao Cawar, mas que será escrito em $\mathrm{C}++$ e executado em ambiente Windows.

\section{OBJETIVOS DO TRABALHO}

Materiais compósitos revestidos têm se tornado comum no cotidiano da engenharia. Atualmente existem poucas máquinas dedicadas a este tipo de trabalho no Brasil. Poucos programas são encontrados para o auxílio à otimização da trajetória das fibras e do movimento dos componentes das máquinas para este fim.

Alguns softwares desenvolvidos para este fim encontrados como:

- $\quad$ CadFil da Crescent Consultants Limited

- $\quad$ Fiber Grafix da Entec Composites Machines

- CadWind da Pattern Master 
No Brasil não há uma empresa específica no ramo de programas para computadores para materiais compósitos revestidos. Alguns fatores que levam a não existência deste ramo são: A falta de estudos dessa tecnologia no país, a maior parte destes materiais compósitos é importado por empresas especializadas em materiais compósitos revestidos; o Brasil não produz fibra de carbono, os únicos países produtores da fibra de carbono são: EUA, Alemanha, Inglaterra, França e Japão; A dificuldade de importar fibras de carbono, necessitando de liberação do exército brasileiro.

Embora o mercado brasileiro utilize muito o compósito reforçado em diversas áreas como na medicina (órteses), na aeroespacial (partes e componentes de aviões), na indústria química (vasos de pressão), entre várias outras áreas, não há um grande produtor interno devido a poucos estudos realizados no país.

O propósito deste trabalho é:

1- Apresentar um protótipo de uma plataforma para o desenvolvimento de um software para o cálculo da trajetória da fibra, conhecendo a superfície que será revestida.

2- Incentivar o estudo do uso de materiais compósitos em pesquisas e projetos mecânicos.

3- Incentivar o desenvolvimento de novos materiais que venham a substituir a aplicação de vários materiais metálicos com o objetivo de redução de peso e ganhos em resistência mecânica e à oxidação.

4- $\quad$ Preparar uma plataforma que seja flexível a alterações e modificações futuras com relação à programação. 
As fases para a conquista deste objetivo são apresentadas:

- Estudar os softwares e teses já desenvolvidas para este assunto;

- Definir uma linguagem de programação para escrever o código fonte do software para revestimento de materiais compósitos com fibras;

- Testar os valores obtidos pelo programa a fim de conferir os resultados;

- Apresentar uma plataforma que tenha uma interface gráfica amigável com o usuário e que seja flexível a alterações e inclusão de novos módulos de programa;

\section{CONTEÚDO DO TRABALHO.}

Este trabalho foi organizado de forma a apresentar a seqüência dos temas necessários para o seu desenvolvimento, abordando o método sistemático de manufatura de materiais compósitos revestidos, as novas tecnologias, os recursos computacionais disponíveis, pesquisas baseadas em material didático relacionado ao assunto, programação, testes e avançando até a conclusão do tema proposto.

1. Desenvolvimento de um software para auxílio ao cálculo das trajetórias - apresenta-se à estrutura de desenvolvimento do software CAWAR orientada a objetos, módulos de cálculo, concepção do sistema, resultados e interface.

2. Conclusões e propostas - verifica se o objetivo do trabalho foi alcançado, suas limitações e trabalhos futuros.

3. Bibliografia citada - lista as literaturas utilizadas de fundamento para o desenvolvimento do trabalho. 


\section{CAPÍTULO 2}

\section{REVISÃO BIBLIOGRÁFICA}

\subsection{EVOLUÇÃO DOS MATERIAIS REFORÇADOS POR FIBRAS}

Observa-se na história da humanidade, que dentre as diversas maneiras de avaliação do padrão de vida de um país ou sociedade, o consumo de materiais de engenharia por indivíduo, disponíveis em formas de bens e serviços, pode ser uma das mais explícitas. Os bens manufaturados querem sejam de consumo ou produção, são obtidos por meio da conversão dos materiais de engenharia, adicionando-lhes valor. A história tem demonstrado que quanto mais eficientemente os sistemas de produção são capazes de realizar esta conversão, maior será o padrão de vida da sociedade. No ano 2000 a.C., isto foi determinado pelo consumo de pederneira ${ }^{1}$, utilizada como ferramenta de corte. Em torno de 1500 a.C., a tonelada de bronze, provavelmente, revelou quem eram as potências mundiais; e recentemente, por volta de 1850 d.C., teria sido o aço, seguido pelas ligas leves (no projeto de aviões) e as superligas (para motores a jato). Então, no final de 1963, uma série de experiências na Royal Aircraft Establishment em 
Farnborough, na Inglaterra, levou a descoberta, em meados de 1964, das fibras de carbono de alta resistência e alta rigidez e dos seus materiais compósitos.

${ }^{1}$ Pederneira é uma pedra composta de sílica cristalizada (quartzo) e sílica hidratada (opala) de alta dureza que quando submetida ao atrito com material metálico, produz o lume(faísca).

Nas duas décadas seguintes, a produção de materiais compósitos reforçados por fibras (MCRF) cresceu a uma taxa desfrutada apenas pelo aço até o seu apogeu.

Sem dúvida, presencia-se atualmente uma revolução dos materiais de engenharia. No início, o grande estímulo à produção de MCRF, estava relacionado à característica de combinar alta resistência e/ou rigidez com baixo peso específico, o que conferia uma grande eficiência estrutural (FILHO, 2001).

Tijolos de barro reforçados por palhas

Arcos laminados de madeira, tendões de animais e seda

Superfícies de aviões revestidas por tecidos

Fenólicos reforçados por tecidos

Plásticos reforçados por fibra de vidro

Fibras de boro e de carbono e seus compósitos

Aramida (Kevlar 49®) e seus compósitos
Egito, 800 a.C.

Mongólia, 700 a.C.

década de 10

década de 30

década de 40

década de 60

década de 70

Tabela 1 Ilustração do histórico das fibras com o passar dos anos. 


\subsection{FIBRAS DE CARBONO}

As fibras carbônicas ou fibras de carbono são matérias primas que provém da pirólise de materiais ricos em carbono que produzem filamentos de alta resistência mecânica usados para os mais diversos fins, entre estes, motores de naves espaciais.

Durante o século XX foram desenvolvidos diversos materias fibrosos de carbono e grafita. Estes têm desempenhado um papel importante no crescimento do desenvolvimento tecnológico humano.

O carbono possui propriedades refratárias excepcionais, sua temperatura de vaporização chega aos $3.700^{\circ} \mathrm{C}$, e sua resistência às modificações químicas e físicas é bastante grande mesmo em altas temperaturas.

Para a produção de fibras de carbono o método utilizado é chamado pirólise, a decomposição de um material, ou seja, ocorre a ruptura da estrutura molecular de um determinado material composto rico em carbono, provocado pelo calor, e o material retém a sua forma fibrosa através de tratamentos térmicos que resultam em carbonização com alto resíduo de carbono.

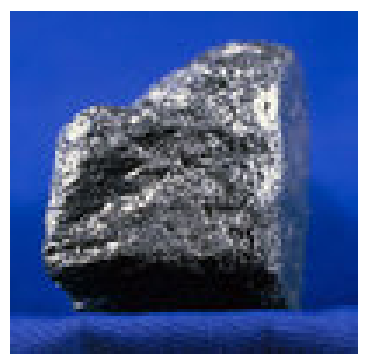

Carbono encontrado na grafite

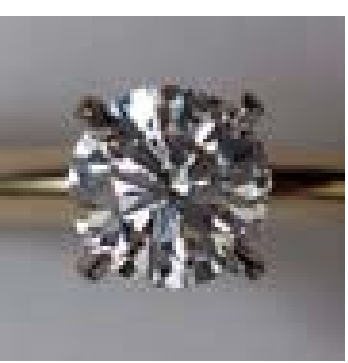

Carbono encontrado no diamante

Figura 1 - Exemplo de carbono encontrado em grafite e diamante. 
Em meados de 1950 iniciaram os estudos para fibras mais resistentes e em 1960 surgiram as primeiras fibras de alta resistência à tração e tensão. Uma destas fibras é a fibra de poliacrilonitrila ou mais conhecida como fibra "PAN", largamente utilizada em aplicações onde o projeto exige peças de alta resistência mecânica. A mais recente pesquisa na evolução das fibras de carbono tem direcionado para os nanotubos de carbono. Fibras cuja estrutura molecular se apresenta em forma de cilindro. Estas fibras tem sido testadas na confecção de roupas à prova de bala.
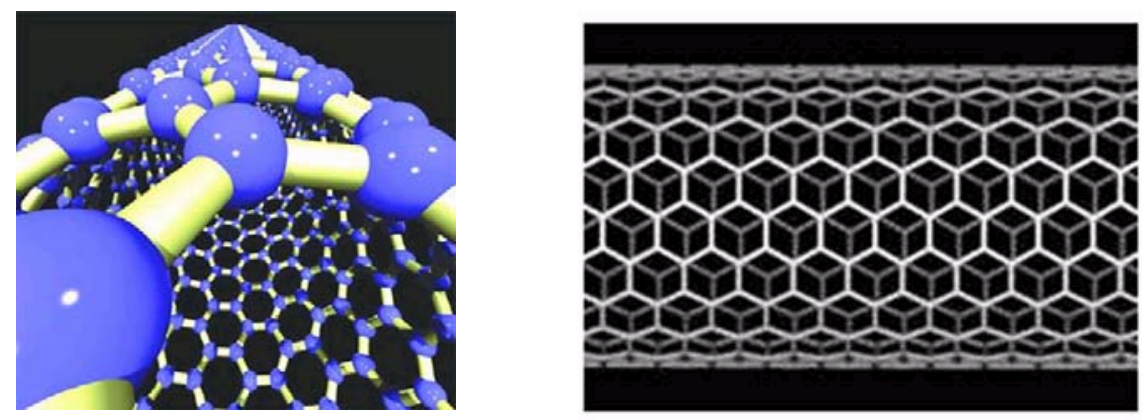

Figura 2- Estrutura molecular do nanotubo de carbono.

\subsection{O PROCESSO DE REVESTIMENTO EM COMPÓSITOS}

O processo de revestir materiais compósitos surgiu com a necessidade de materiais com maior resistência mecânica, mais leves e mais resistentes a corrosão. No início deste processo, era restrita a indústria aeronáutica, com o passar do tempo, a necessidade da indústria automobilística, a pesquisa no campo de novos materiais que viessem a satisfazer os desafios de outras áreas, os materiais compósitos revestidos começou a ser mais difundido e utilizado.

Scholliers (1992) descreve o processo de revestimento de compósitos como: "Processo de fabricação de estruturas compostas revestidas com fibras reforçadas na qual a fibra é impregnada continuamente com resina e guiada através de um olho em 
movimento linear ao longo de um mandril com uma trajetória previamente determinada”.

Essa trajetória da fibra é calculada pelo programa que determinará o movimento do olho durante o processo. Em um programa de otimização da trajetória da fibra, é possível determinar a melhor rotação para o mandril, o tempo e a estratégia de revestimento e o comprimento total da fibra a ser utilizada. A Erro! A origem da referência não foi encontrada. ilustra um exemplo de revestimento. A fibra é fornecida pelos fabricantes, em bobinas. No processo de revestimento, a fibra passa pelo controlador de tensão que tem a finalidade de mantê-la esticada durante o processo, em seguida passa pelo molhador que tem a função de impregná-la com resina e por fim passa pelo olho que tem a finalidade de guiá-la na superfície da peça a ser revestida. $\mathrm{O}$ olho tem a liberdade de movimento longitudinal, porém em alguns casos como em peças não geodésicas, o projeto da máquina para revestimento com fibras permite que o olho tenha liberdade de rotação para melhor direcionar a fibra.

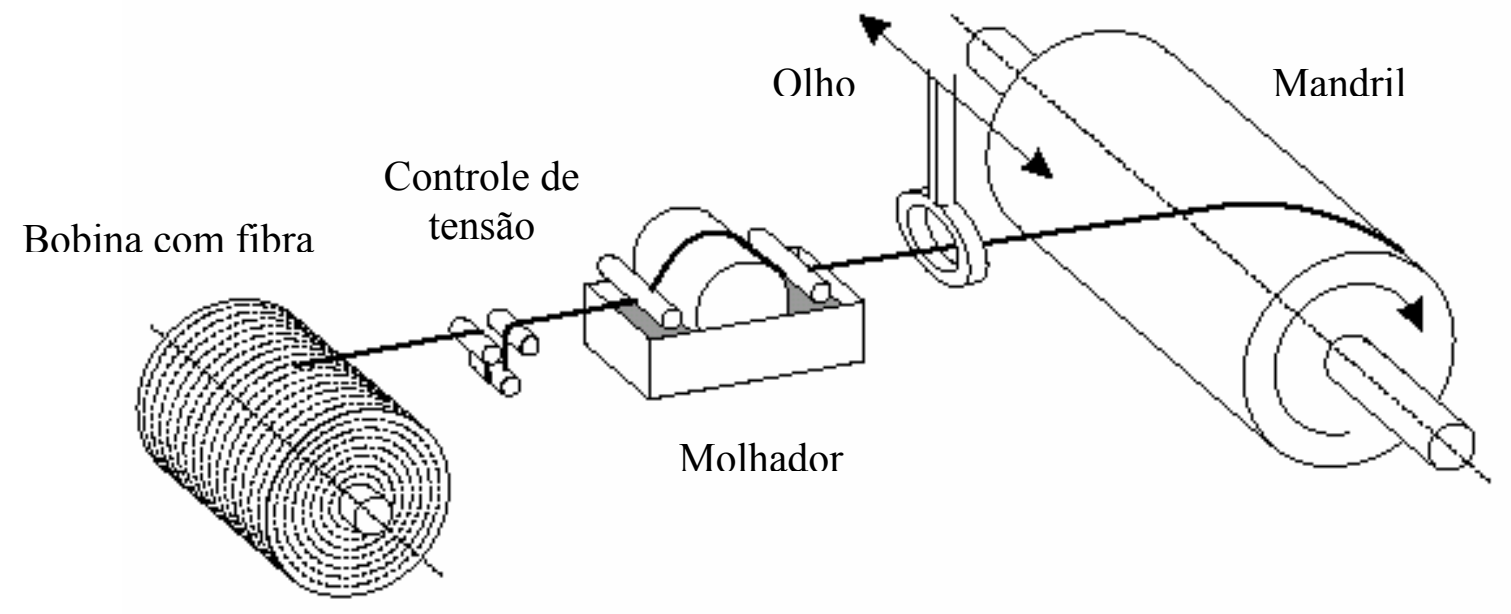

Figura 3 Exemplo de Revestimento com Fibra (SCHOLLIERS, 1992). 
O processo de revestir materiais compósitos consiste em depositar camadas de fibras com resina em toda a superfície da peça desejada. Neste processo, o método convencional consiste no revestimento em que a peça é presa a um mandril com rotação determinada, um olho que determina a trajetória da fibra na peça, sendo esta trajetória calculada no sentido de otimizar e dar resistência ao revestimento.

Segundo Carvalho (1996) as principais vantagens deste processo são:

- Alto grau de repetibilidade e precisão no posicionamento da fibra;

- A capacidade, embora limitada, de posicionar a fibra em muitas e apropriadas direções;

- O alto grau de automação que pode ser obtido direcionando para um baixo custo de manufatura e larga escala de produção;

- Baixo custo relativo ao material da fibra e da resina a ser impregnada na fibra;

Entretanto algumas desvantagens são inerentes ao processo:

- Um mesmo mandril pode não atender todas as necessidades de revestimento dependendo do formato da peça a ser revestida. Haveria a necessidade de que houvesse vários mandris intercambiáveis;

- Dificuldade em revestir peças com formatos côncavos devido ao problema do deslizamento no contato entre a fibra e o mandril;

- Limitações de projetos e trajetórias, onde o deslizamento pode limitar o posicionamento das fibras na posição apropriada. Também a inabilidade de mudar a trajetória da fibra em um mesmo ciclo; 
- Baixa qualidade de acabamento da superfície externa. A peça não apresenta uma superfície lisa e sim uma superfície rugosa marcada pelo perfil da fibra;

Mesmo com estas desvantagens, os materiais compósitos e os MCRF vêm substituindo com sucesso os metais e estruturas metálicas em vários setores como aeronáutico, automobilístico, medicina, etc.

As vantagens oferecidas pelos materiais compósitos e MCRF são diversas como baixo peso associado à alta tensão admissível e rigidez dos componentes, desempenho aprimorado devido à habilidade de ser revestido por fibras e alto potencial na redução de custos.

As fibras que revestem os materiais compósitos provêem característica como melhor resistência, maior rigidez, melhor resistência à compressão, melhor distribuição de cargas e protegem o mesmo contra efeitos ambientais.

Entretanto diversos obstáculos ainda estão sendo vencidos na integração de compósitos revestidos, como a dificuldade de prever exatamente o modo de falha, os efeitos em ambientes com lubrificantes e produtos químicos e o processo de revestimento não atingiu um grau de automação desejado ainda (CARVALHO, 1996).

\subsection{TIPOS DE REVESTIMENTOS}

No processo de revestimento, diferentes tipos podem ser usados. A determinação é feita levando em consideração a máquina que irá executar todo o processo, a 
geometria do componente e a trajetória desejada. Três padrões básicos podem ser distinguidos:

\section{- Revestimento polar (“Polar Winding”):}

Neste caso o caminho da fibra é um plano tangencial para ambos os pontos polares do mandril. A maior vantagem deste revestimento é a simplicidade e a possibilidade de manter regular a velocidade de revestimento.

\section{- Revestimento helicoidal (“Helical Winding”):}

A rotação do mandril e a velocidade de carregamento da fibra são sincronizadas de tal forma que a hélice desejada e o ângulo seja gerada. Este tipo de revestimento é muito mais versátil que o revestimento polar, tendo um largo número de combinações de diâmetro, comprimento e ângulos de revestimento. O conceito básico do revestimento helicoidal tem sido estendido aos formatos não simétricos. Algoritmos especiais determinam a seqüência adequada para o revestimento de superfícies mais complexas.

\section{- Revestimento circular (“Hoop Winding”):}

Revestimento circular ou em forma de aro é basicamente o revestimento helicoidal em um ângulo fechado próximo a 90 graus, o caminho das fibras são sempre perpendicular ao eixo da peça a ser revestida. Revestimento circular é geralmente combinado com revestimento polar ou helicoidal em ordem de encontrar um adequado grau de compactação e uma distribuição uniforme de tensões. 


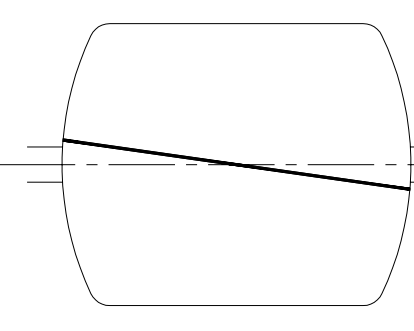

REVESTIMENTO POLAR

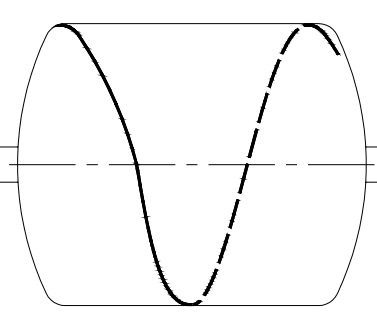

REVESTIMENTO HELICOIDAL

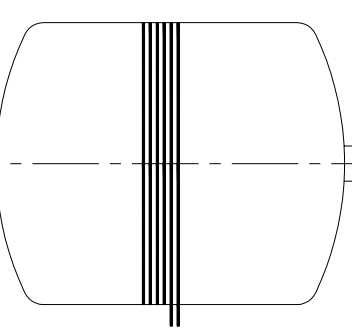

REVESTIMENTO CIRCULAR

Figura 4 Exemplo de tipos de revestimento (CARVALHO, 1996).

\subsection{PROTOCOLOS IGES e STL}

IGES - "Initial Graphics Exchange Specification” (Especificação Inicial de Intercâmbios de Gráficos) é a interface padrão mais usada para efetuar a troca de dados geométricos (pontos, linhas e superfícies) e não geométricos (camadas).

Segundo Smith (Junho de 1988), a especificação é concedida com os dados requeridos para descrever e comunicar as características essenciais de engenharia dos objetos físicos, como formato, dimensão e informações como descrição e informação do produto.

$\mathrm{O}$ uso de linhas retas para representação de polígonos planos de forma a aproximar curvas e superfícies tem limitado o estado-da-arte em computação gráfica. Até com a mais sofisticada técnica de alisamento, os polígonos resultam em aproximações visualmente ruins. Os métodos poligonais geralmente requerem grande quantidade de memória e a resolução é fixa, ou seja, não importa a distância que o polígono está do observador, a quantidade de memória e processamento é constante, ao 
contrário das técnicas de superfícies curvas que resultam em imagens diferentes computadas a cada nível de demanda.

O termo "spline" se originou de longas tiras flexíveis usadas para desenhar superfícies curvas de aviões, carros e navios. O equivalente na matemática dessas tiras são as "splines” cúbicas naturais com continuidade na primeira e segunda derivada.

Muitas das primeiras tentativas de modelar objetos deformáveis surgiram do campo de ferramentas de “design” geométricas (Computer Aided Geometric Design). Os projetistas necessitavam de uma maneira de especificar as curvas e superfícies numericamente e intuitivamente modificá-las para refinar estes objetos. Como conseqüências, surgiram as curvas de Bezier e outros métodos de descrever curvas e superfícies com um restrito número de vetores, incluindo as curvas quadráticas duplas, B-splines, B-splines racionais, B-splines não racionais(NURBS), e Beta-splines. Estes métodos podem representar curvas planas e tridimensionais.

As paramétricas B-splines têm muitas vantagens. Elas têm a habilidade para controlar a continuidade nas junções entre os segmentos das curvas adjacentes e nas bordas do retalho ("patches"), independente da ordem dos segmentos ou dos vértices de controle. Uma curva “spline” é uma seqüência de parâmetros de segmentos de polinômios.

A representação paramétrica de uma curva tem cada componente expresso como função univariada separada. Analogamente a representação de superfícies pode ser 
expressa por funções bivariadas separadas. As coordenadas de um ponto podem ser expressas como um conjunto vetorial da seguinte forma:

$[\mathrm{X}(\mathrm{u}), \mathrm{Y}(\mathrm{u})] \quad$ para uma curva no espaço bidimensional.

$[\mathrm{X}(\mathrm{u}), \mathrm{Y}(\mathrm{u}), \mathrm{Z}(\mathrm{u})] \quad$ para uma curva no espaço tridimensional.

$[\mathrm{X}(\mathrm{u}, \mathrm{v}), \mathrm{Y}(\mathrm{u}, \mathrm{v}), \mathrm{Z}(\mathrm{u}, \mathrm{v})] \quad$ para uma superfície no espaço tridimensional.

A derivada parcial, com relação a algum parâmetro ou vários parâmetros, também pode ser representada por um conjunto de vetores. Cada componente é a derivada da função correspondente à sua coordenada. Para curvas tridimensionais os vetores podem ser expressos da seguinte forma:

$$
\frac{\partial^{a+b}}{\partial u^{a} \partial v^{b}} Q(u, v)=\left[\frac{\partial^{a+b}}{\partial u^{a} \partial v^{b}} X(u, v), \frac{\partial^{a+b}}{\partial u^{a} \partial v^{b}} Y(u, v), \frac{\partial^{a+b}}{\partial u^{a} \partial v^{b}} Z(u, v)\right]
$$

Nesta plataforma, os módulos para os cálculos de superfícies a partir dos protocolos IGES e STL, não estão implementados. Esta parte da programação deverá ocorrer no futuro, para isso, serão utilizadas as entidades 126 e 128 da especificação IGES que tratam respectivamente das curvas e da superfície de uma entidade. A entidade 126 representa analiticamente a curva racional B-Spline. 
Tabela 2 Valor das indicações fornecidas pela entidade 126 e o formato das "Splines".

\begin{tabular}{|c|l|}
\hline Valor & \multicolumn{1}{|c|}{ Indicação } \\
\hline 0 & Formato da curva deve ser determinada pelos parâmetros da racional B- \\
& Spline \\
\hline 1 & Linha \\
\hline 2 & Arco circular \\
\hline 3 & Arco elíptico \\
\hline 4 & Arco parabólico \\
\hline 5 & Arco hiperbólico \\
\hline
\end{tabular}

A entidade 128 representa analiticamente a superfície racional B-Spline.

\begin{tabular}{|c|l|}
\hline Valor & \\
\hline 0 & Formato da superfície deve ser determinada pelos parâmetros da racional \\
& B-Spline \\
\hline 1 & Plano \\
\hline 2 & Cilindro circular reto \\
\hline 3 & Cone \\
\hline 4 & Esfera \\
\hline 5 & Toroidal \\
\hline 6 & Superfície de revolução \\
\hline 7 & Cilindro tabulado \\
\hline 8 & Perfil de superfície \\
\hline 9 & Superfície quadriculada \\
\hline
\end{tabular}

Tabela 3 Tipos de superfície fornecidos pela entidade 128. 
STL - O formato STL ("Linguagem Padrão de Triangularização") é uma malha simples de triângulos que reveste toda a superfície de um modelo sólido feito no CAD. O nome deste formato é derivado do processo de prototipagem rápida por Estereolitografia. Este formato de arquivo eletrônico tem se tornado um padrão na indústria de prototipagem. A figura 3 abaixo ilustra um modelo sólido de um cubo gerado pelo STL em 12 (doze) triângulos.

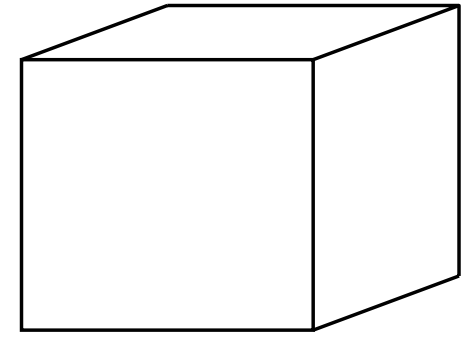

Modelo Sólido

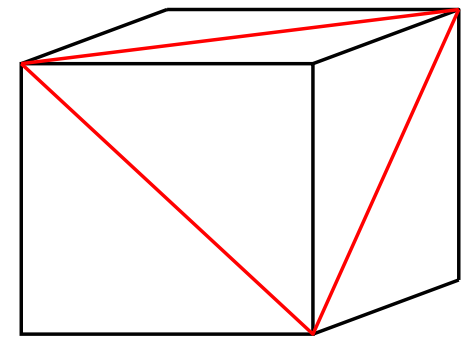

Modelo Sólido em STL

Figura 5 Exemplo de STL.

Atualmente quase todos os sistemas CAD são capazes de gerar o formato STL.

\subsection{DESCRIÇÃO MATEMÁTICA}

Segundo CARVALHO (1996), o cálculo da trajetória das fibras pode ser obtido através de métodos analíticos ou por processos de aproximação. O processo analítico tem a vantagem de se poder usar à descrição geométrica fornecida pelo desenho feito em CAD diretamente nos cálculos. 


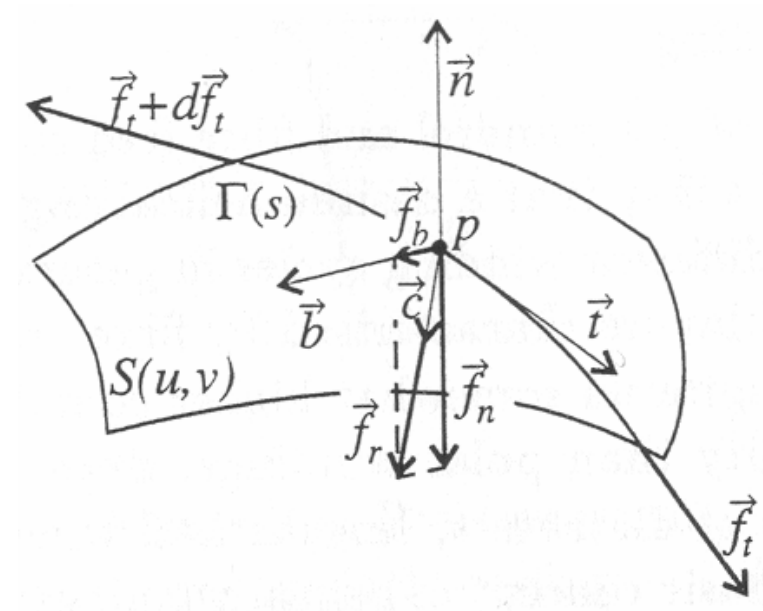

Figura 6 Vetores das forças que atuam na superfície da peça durante o processo de revestimento.

As melhores trajetórias são as descritas para curvas geodésicas. Curvas Geodésicas são curvas que conectam dois pontos em uma superfície concordando na menor distância entre eles sobre esta superfície.

Para superfícies de revolução, a equação geodésica pode ser expressa pela lei de Clairaut:

$$
R . \operatorname{sen} \alpha=\text { constante }
$$

O ângulo $\propto$ da fibra com relação à curva do meridiano no ponto da trajetória da fibra, $R$ o raio da superfície no ponto.

Para desenvolver os cálculos para superfícies não geodésicas, vamos considerar a trajetória descrita pela curva $\Gamma(\mathrm{s})$ na superfície $\mathrm{S}(u, v)$ mostrados na figura 6 . Um triedro de Frenet é preso a cada ponto $p$ de $\Gamma$. Ele consiste de três vetores ortogonais: a tangente $\vec{t}$, a direção externa normal $\vec{n}$, e a binormal $\vec{b}$.

$$
\begin{gathered}
\text { A tangente } \vec{t} \text { é calculada por: } \\
\vec{t}(s)=\frac{d \Gamma(s)}{d s}=\frac{\partial S(u, v)}{\partial u} \frac{d u}{d s}+\frac{\partial S(u, v)}{\partial v} \frac{d v}{d s}=\vec{S}_{u} \frac{d u}{d s}+\vec{S}_{v} \frac{d v}{d s}
\end{gathered}
$$


onde $\overrightarrow{S_{u}}$ e $\overrightarrow{S_{v}}$ corresponde às derivadas nas direções $u$ e $v$ respectivamente.

Se $s$ corresponde ao parâmetro da trajetória, a tangente $\vec{t}$ tem seu comprimento determinado por:

$$
\vec{t} \cdot \vec{t}=1 \Rightarrow \frac{d(\vec{t} \cdot \vec{t})}{d s}=0 \text { ou } 2 \vec{t} \cdot \frac{d \vec{t}}{d s}=0
$$

A curvatura do vetor $\vec{c}=\frac{d \vec{t}}{d \vec{s}}$ da trajetória $\mathrm{T}(\mathrm{s})$ é, de acordo com a equação 3, sempre normal a tangente $\vec{t}$ como curva natural parametrizada $\mathrm{T}(\mathrm{s})$ :

$\vec{c} \cdot \vec{t}=0$

é igual a:

$\vec{c}=S_{u} \frac{d^{2} u}{d s^{2}}+\vec{S}_{v} \frac{d^{2} v}{d s^{2}}+\vec{S}_{u u}\left(\frac{d u}{d s}\right)^{2}+2 \vec{S}_{u v} \frac{d u}{d s} \frac{d v}{d s}+\vec{S}_{v v}\left(\frac{d v}{d u}\right)^{2}$

A tensão da fibra $\vec{f}_{t}$, alinhada com a tangente $\vec{t}$, direciona a força $\vec{f}_{r}$ para a unidade de comprimento da superfície do mandril, a qual é direcionada para o centro de curvatura da trajetória da fibra. A força resultante $\vec{f}_{r}$ pode ser decomposta em duas componentes: a força normal $\vec{f}_{n}$, perpendicular à superfície da força transversal $\vec{f}_{b}$ tangencial à superfície do mandril mas transversal à fibra.

A tendência de deslizamento $\lambda$ é definida como a razão entre a força transversal $\vec{f}_{b}$ e a força normal $\vec{f}_{n}$ : 


$$
\lambda= \pm \frac{\left\|\overrightarrow{f_{b}}\right\|}{\left\|\overrightarrow{f_{n}}\right\|}=\frac{\overrightarrow{f_{b}}}{\overrightarrow{f_{n}}}
$$

Para obter uma trajetória estável da fibra, a força transversal $\vec{f}_{b}$ deve ser menor que a força de atrito $\vec{f}_{w}$. Esta força de atrito pode ser expressa por:

$$
f_{w}=\mu \overrightarrow{f_{n}}
$$

com $\mu$ o coeficiente estático de atrito. A condição de estabilidade:

$$
\left\|\vec{f}_{b}\right\| \leq\left\|\vec{f}_{w}\right\|
$$

pode ser escrita como:

$$
|\lambda| \leq \mu
$$

Esta condição deve ser respeitada quando estão sendo projetadas superfícies não simétricas. Se a tendência ao deslizamento $\lambda$ é igual a zero, a trajetória da fibra corresponde a geodésica.

A força (por unidade de comprimento) $\vec{f}_{r}, \vec{f}_{n}$ e $\vec{f}_{b}$, atua na fibra no ponto $p$, podem ser escritas na função da unidade da tangente $\vec{t}$, a normal $\vec{n}$ e binormal $\vec{b}$ do triedro de Frenet em $p$ :

$$
\begin{aligned}
& f_{r}=\frac{d \vec{f}_{t}}{d s}=\left\|\vec{f}_{t}\right\| \frac{d \vec{t}}{d s}=T \vec{c} \\
& \vec{f}_{n}=-\left(\vec{f}_{r} \cdot \vec{n}\right) \vec{n}=-T(\vec{c} \cdot \vec{n}) \vec{n}
\end{aligned}
$$




$$
\begin{aligned}
& \vec{f}_{b}=\left(\vec{f}_{r} \cdot \vec{b}\right) \vec{b}=T(\vec{c} \cdot \vec{b}) \vec{b} \\
& \text { com } \Gamma=\left\|\vec{f}_{t}\right\| \text { a tensão da fibra.O deslizamento da fibra é descrito pela equação }
\end{aligned}
$$

7 definindo o raio entre a força transversal e normal ou:

$$
\vec{c} \cdot \vec{b}=-\lambda \vec{c} \cdot \vec{n}
$$

O resultado das equações:

$$
\begin{aligned}
& \vec{c} \cdot \vec{t}=0 \\
& \vec{c} \cdot(\vec{b}+\lambda \vec{n})=0
\end{aligned}
$$

Podem ser escritas como:

$$
\begin{aligned}
& a_{11} \frac{d^{2} u}{d s^{2}}+a_{12} \frac{d^{2} v}{d s^{2}}=b_{1} \\
& a_{21} \frac{d^{2} u}{d s^{2}}+a_{22} \frac{d^{2} v}{d s^{2}}=b_{2}
\end{aligned}
$$

Com:

$$
\begin{aligned}
& a_{11}=\vec{s}_{u} \cdot \vec{t} \\
& a_{12}=\vec{s}_{v} \cdot \vec{t} \\
& a_{21}=\vec{s}_{u} \cdot(\vec{b}+\lambda \vec{n}) \\
& a_{22}=\vec{s}_{v} \cdot(\vec{b}+\lambda \vec{n}) \\
& b 1=-\left[\vec{s}_{u u}\left(\frac{d u}{d s}\right)^{2}+2 \vec{s}_{u v} \frac{d u}{d s} \frac{d v}{d s}+\vec{s}_{v v}\left(\frac{d v}{d s}\right)^{2}\right] \cdot \vec{t}
\end{aligned}
$$




$$
b 1=-\left[\vec{s}_{u u}\left(\frac{d u}{d s}\right)^{2}+2 \vec{s}_{u v} \frac{d u}{d s} \frac{d v}{d s}+\vec{s}_{v v}\left(\frac{d v}{d s}\right)^{2}\right] \cdot(\vec{b}+\lambda \vec{n})
$$

O sistema de equações diferenciais 16 e 17 é resolvido numericamente. A trajetória da fibra é determinada pelos parâmetros $u$ e $v$ no ponto inicial e as derivadas $\frac{d u}{d s}$ e $\frac{d v}{d s}$ no ponto inicial, os quais são definidos pelo início da tangente.

Com respeito à tendência ao deslizamento, uma outra restrição é relacionada a concavidade: se uma parte da peça é convexa, a fibra perderá o contato com a superfície do mandril. Isto é chamado de deslocamento da fibra ("fibre bridging”). Para prevenir isto, a resultante da força $\vec{f}_{r}$ deve ser direcionada para o lado da superfície do material em oposição a normal $\vec{n}$ :

$$
\vec{n}_{\vec{f}} \vec{f}_{r} \leq 0 \text { ou } T(\vec{n} \cdot \vec{c}) \leq 0
$$

\subsection{ESTRATÉGIA DE REVESTIMENTO}

Em geral, o revestimento helicoidal, somente após certo número de ciclos de revestimentos, será possível fazer uma prévia da nova estrutura que estará ocorrendo ao longo da superfície presa ao mandril. Essa propriedade de poder fazer uma prévia da nova estrutura pode ser concedida pela chamada estratégia de revestimento ("winding strategy”) proposta por Lossie (1994): O tempo da seqüência da trajetória da fibra em 
uma seção transversal de um mandril. Essa estratégia é caracterizada pela mudança angular entre sucessivos ciclos de revestimentos. Isto quer dizer que se a circunferência é subdividida dentro de um número de segmentos correspondendo ao número de revestimentos por camada, a estratégia pode ser expressa pela razão do número de posições mudando no início de um novo ciclo e o número total de ciclos considerando as posições ao longo da circunferência.

Como exemplo a figura 7 mostra a estratégia chamada " $5 / 16$ " que indica que a cada novo ciclo o mandril irá girar sobre uma fração de $5 / 16$ da circunferência resultando em uma seqüência: 1, 6, 11, 16, 5, 10, etc. Essa seqüência se dará até que a superfície esteja completamente revestida.

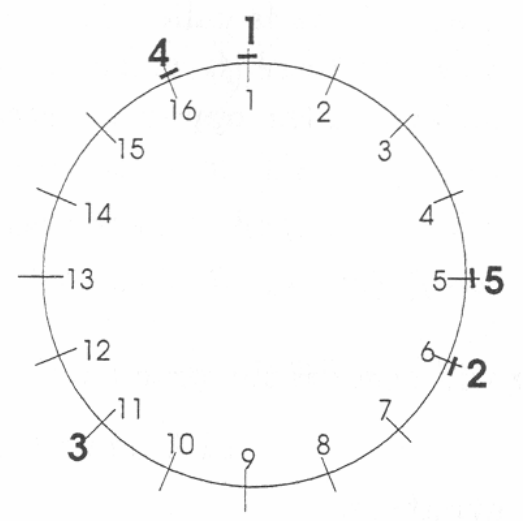

Figura 7 Estratégia de revestimento (CARVALHO, 1996)

\subsection{REVESTIMENTO}

Com a estratégia adotada, o próximo passo é encontrar a estratégia para execução do revestimento. Isto depende muito da geometria da peça a ser revestida. 
Peças simétricas: requerem um revestimento circular simples para uma cobertura completa. Revestimento circular (Figura 4 - pág. 14) entende-se como a trajetória com que a fibra é depositada sobre uma peça enquanto esta gira em seu eixo de revolução. O número de revoluções para se revestir uma peça simétrica pode ser calculado pela fórmula:

$$
N=\frac{l \cdot \cos \alpha}{w}
$$

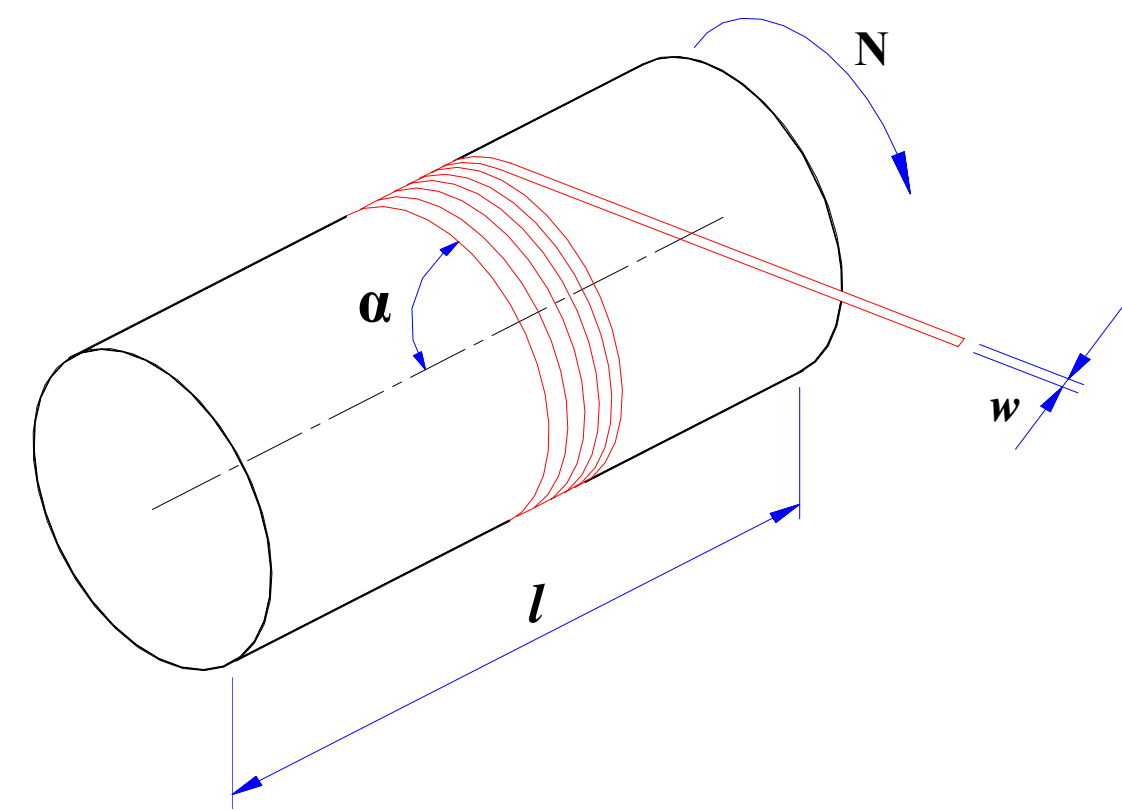

Figura 8 Revestimento circular.

Peças tubulares: Estas peças são caracterizadas por terem um eixo central e uma seção transversal de formato constante. Neste tipo de projeto, a trajetória das fibras é diferente da trajetória dos projetos assimétricos. O cálculo se inicia com a trajetória básica da fibra, onde as direções desejadas são impostas. Estas trajetórias são definidas pela estratégia de revestimento adotada. 
Peças assimétricas: Este caso não é similar ao caso das peças tubulares, não é possível encontrar uma única trajetória para a fibra ao longo do revestimento, que pode se repetir sobre toda a superfície. Entretanto, cada trajetória deve ser projetada separadamente requerendo uma gama alta de dados para cobrir completamente a superfície da peça. Este processo inicia com o cálculo de peças com pontos geodésicos para diferentes combinações de posição e orientação iniciais. Estas geodésicas são representadas pela seqüência de superfície por onde a fibra passa.

O ponto inicial é movido ao longo da superfície da peça, esta seqüência de superfícies é descrita como mapa da trajetória representando diferentes pontos iniciais e orientações de revestimento.

\subsection{FIBRAS}

Conforme a classificação de MATHEUS \& RAWLINGS (1994) com relação aos esforços provocados nos materiais compósitos reforçados, as fibras apresentam-se em duas formas: Fibras contínuas e fibras descontínuas. Como componente estrutural ambas têm a função de suportar esforços provenientes da matriz, porém com características distintas que influenciam o desempenho mecânico dos compósitos. A 9 mostra o exemplo de deformação das fibras sob tensão.

A característica mecânica dos materiais reforçados por fibras não depende somente das propriedades das fibras, mas também da magnitude com que o carregamento é transmitido às fibras por meio da matriz. Este fenômeno de 
transferência de carregamento demonstrado na Figura 9 é função do comprimento da fibra e da adesão interfacial entre a fibra e a matriz (CALLISTER, 1994).

Assim, para cada combinação fibra-matriz é necessário estabelecer um comprimento mínimo da fibra capaz de garantir efetivamente a rigidez e resistência do compósito.

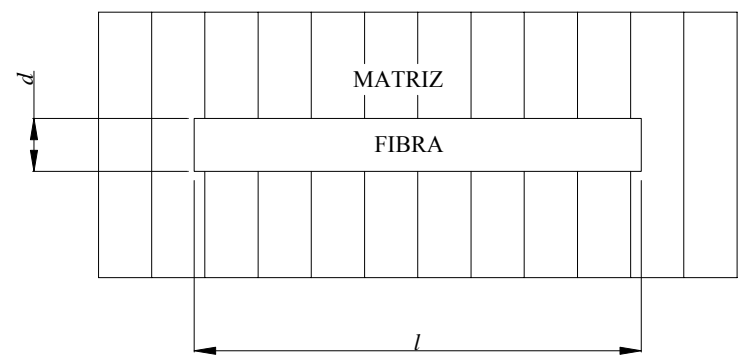

(a)
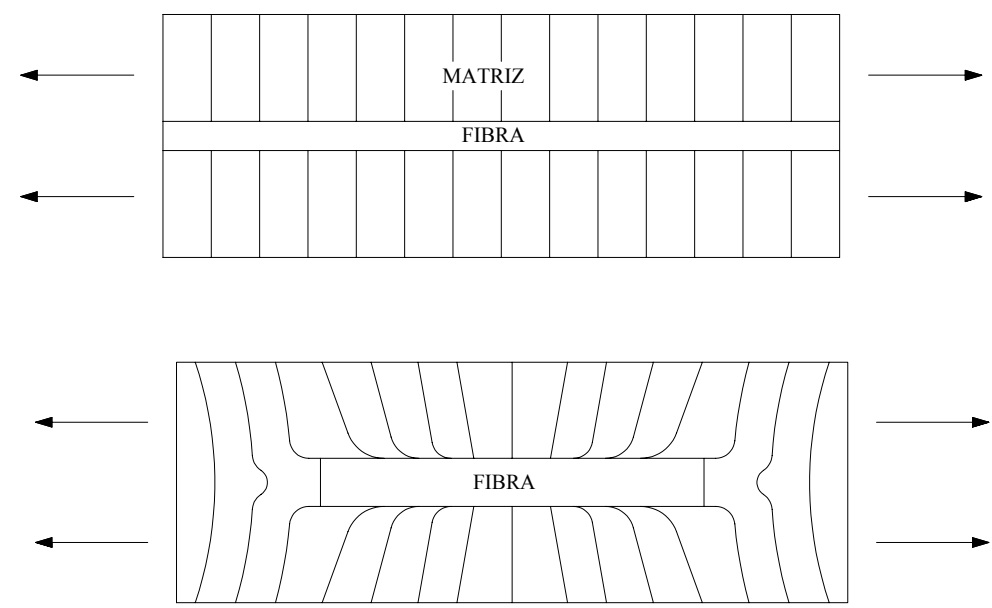

(b)

Figura 9 Efeito da deformação ao redor da fibra na matriz sob tensão: (a) fibra contínua; (b) fibra descontínua (MATHEUWS \& RAWLINGS, 1994).

Desta forma, MATTHEWS \& RAWLINGS (1994) definem o comprimento crítico da fibra $\left(l_{c}\right)$ como sendo o comprimento mínimo da fibra necessário para a tensão transmitida alcançada a tensão de ruptura a tração da fibra.

$l_{c}=\frac{\sigma_{c} \cdot w}{2 \cdot \tau_{f}}$ 


\subsection{INTERFACE ENTRE A FIBRA E A MATRIZ}

A interface fibra e matriz é chamada de “o coração" dos Materiais Compósitos Reforçados por Fibras (FILHO, 2001). A interface representa o papel principal em determinar o desempenho mecânico e a integridade estrutural dos materiais compósitos reforçados por fibras. Segundo HULL (1981) as tensões atuantes na fibra são transmitidas para a matriz através da interface. HULL (1981) destaca algumas hipóteses que devem ser adotadas com relação às propriedades da interface:

(i) a matriz e a fibra se comportam como materiais elásticos;

(ii) a interface é infinitamente delgada;

(iii) a interação entre a fibra e a matriz é perfeita, de forma que não ocorre descontinuidade de deslocamento ao longo da interface;

(iv) a interface que se forma ao redor da fibra tem as mesmas propriedades que um material no estado sólido;

(v) a geometria do empacotamento das fibras é regular. Entretanto as hipóteses (ii) e (iv) não estão totalmente corretas, porque a interface real apresenta uma estrutura física e química complexa.

A natureza da interação entre fibra e matriz depende das propriedades de ambas. Isto exerce influência na escolha dos materiais a serem empregados, pois a combinação destes nem sempre resultará na integração adequada da fibra com a matriz, sendo necessário um tratamento superficial para que a fibra interaja fortemente com a matriz. 


\subsection{IMPREGNAÇÃO}

Segundo CARVALHO (1996) a resina de impregnação usada em filament winding pode ser obtida por diversas formas. O método mais comum é o chamado revestimento úmido (wet filament) que servirá de base para este trabalho. Consiste na passagem da fibra através do banho de resina líquida ou por correr a fibra sobre um rolo que contém um filme de resina antes de ser direcionada par ao mandril. A principal vantagem deste tipo de impregnação é o baixo custo da matéria prima e a larga flexibilidade da combinação fibra matriz. Entretanto, este processo só é possível com resina de baixa viscosidade e regular pot-life. A impregnação limita a velocidade do revestimento e a resina carregada para o mandril deve ter um controle preciso para assegurar o uma boa qualidade no produto final. Este processo também requer o trabalho intensivo de limpeza na resina e nas guias por onde a fibra passa.

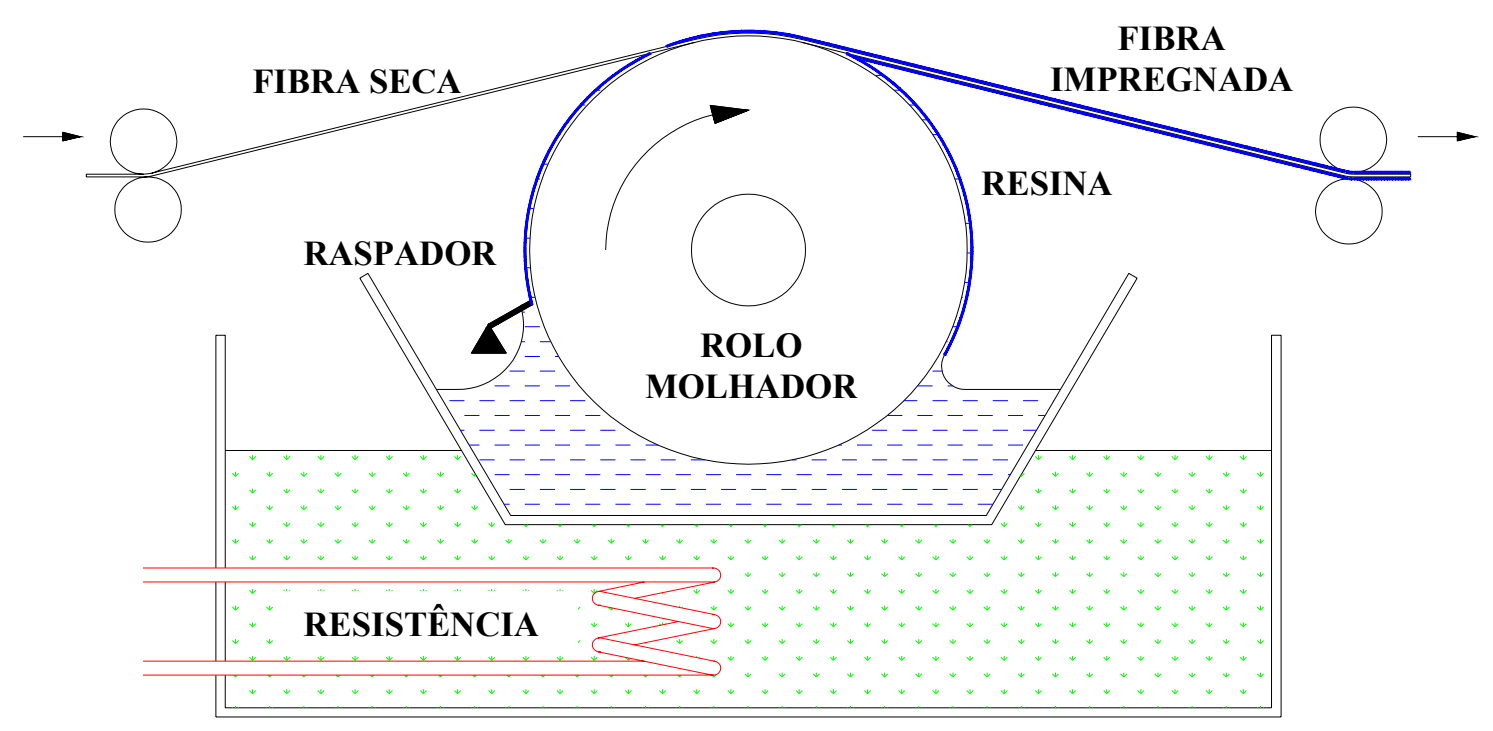

Figura 10 Exemplo de revestimento umedecido por resina (wet filament).

Outros métodos de impregnação mais comumente usados: 


\section{Revestimento Impregnado (“Prepeg Winding”)}

As fibras são impregnadas com resina de um molhador. O ajuste de temperatura da resina deixa esta parcialmente curada a uma condição de alta viscosidade e abrigada a baixa temperatura para retardar a cura. É recomendado aquecer o olho e o mandril para obter a temperatura necessária do fluxo da resina e da compactação do material quando se faz um pré-revestimento, e isto pode introduzir complicações no processo como escorrimento da resina impregnada na fibra no olho. O pré-revestimento é por si só um material compósito (isto é, uma combinação de fibras e resina) e permite boa qualidade no controle e previsão da resina contida em vantagem para o processo de revestimento. Em termos de projeto, o revestimento impregnado pode dar uma melhor estabilidade em superfícies assimétricas comparada com o revestimento molhado.

\section{Enrolamento Úmido (“Wet Rerolled”)}

Neste caso, fibra impregnada, é bobinada no mandril antes da cura, e então é usada prontamente ou refrigerada. Assim como o pré-revestimento, o controle de qualidade pode ser desenvolvido a parte da operação de manufatura.

\section{Revestimento a seco ("Dry Winding )}

A impregnação é feita depois do processo de revestimento. A peça enrolada a seco é enclausurada em um molde e a resina líquida é injetada. A peça é curada no molde, a resina penetra bem suavemente no interior e em outras superfícies. A resina 
deve ter uma viscosidade muito baixa para penetrar entre as fibras sem deixar áreas secas.

Em todos os métodos de revestimentos citados acima, existe um processo de cura no qual a resina impregnada em estado líquido sofrerá o processo de solidificação. Este processo será descrito abaixo.

\section{Cura}

Quando se utiliza o revestimento molhado, o mandril deve ser mantido em rotação continua para evitar concentração de resina e formação de gotas no mandril durante o primeiro estágio do ciclo de cura, antes de obter o ponto de gel. Se for necessário, o excesso de resina pode ser removido com pás ou raspadores de plástico antes do procedimento de cura. Ao longo da cura, exposição a alta temperatura ou tempo adicional é necessário para completar o ciclo. A cura pode ser feita em um forno, autoclave ou por meio de lâmpadas infravermelhas posicionadas próximas ao mandril. Uma pós cura pode ser executada depois que o mandril for removido para reduzir as tensões residuais.

\subsection{LINGUAGEM JAVA}

Em 1991, a Sun ${ }^{\circledR}$ estava direcionando suas pesquisas para integrar digitalmente dispositivos como televisões, microcomputadores, tocadores de CD entre outros. A linguagem $\mathrm{C}$ demonstrou ser funcional, porém havia algumas restrições. A linguagem $\mathrm{C}$ 
não possuía uma portabilidade específica para comunicação entre estes dispositivos e as linhas de códigos necessários à operação destes dispositivos requeriam uma quantidade maior de memória.

Diante deste quadro, o programador líder da Sun, James Gosling, criou a linguagem de programação Oak. O nome Oak foi dado por James, significa Carvalho, a motivação deste nome foi a uma árvore de carvalho que havia em frente à janela de seu escritório na Sun®. Mais adiante a equipe de programação da Sun descobriu que já existia. O nome Java foi sugerido devido a uma cidade origem de um tipo de café muito apreciado.

No início a linguagem não foi muito apreciada, mesmo após várias parcerias como a Time Warner ${ }^{\circledR}$. A Sun ${ }^{\circledR}$ resolveu investir na Internet e criou seu próprio “Browser" chamado de Hot.Java, que inovou a animação tridimensional na Internet. Mas em 1995, a decisão mais importante ocorreu na $\operatorname{Sun}{ }^{\circledR}$, decidiram abrir o código fonte aos programadores, desde então Java se tornou um sucesso.

Java é uma linguagem orientada a objetos, tendo em mente que muitos programadores utilizavam $\mathrm{C}$ e $\mathrm{C}++$, James fez uma sintaxe de básica de $\mathrm{C}++$, implementações para ponteiros e desalocação de memória, não foram incluídas em Java. O interesse de James era no tempo de depuração que foi economizado com essa decisão de James.

Java tem uma particularidade para dispositivos de entretenimento citados acima e "browser" para internet. Muito embora uma boa linguagem para estas situações, C++ 
demonstrou ser mais rápida em algumas situações e no caso de máquinas de manufatura, a linguagem $\mathrm{C}$ ainda é mais usada que Java pelos programadores.

\subsection{LINGUAGEM DELPHI}

Criado em 1994 sua primeira versão teve como objetivo, ser uma linguagem totalmente orientada a objetos numa versão 16 bits. Em 1995 foi lançada a versão 32 bits e em 1997 Delphi traz uma nova versão com suporte a internet.

Delphi é uma linguagem ObjectPascal, uma grande evolução do antigo Pascal. Delphi surgiu como sucessor do Turbo Pascal. O arquiteto do Pascal é Delphi é Ander Hejlsberg, em 1996 ingressou a Microsoft ${ }^{\circledR}$ e desenvolveu a linguagem C\#.

Delphi tem uma ênfase muito boa quando se trata de conexão com banco de dados, este é um referencial que a distingue das outras linguagens de programação. A existência de grande quantidade de componentes prontos em sua biblioteca, facilidade de uso e aprendizado, desenvolvimento rápido e velocidade de execução no código se comparam apenas a linguagem $\mathrm{C}$.

Delphi é uma linguagem que poderia ser muito bem aplicada a este trabalho. Sua programação tem sido largamente utilizada nos Desktops, mas ainda sim a Linguagem C tem um suporte superior no que diz respeito à linguagem de baixo nível que deverá ser necessário numa fase em que este projeto alcançar seu objetivo final. 


\subsection{LINGUAGEM C}

A primeira utilização da linguagem $\mathrm{C}$ fora do ambiente acadêmico ocorreu em junho de 1983. A linguagem C pode ser considerada uma evolução da linguagem de programação BCPL criada por Martin Richards. Em 1970, Ken Thompson efetuou algumas melhorias na linguagem BCPL e a chamou de linguagem B. Em 1972, Dennis M. Ritchie, implementou diversas melhorias na linguagem B, que considerada uma sucessora da linguagem B foi chamada de linguagem C, sendo executada pela primeira vez num computador DEC PDP-11 no sistema operacional UNIX (MAIA e MORELLI, 2003).

A linguagem $\mathrm{C}$ demonstrou ser uma linguagem muito poderosa para programação e foi utilizada para reescrever o sistema operacional UNIX que estava escrito em linguagem Assembly. A linguagem $\mathrm{C}$ se tornou muito popular devido as suas propriedades. Algumas delas como de possuir características de trabalhar como linguagem de alto e baixo nível, a portabilidade, isto é, pode ser utilizada em máquinas de diferentes configurações e diferentes sistemas operacionais.

Mais tarde, a linguagem C sofreu uma evolução e foi chamada de linguagem $\mathrm{C}++$. O motivo pelo qual não foi chamada de linguagem D. A linguagem $\mathrm{C}++$ é fornecida por diversos fabricantes como Microsoft ${ }^{\circledR}$ (Visual $\left.\mathrm{C}++\right)$, Borland ${ }^{\circledR}(\mathrm{C}++$ Builder), Intel Softwares ${ }^{\circledR}$, entre outros.

Neste trabalho será utilizada a linguagem de programação $\mathrm{C}++$. Os fatores que levaram a escolha da linguagem $\mathrm{C}++$ para a programação da plataforma para o Cawar e futuramente para a implantação dos módulos foram: 
1- o primeiro software CAWAR estar escrito em C;

2- $\mathrm{C}++$ é uma linguagem que permite ser executada nas mais variadas configurações;

3- é uma linguagem de fácil interface com programas de linguagem de baixo nível (linguagem de máquina);

4- por ser uma linguagem que permite o desenvolvimento do trabalho em orientação a objetos que sofrerá alterações e inclusões de módulos para a continuidade do programa;

Para o desenvolvimento deste trabalho, o software escolhido foi o $\mathrm{C}++$ Builder da Boorland. Os fatores que levaram à sua escolha além dos fatores da escolha do $\mathrm{C}++$ citado acima foram:

1- possui uma interface amigável com o usuário;

2- praticidade para programar;

3- bons recursos para programação;

4- possibilidade de incrementar visualização tridimensional num dos módulos futuros do programa;

\subsection{PROGRAMAÇÃO ORIENTADA A OBJETOS}

No final da década de 60, a linguagem simula67, desenvolvida na Noruega, introduzia os primeiros conceitos hoje encontrados nas linguagens orientadas a objetos. Em meados de 1970, o Centro de Pesquisa da Xerox (PARC) desenvolveu a linguagem Smalltalk, a primeira totalmente orientada a objetos (OO). No início da década de 80 , a AT\&T lançaria a Linguagem $\mathrm{C}++$ em direção à orientação a objetos. 
Atualmente, a grande maioria das linguagens incorpora características de Orientação a Objetos, como Java e Object Pascal. Além das linguagens de programação, é possível encontrar o conceito de $\mathrm{OO}$ em sistemas operacionais, como no caso do Windows 2000, e em banco de dados, como no Oracle8.

Segundo Maia e Morelli (2003), a programação orientada a objetos tem como principais objetivos reduzir a complexidade no desenvolvimento de software e aumentar sua produtividade. A análise, o projeto e a programação orientada a objetos são as respostas para os sistemas que possuem uma maior complexidade dos ambientes computacionais e que se caracterizam por sistemas heterogêneos, distribuídos em redes, em camadas e baseados em interfaces gráficas.

A programação OO não tem a intenção de substituir a programação estruturada tradicional. Podemos considerar que a programação OO é uma evolução de práticas que são recomendadas na programação estruturada, mas não formalizadas como o uso de variáveis locais, visibilidade e escopo. O modelo de objetos permite a criação de bibliotecas que tornam efetivos o compartilhamento e a reutilização de código, reduzindo o tempo de desenvolvimento e, principalmente, simplificando o processo de manutenção das aplicações.

Um objeto é uma abstração de software que pode representar algo real ou virtual. Um objeto é formado por um conjunto de propriedades (variáveis) e procedimentos (métodos). As variáveis possuem um tipo, que define os possíveis valores que a variável pode representar, como um número inteiro, número real ou string. Os métodos são 
rotinas que, quando executadas, realizam alguma tarefa, como alterar o conteúdo de uma variável do objeto.

Os objetos se comunicam apenas através de mensagens. Quando um objeto deseja alguma tarefa de um outro objeto, ele envia uma mensagem contendo o nome do objeto-origem, nome do objeto-destino, nome do método a ser ativado no objeto-destino e, se necessário, os parâmetros (variáveis) que permitem especificar alguma função especial a ser executada pelo método. Este conceito se assemelha à chamada de uma rotina em uma linguagem tradicional. O conjunto de mensagens que um objeto pode responder é definido como protocolo de comunicação.

As variáveis de um objeto só podem ser alteradas por métodos definidos na própria classe. A única maneira de um objeto alterar as variáveis de um outro objeto é a através da ativação de um de seus métodos por uma mensagem. Este conceito, onde variáveis e métodos são visíveis apenas através de mensagens, é conhecido como encapsulamento. O encapsulamento funciona como uma proteção para as variáveis e métodos, além de tornar explícito qualquer forma de comunicação com o objeto.

Uma classe consiste de variáveis e métodos que representam características de um conjunto de objetos semelhantes. O conceito de classe é um dos pilares da programação orientada a objetos, por permitir a reutilização efetiva de código.

O conceito de herança permite definir uma nova classe, com base em uma já existente. A classe criada (subclasse ou classe derivada) automaticamente herda todas as variáveis e métodos da classe já existente (superclasse). O mecanismo de herança 
permite ainda que a subclasse inclua novas variáveis ou sobreponha variáveis existentes e métodos da superclasse.

O mecanismo de herança é recursivo, permitindo criar-se uma hierarquia de classes. Nos níveis mais altos da hierarquia estão características comuns a todos os objetos desta hierarquia de classe, enquanto nos níveis inferiores estão especializações das classes superiores. As subclasses herdam as características comuns, além de definirem suas propriedades específicas.

Existem dois tipos de mecanismos de implementação de herança: simples e múltipla. Na herança simples, as subclasses podem herdar variáveis e métodos apenas de uma classe, enquanto na herança múltipla, as subclasses podem herdar variáveis e métodos de mais de uma classe.

Uma das grandes vantagens da programação OO é a utilização de bibliotecas de classes. Estas bibliotecas lembram as bibliotecas de código (procedimentos e funções), utilizadas na programação modular. As bibliotecas de classes permitem uma capacidade muito maior de compartilhamento e reutilização de código, pois é possível criar-se subclasses para atender novas necessidades, em função das classes já existentes. Muitas bibliotecas são oferecidas juntamente com as ferramentas de desenvolvimento para reduzir o tempo e a complexidade de projetos de software.

O termo polimorfismo é utilizado em biologia para definir variações em forma e função de membros de uma mesma espécie. Utilizando a mesma analogia, o mecanismo de polimorfismo permite tratar objetos semelhantes de uma maneira uniforme. Neste 
caso, é possível que se envie uma mesma mensagem para um conjunto de objetos e que cada objeto responda de maneira diferente da mensagem recebida.

O polimorfismo para ser implementado exige a utilização do conceito de herança e aplica-se apenas aos métodos da classe. O protocolo de comunicação é estabelecido na classe mais alta da hierarquia, que será herdada por todas as subclasses definidas posteriormente. Este mecanismo cria um protocolo padrão de comunicação com um conjunto de objetos, permitindo uma grande flexibilidade na agregação de objetos semelhantes, mas não idênticos.

Em programas que não utilizam orientação por objetos, sempre que uma nova funcionalidade deve ser acrescentada, a aplicação deve ser alterada e recompilada. Com o conceito de polimorfismo, é possível acrescentar novos métodos a classes já existentes sem a necessidade de recompilar a aplicação. Isto é possível através da técnica de "late binding" ou "dynamic binding", que permite que novos métodos sejam carregados e ligados (“binding”) à aplicação em tempo de execução.

Concluindo, baseado nos conceitos de objetos, classes, encapsulamento, herança e polimorfismo, o paradigma da OO representa uma forma evolucionária de pensar e desenvolver software, trazendo inúmeros benefícios à criação de programas, dentre os quais o mais notável é a reutilização de código, que reduz drasticamente os tempos de desenvolvimento e manutenção de programas. 


\subsection{SOFTWARES PARA “FILAMENT WINDING”}

Existem vários programas para o cálculo das trajetórias das fibras, sejam elas de carbono, vidro, kevlar, etc, a maioria destes softwares são compostos por pacotes que calculam desde cilindros até superfícies complexas. Alguns trazem diferenciais de outros como o suporte à análise de elementos finitos (CAE), visualização tridimensional, etc. As características peculiares de cada programa são fatores essenciais na aquisição de um bom programa para "Filament Winding”. Em geral todos eles possuem características como disposição para controle de seis eixos, visualização bidimensional, possibilidade de mudar de ângulo nas diversas camadas e revestimento de peças simétricas e assimétricas.

A diferença do programa que se pretende desenvolver neste trabalho e os outros programas existentes no mercado é a possibilidade deste programa calcular a tendência ao deslizamento e otimizar a trajetória da fibra nos diversos tipos de superfícies fornecidas pelos sistemas CAD nos protocolos IGES e STL.

\subsubsection{CADFIL}

CADFIL é um programa desenvolvido pela Crescent Consultants Limited®. Um sistema integrado que possui visualização bidimensional da superfície que será revestida, possui um sistema de segurança para evitar colisões com o mandril, o usuário tem a possibilidade de alterar o ângulo entre as camadas de revestimento, auto ajuste a superfícies cônicas, ele consegue gerar protocolos para análise de elementos finitos 
(CAE) e saída para comando numérico computadorizado (CNC) e a possibilidade de utilizar uma máquina com cinco olhos de revestimento e o mandril, totalizando o controle de seis eixos.

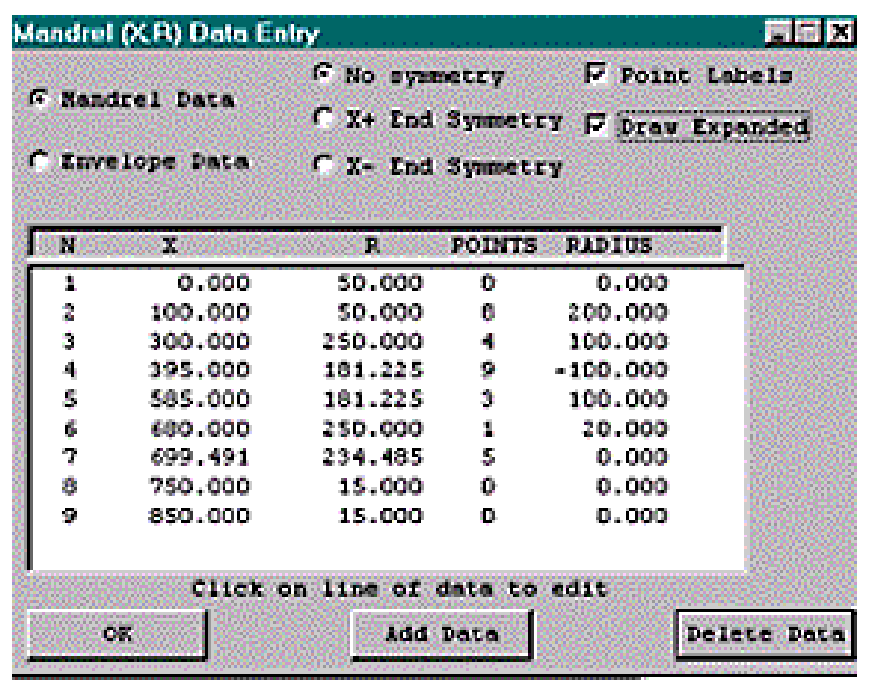
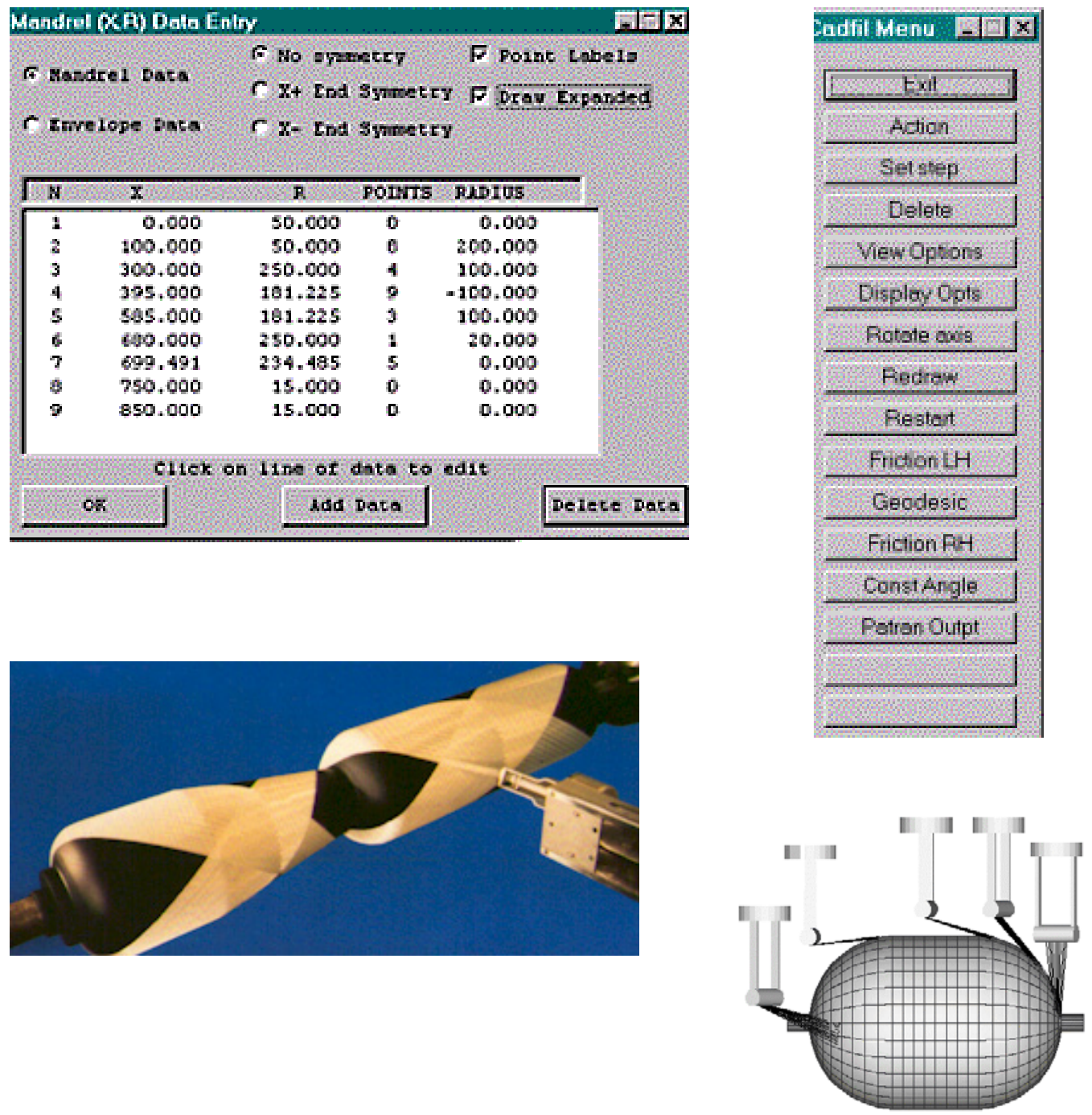

Figura 11 Softwre Cadfil

\subsubsection{FIBER GRAFIX}

FIBER GRAFIX é um programa desenvolvido pela Entec Composites Machines ${ }^{\circledR}$. Assim como o CADFIL, FIBER GRAFIX possui vários recursos para “Filament Winding”. Este programa permite o revestimento de peças simétricas ou 
assimétricas, mudança no ângulo de revestimento das camadas, os dados resultantes de seus cálculos são dispostos em arquivos textos, podendo ser editados pelo usuário, possui a capacidade de operar com seis eixos e consegue importar arquivos com extensão dxf gerados pelo AutoCad da Autodesk®.

Este programa possui um pacote para análise de elementos finitos dentro do próprio programa o FEA ( “Finite Element Analysis”), o usuário não necessita exportar os dados resultantes a um programa específico de análise de elementos finitos como o Ansis, Abaqus, Nastran, etc. Isto poupa tempo e facilita o trabalho do usuário.
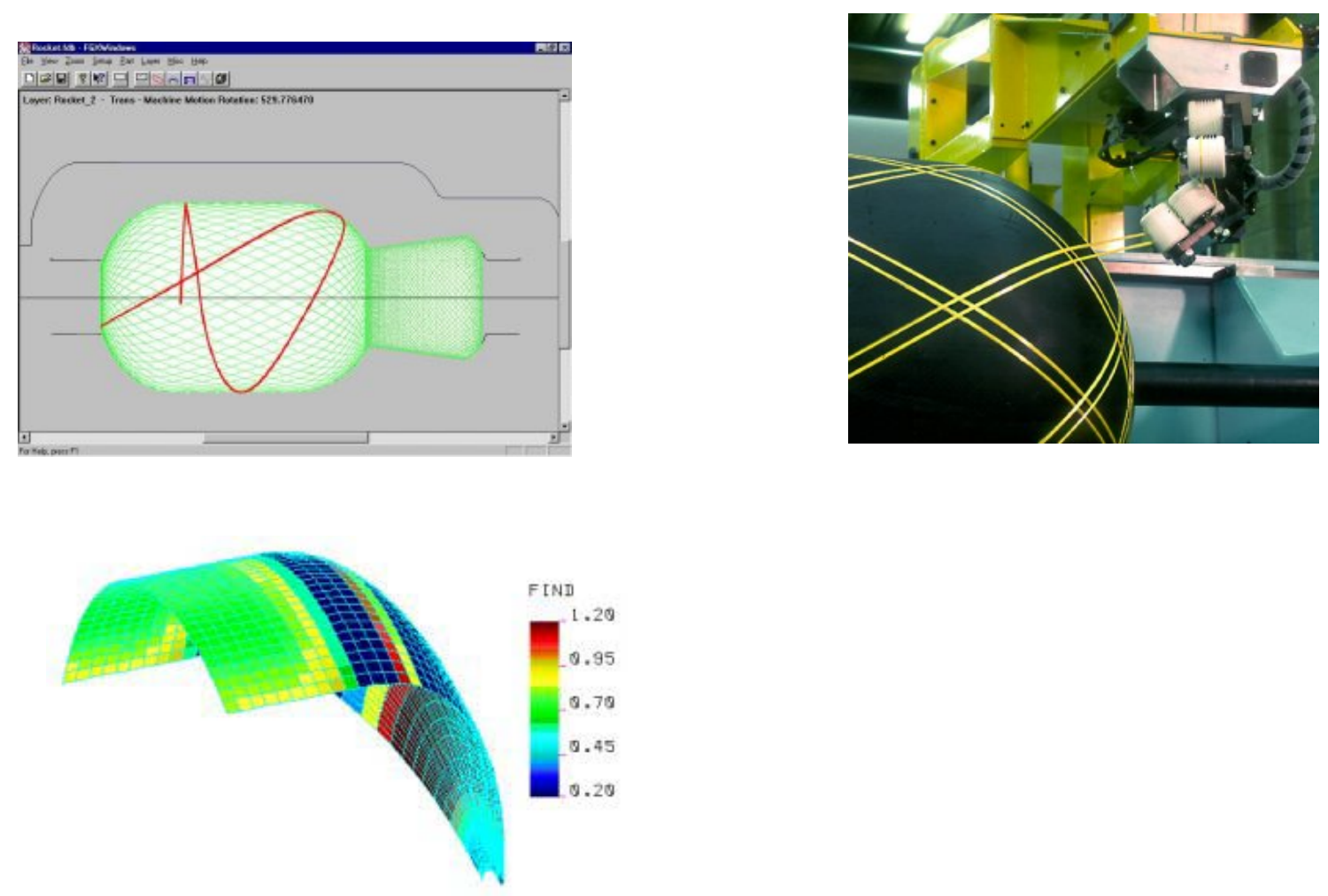

Figura 12 Software Fiber Grafix

\subsubsection{CADWIND}

CADWIND foi desenvolvido pela Pattern Máster®. Este programa apresenta características similares aos demais citados, como o revestimento de peças simétricas e 
assimétricas, possibilidade de mudança de ângulo nas diversas camadas de revestimento, visualização bidimensional e importação de arquivos CAD. Um diferencial neste programa é a biblioteca de otimização do tempo de revestimento, análise de elementos finitos e um módulo dedicado a vasos de pressão.
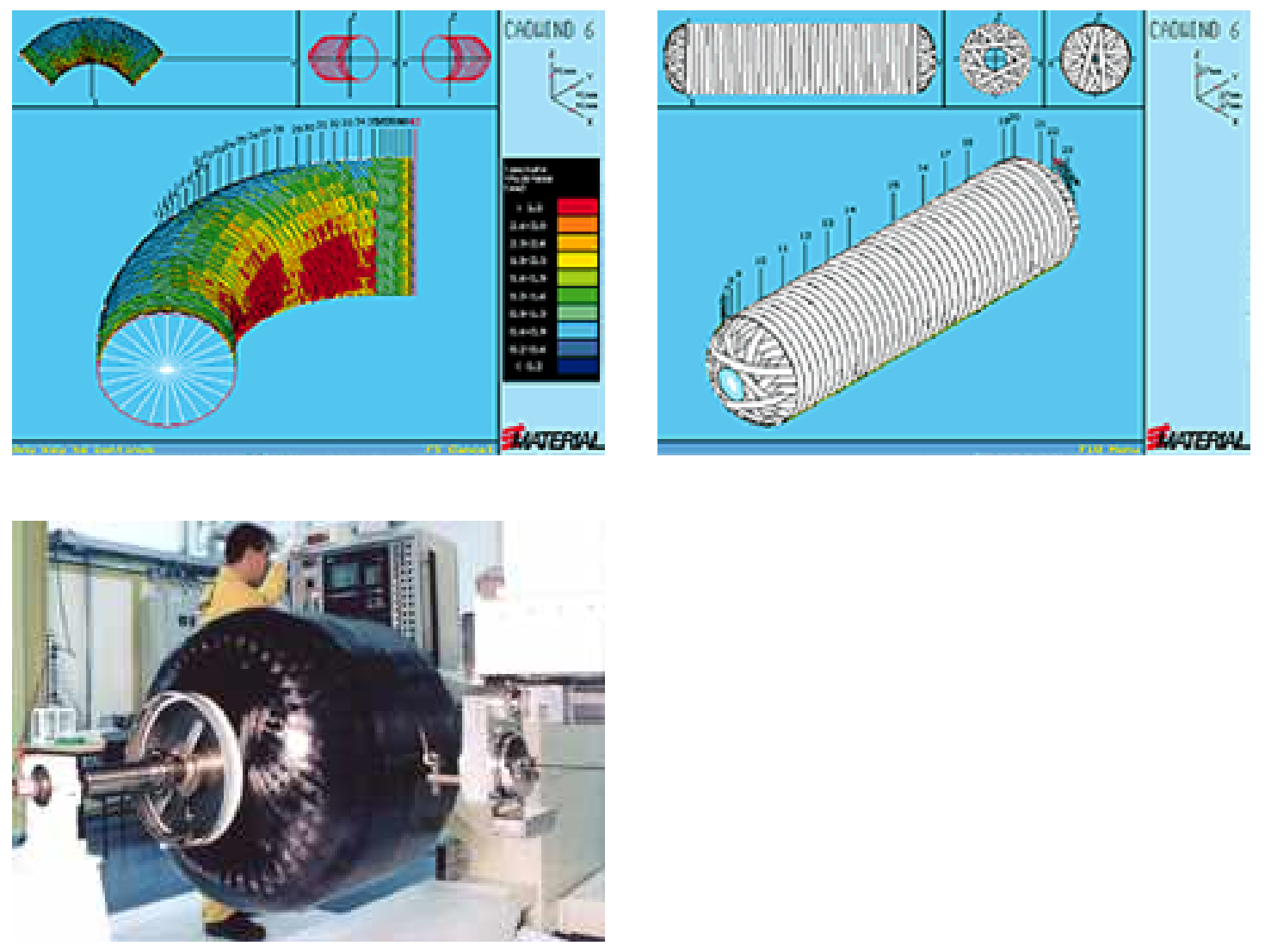

Figura 13 Software Cadwind 


\section{CAPÍTULO 3}

\section{METODOLOGIA E DESENVOLVIMENTO}

\subsection{INTRODUÇÃO}

O Software Cawar foi desenvolvido na Bélgica por Johan Scholliers (SCHOLLIERS, 1992) em Novembro de 1992. Ele utilizou a linguagem C para elaboração de um software que calculasse a trajetória das fibras no processo de revestimento de materiais compósitos. Após seu trabalho, Jonas de Carvalho em janeiro de 1996 concluiu seu trabalho dando seqüência ao trabalho de Johan. Carvalho desenvolvia a técnica de revestir materiais compósitos com fibras levando em consideração o erro da trajetória e a força de atrito entre as fibras. Deu seqüência ao trabalho aprimorando o software e os cálculos da trajetória. O software está continua escrito em $\mathrm{C}$ e sendo executado em DOS.

O objetivo deste trabalho é preparar uma plataforma onde possam ser implementados módulos para os cálculos futuros que venham a calcular a trajetória da fibra de modo otimizado. Módulos estes que poderão contemplar os mais diversos e 
complicados cálculos como peças assimétricas a partir de protocolos IGES ou STL, permitir a mudança do ângulo de revestimento entre uma camada e outra e gerar imagens para a visualização da peça acabada ou em suas camadas.

\subsection{MODELAGEM DO PROGRAMA}

Para modelar o programa de modo que um programador possa visualizar a plataforma de um modo geral e claro, bem como suas funções, seus objetos, classes e interação do programa, o programa é desenhado em UML (Linguagem de Modelagem Unificada). Diagrama de Classes:

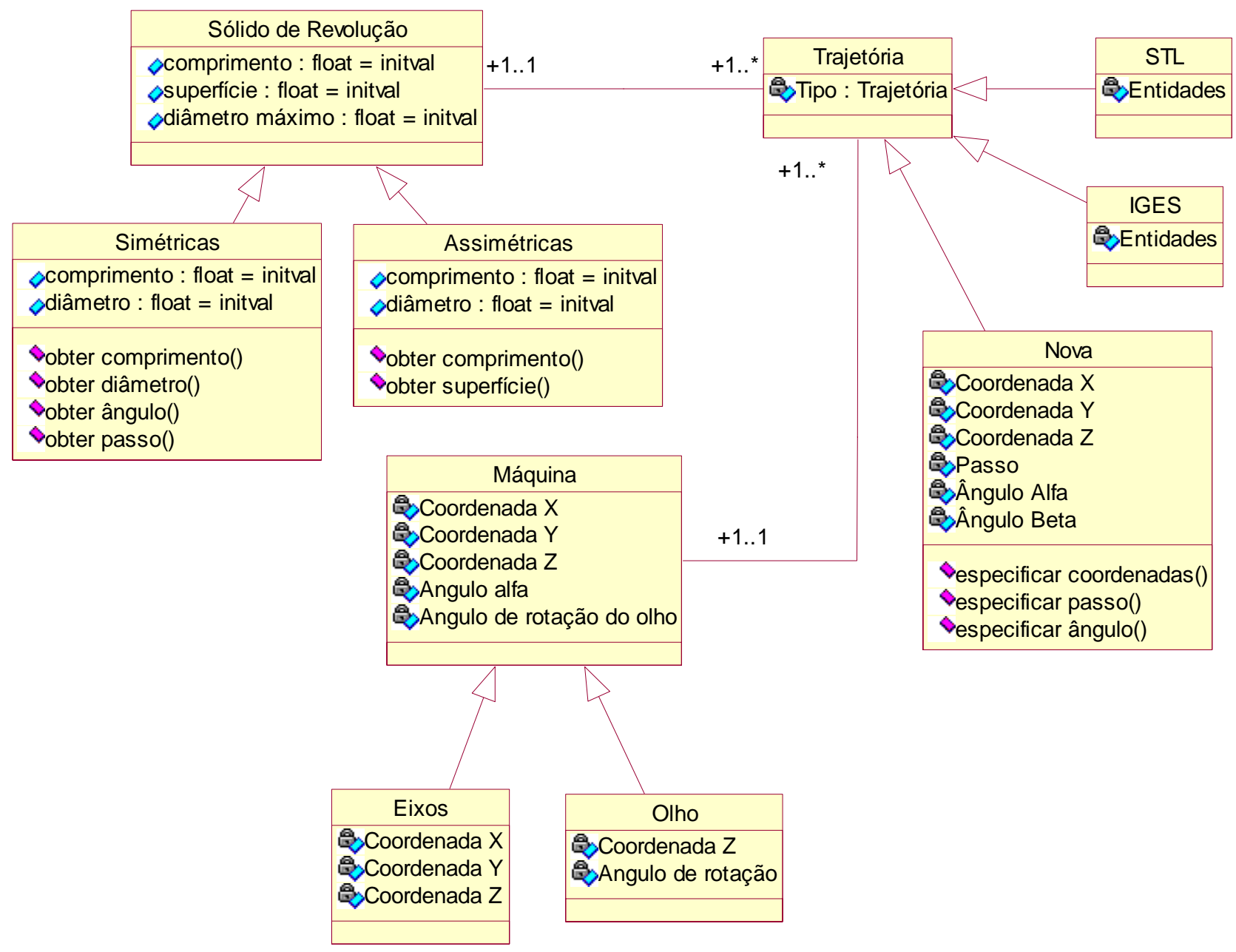




\section{Diagrama de seqüência:}

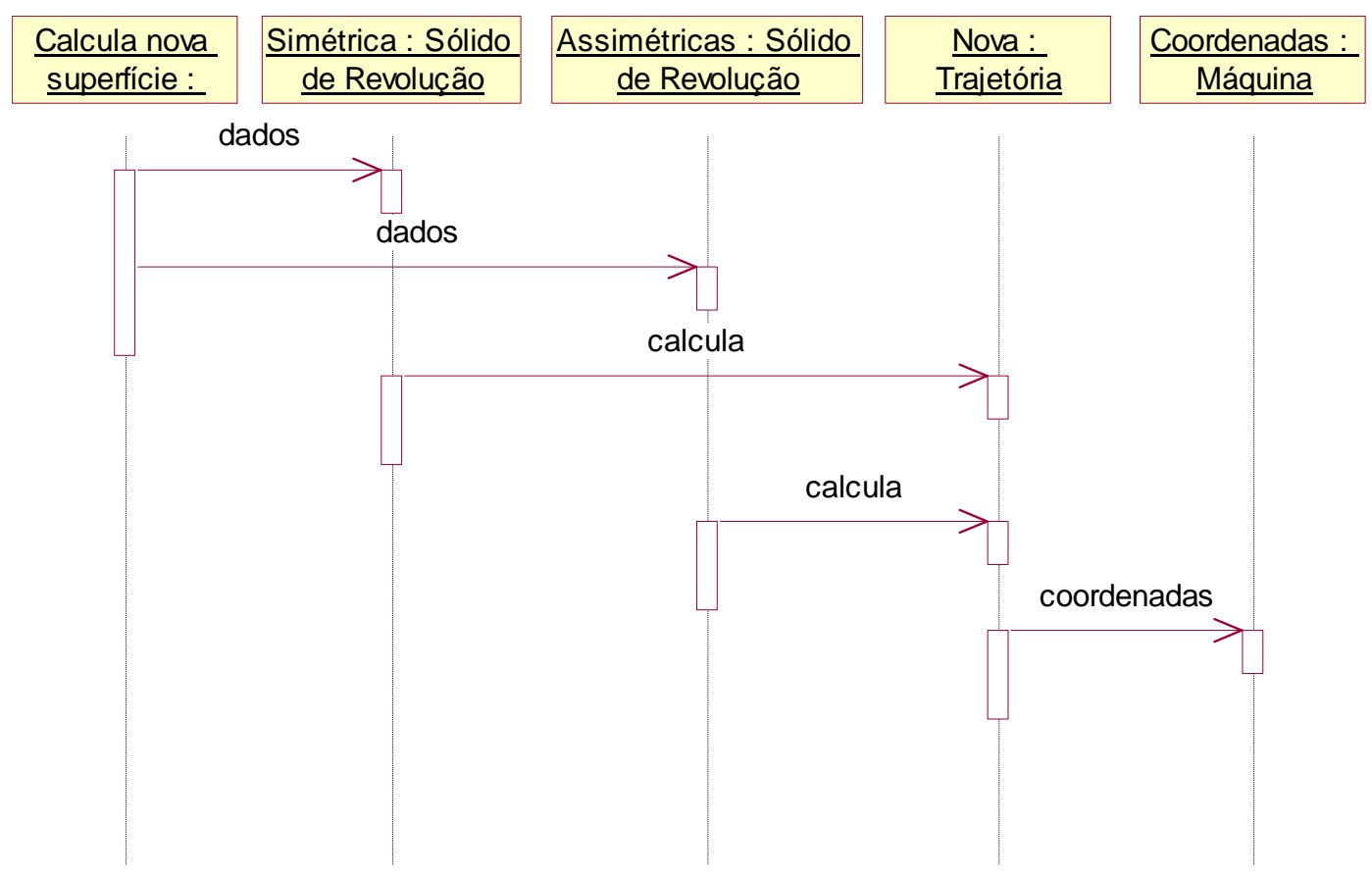

Diagrama de Interação:

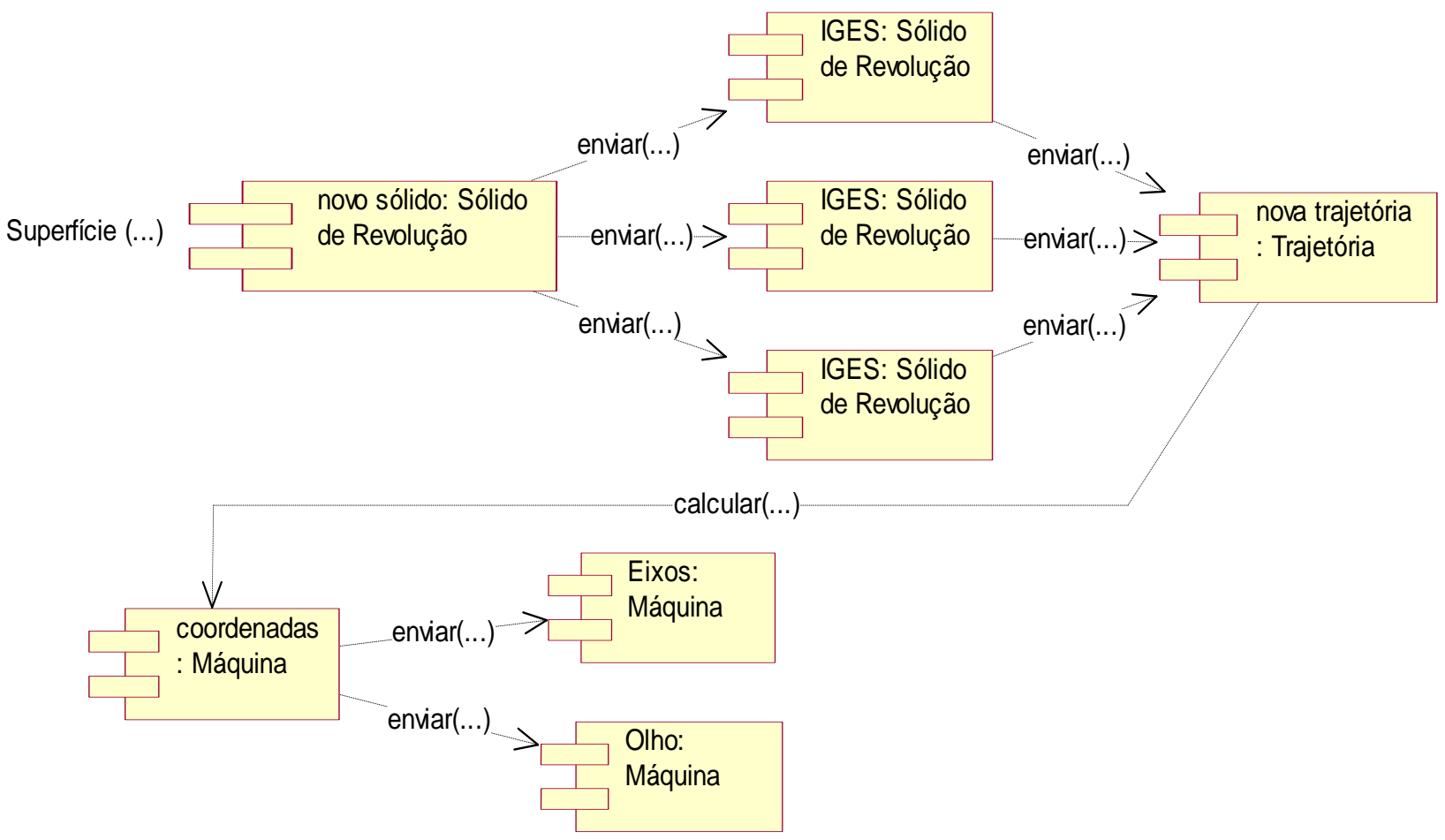




\subsection{ELABORAÇÃO E FUNCIONAMENTO DO PROGRAMA}

O programa será composto de módulos e funções do programa Cawar, que serão implementados no futuro. Nesta primeira etapa do desenvolvimento do programa, serão implementadas apenas funções para o cálculo de um sólido simétrico de revolução, um cilindro simples com diâmetro, comprimento e ângulo da fibra ou passo, que serão dados fornecidos pelo usuário.

Quatro vetores foram criados para armazenar os dados resultantes dos cálculos do programa. São os vetores $\mathrm{X}, \mathrm{Y}$ e Z para armazenar as coordenadas e o vetor Beta para armazenar os valores do ângulo de localização da trajetória nos quatro quadrantes. Este ângulo armazenado no vetor Beta definirá o quadrante em que o processo se encontra durante o cálculo das coordenadas e o sinal para as coordenadas que serão armazenadas nos vetores $\mathrm{Y}$ e Z. Estes valores adotam o milímetro (mm) para a realização dos cálculos.

As funções que serão implementadas nesta primeira fase serão:

- Nova superfície

- Escolha da Fibra

- Passo e Ângulo Beta

- Coordenadas X, Y e Z

- Salvar arquivos 
O programa utiliza dados de entrada fornecidos pelo usuário e o valor do diâmetro do fio que o usuário deseja utilizar, para os cálculos de cilindros simples e simétricos. Ao abrir o programa o usuário terá uma visão da tela de abertura com os menus nos quais o mesmo utilizará.

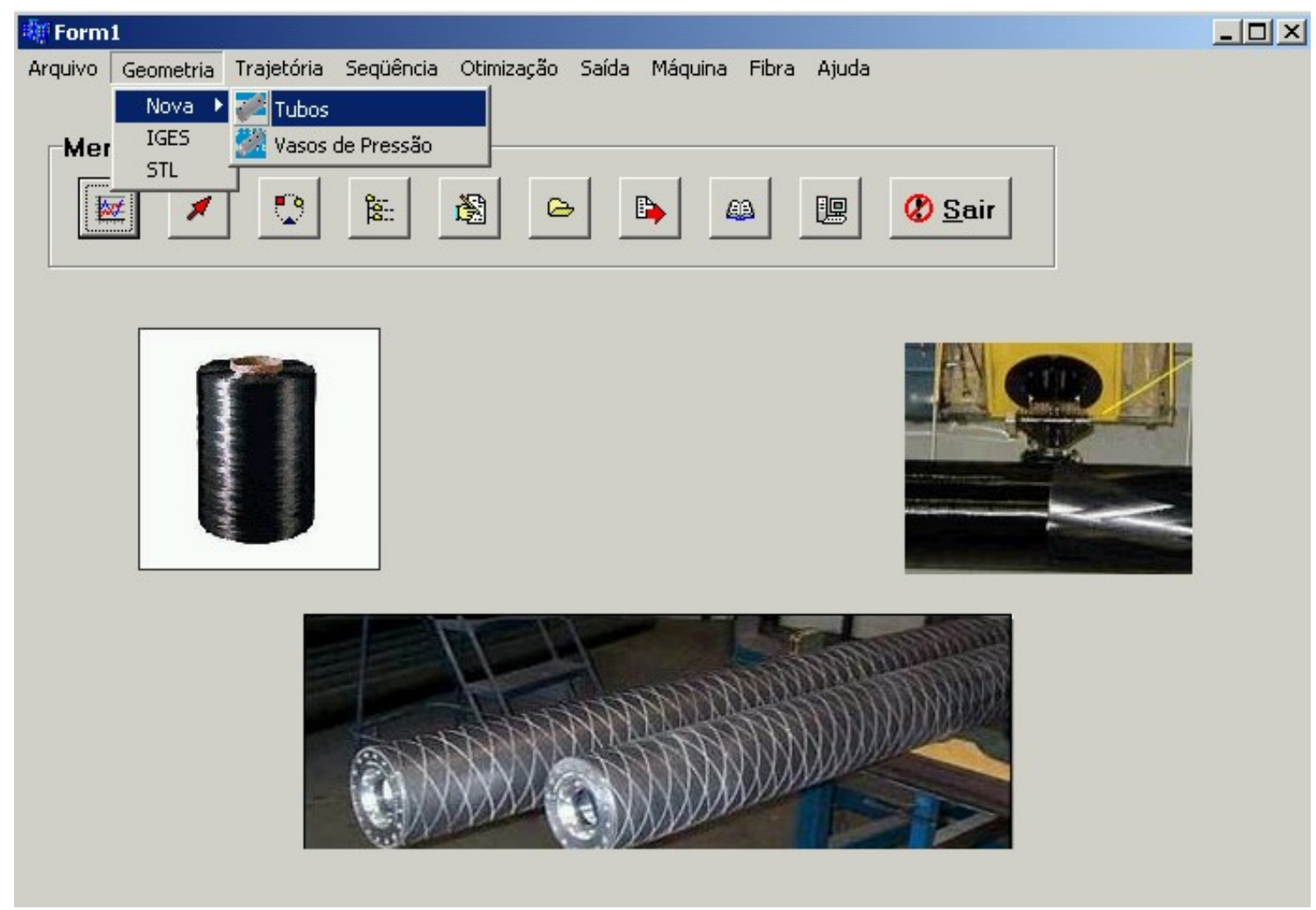

Figura 14 Tela de abertura do programa

Na tela de abertura, no menu fibras, o usuário encontrará outra tela que o levará a tela com os dados da fibra que o programa contêm, fornecidos pelo fabricante da fibra. Neste momento o usuário deve escolher a fibra que será utilizada para o revestimento do cilindro. O usuário após acionar este evento encontrará uma tabela de fibras e valores fornecidos pelo fabricante. 


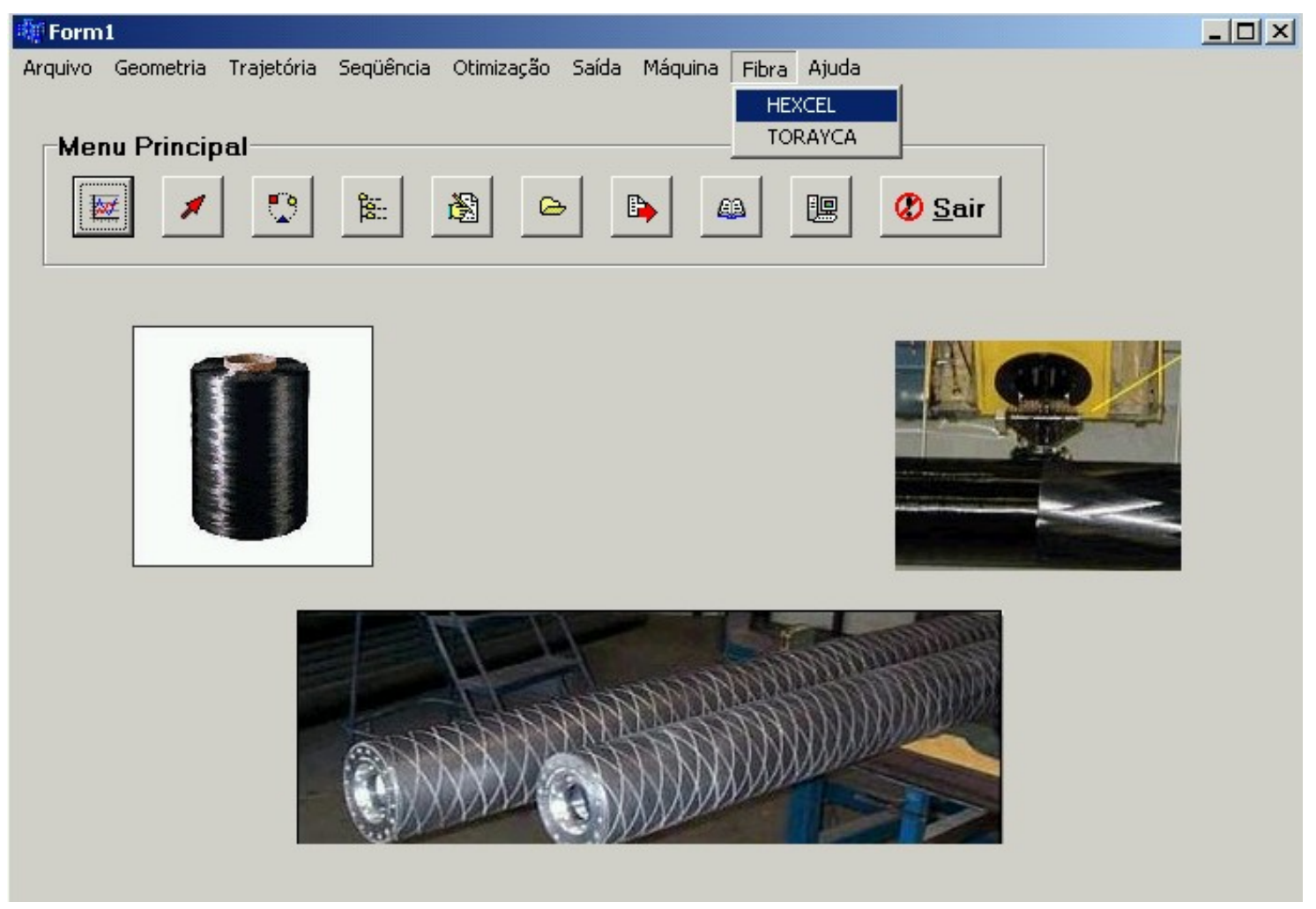

Figura 15 Menu do evento para escolha da fibra.

O programa levará o usuário a uma tela onde são mostrados os dados da fibra. Estes dados são encontrados na Internet pelo fabricante HECXEL ${ }^{\circledR}$ obtidos através de experiências executadas pelo próprio fabricante. 


\begin{tabular}{|c|c|c|c|c|c|c|}
\hline Form9 & & & & & & $-1 ㅁ ㅣ$ \\
\hline \multicolumn{7}{|l|}{ FIBRAS } \\
\hline $\begin{array}{c}\text { TIPO DE } \\
\text { FIBRA }\end{array}$ & $\begin{array}{l}\text { NÚMERO DE } \\
\text { FILAMENTOS }\end{array}$ & $\begin{array}{c}\text { RESISTENCIA A } \\
\text { TRACAOA MPA }\end{array}$ & $\begin{array}{c}\text { MÓDULO DE } \\
\text { ELASTICIDADE GPA }\end{array}$ & $\begin{array}{c}\text { SECCAOO } \\
\text { TRANSVERSALmm² }\end{array}$ & $\underset{\mathrm{g} / \mathrm{cm}^{3}}{\text { DENSIDADE }}$ & $\underset{\mathrm{mm}}{\text { DIÂMETRO }}$ \\
\hline \multirow[t]{3}{*}{ AS4 } & $C \mathbf{3 0 0 0}$ & 4278 & 228 & 0,12 & 1,79 & 0,390 \\
\hline & $\curvearrowright 6000$ & 4278 & 228 & 0.24 & 1,79 & 0,553 \\
\hline & $C 12000$ & 4278 & 228 & 0.48 & 1.79 & 0,782 \\
\hline \multirow[t]{3}{*}{ AS4C } & $C \mathbf{3 0 0 0}$ & 4347 & 231 & 0.11 & 1,78 & 0,374 \\
\hline & $C 6000$ & 4347 & 231 & 0,22 & 1.78 & 0,529 \\
\hline & C 12000 & 4347 & 231 & 0,44 & 1,78 & 0,748 \\
\hline AS 4D & C 12000 & 4692 & 245 & 0,43 & 1.79 & 0.740 \\
\hline IM4 4 & C 12000 & 4796 & 276 & 0.41 & 1.78 & 0,723 \\
\hline IM6 & C 12000 & 5589 & 279 & 0.25 & 1.76 & 0,740 \\
\hline \multirow[t]{3}{*}{ IM7 } & $\subset 6000$ & 5175 & 276 & 0,13 & 1,78 & 0,407 \\
\hline & C 12000 & 5520 & 276 & 0.25 & 1.76 & 0,564 \\
\hline & C 12000 & 5760 & 292 & 0.25 & 1,79 & 0,564 \\
\hline IM7C & $C 12000$ & 5796 & 290 & 0.28 & 1.80 & 0,597 \\
\hline IM8 & $\subset 12000$ & 5589 & 304 & 0.25 & 1,79 & 0,564 \\
\hline IMC & C 12000 & 5520 & 290 & 0,28 & 1.80 & 0,597 \\
\hline $\mathrm{PV} 36 / 700$ & $C 12000$ & 4690 & 248 & 0,43 & 1.79 & 0.740 \\
\hline $\mathrm{PV} 42 / 800$ & $C 12000$ & 5520 & 290 & 0.28 & 1,80 & 0.597 \\
\hline PV42/850 & C 12000 & 5760 & 292 & 0,25 & 1.79 & 0,564 \\
\hline 學 $\underline{a k}$ & (2) Sair & & & & & \\
\hline
\end{tabular}

Figura 16 Tabela de fibras e valores. Fonte: Hexcel ${ }^{\circledR}$.

O fabricante não fornece o diâmetro do fio composto por vários filamentos, porém fornece a densidade e o peso para um comprimento de 1000 meros. Com estes dados é possível calcular o diâmetro do fio usando a relação densidade, massa e volume.

$$
v=\frac{m}{d}
$$

$$
\text { Sendo } v=\frac{\pi \cdot d^{2}}{4} \cdot h
$$

Onde: $\frac{\pi \cdot d^{2}}{4}=$ secção do fio 
A massa e a densidade são fornecidas pelo fabricante. Com estes dados podemos calcular o diâmetro do fio.

$$
\begin{aligned}
& \frac{\pi \cdot d^{2}}{4} \cdot h=\frac{\left.m_{2} 2\right)}{D} \\
& d=\sqrt{\frac{4 \cdot m_{23}}{D \cdot \pi \cdot h}}
\end{aligned}
$$

Após a escolha da fibra, o usuário aciona o botão OK e em seguida o botão Sair. Levando-o a tela inicial. Na tela inicial o usuário escolhe a opção Geometria, Nova, Tubos.

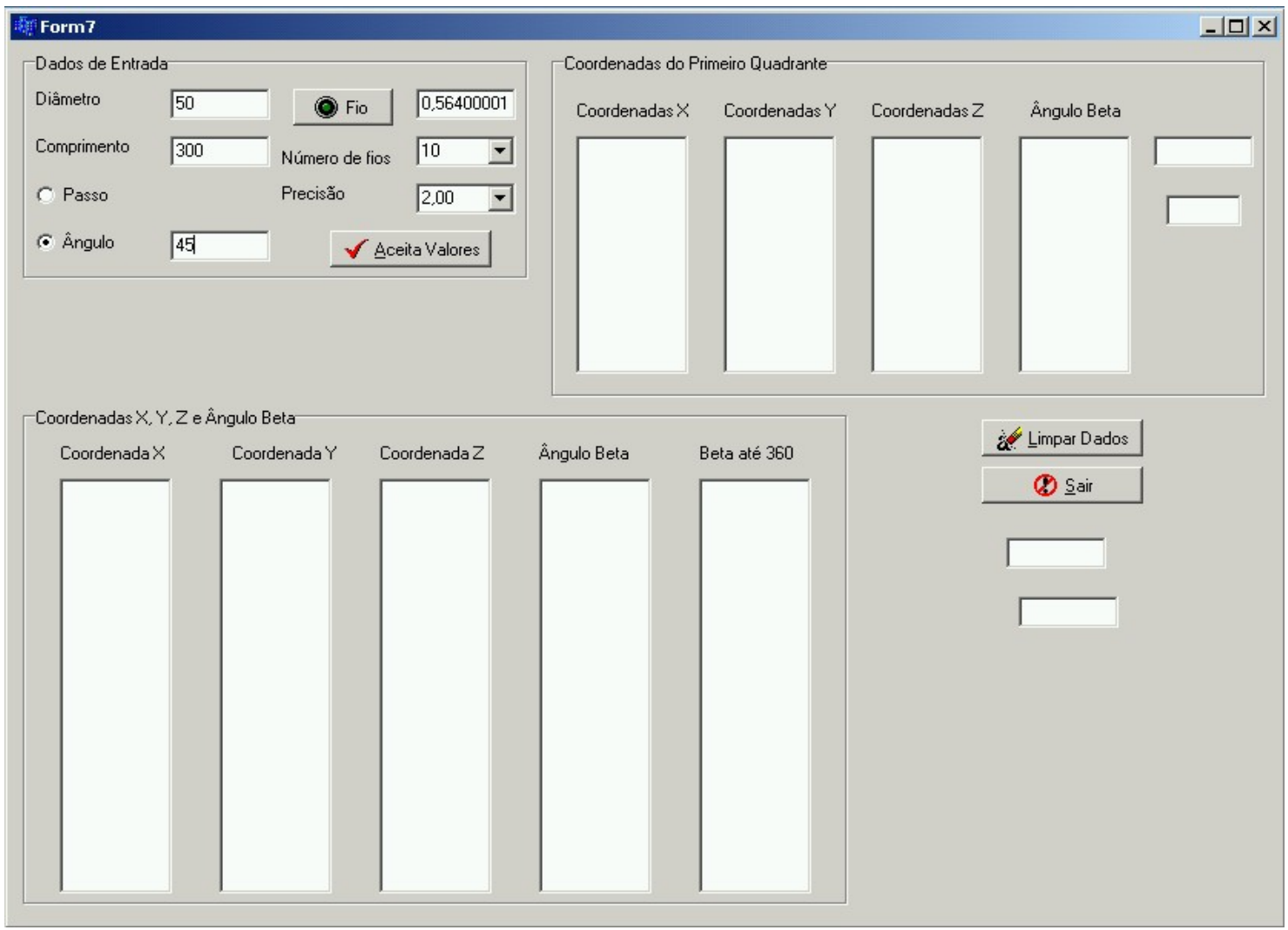

Figura 17 Menu para escolha do revestimento de um cilindro. 
Será aberta uma janela de diálogo onde o usuário fornecerá os dados do cilindro que ele deseja revestir. Os dados que o usuário fornecerá são: diâmetro do cilindro, comprimento do cilindro, passo ou ângulo e precisão. Em seguida o usuário deve acionar o botão Fio que trará para esta janela o valor do diâmetro da fibra de carbono que o usuário escolheu, calculado com base nos dados do fabricante e em seguida o usuário fornecerá o número de fios que usará para revestir.

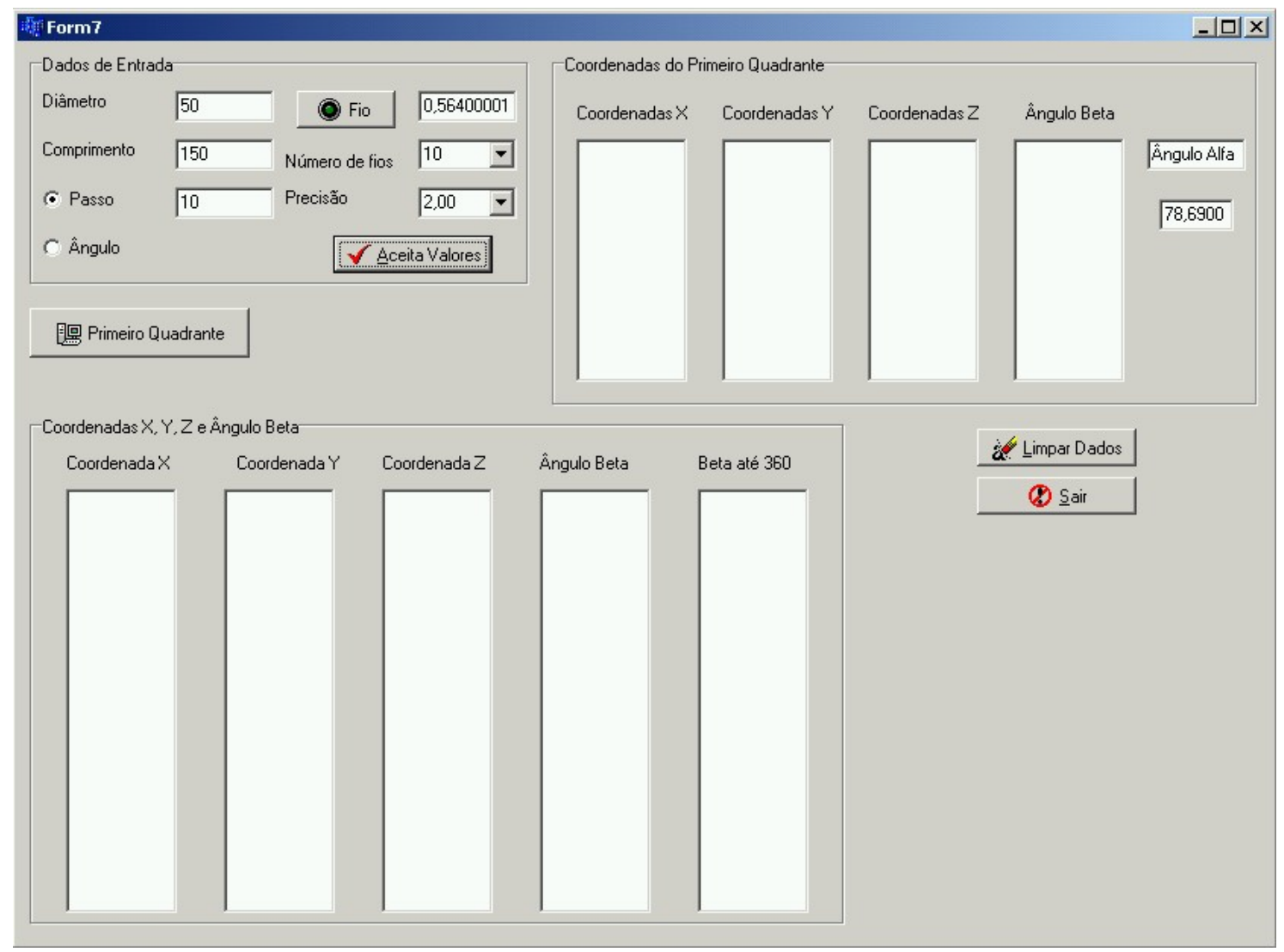

Figura 18 Tela dos valores do cilindro e dos resultados dos cálculos.

Se porventura o usuário não acionou o botão Ok na tela de escolha da fibra, quando o mesmo acionar o botão fio, o programa levará o usuário à tela de fibra novamente com uma mensagem para que o usuário escolha uma fibra e acione o botão OK. 
O usuário fornece o ângulo ou passo que a fibra terá na superfície do cilindro e o programa calcula o passo ou o ângulo da fibra para o revestimento de acordo com a opção que o usuário escolheu. O ângulo deve estar entre zero e noventa graus. Se nos cálculos para ângulo ou passo, o passo não for maior que o comprimento da peça, o botão de Coordenadas do Primeiro Quadrante será habilitado, caso contrário aparecerá uma mensagem de erro no passo ou no ângulo, onde o usuário deverá corrigir um destes dados.

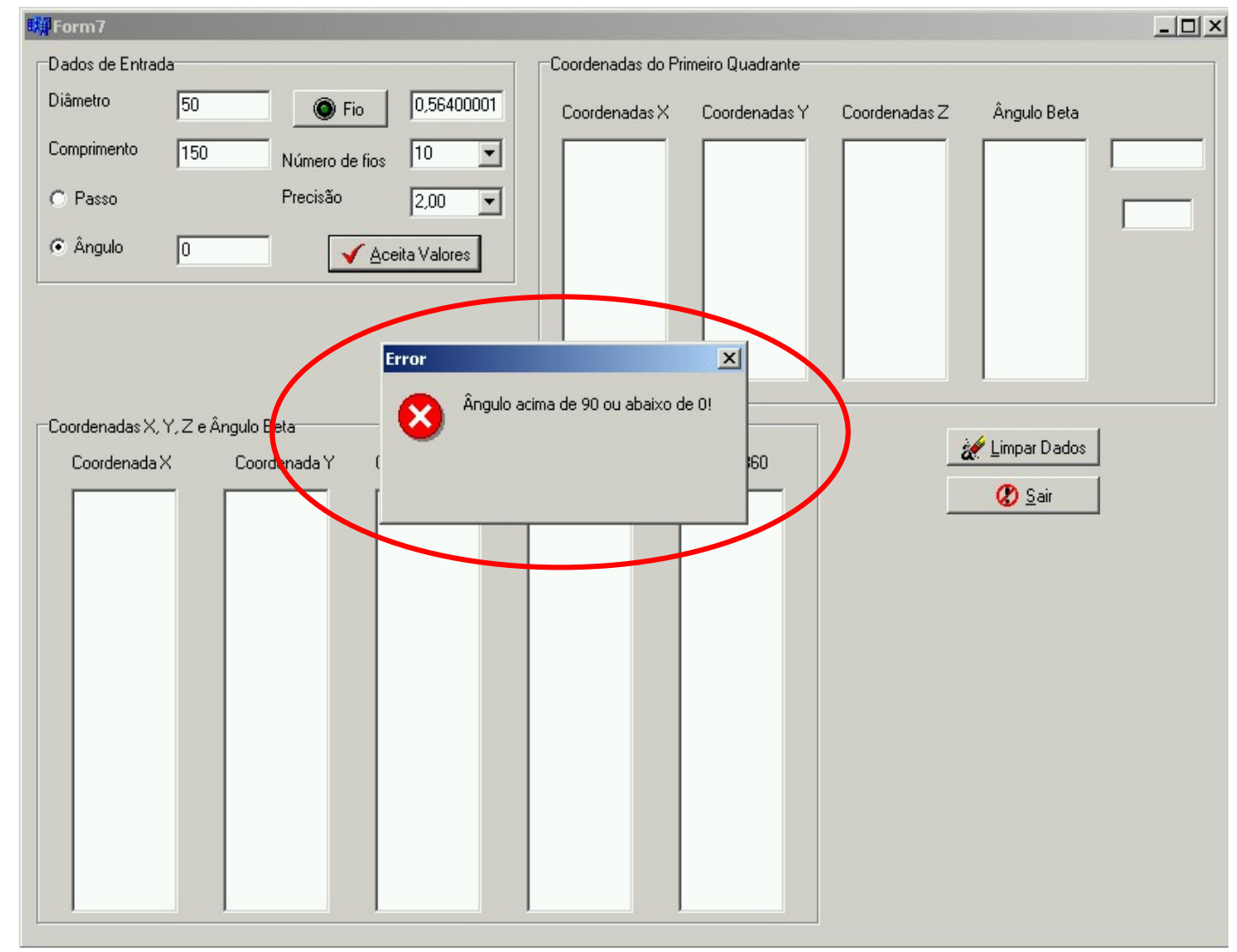

Figura 19 Ilustração um exemplo de erro quando o usuário fornece um valor para passo ou ângulo que ultrapasse o limite de comprimento ou esteja fora da janela de zero a 90 graus. 


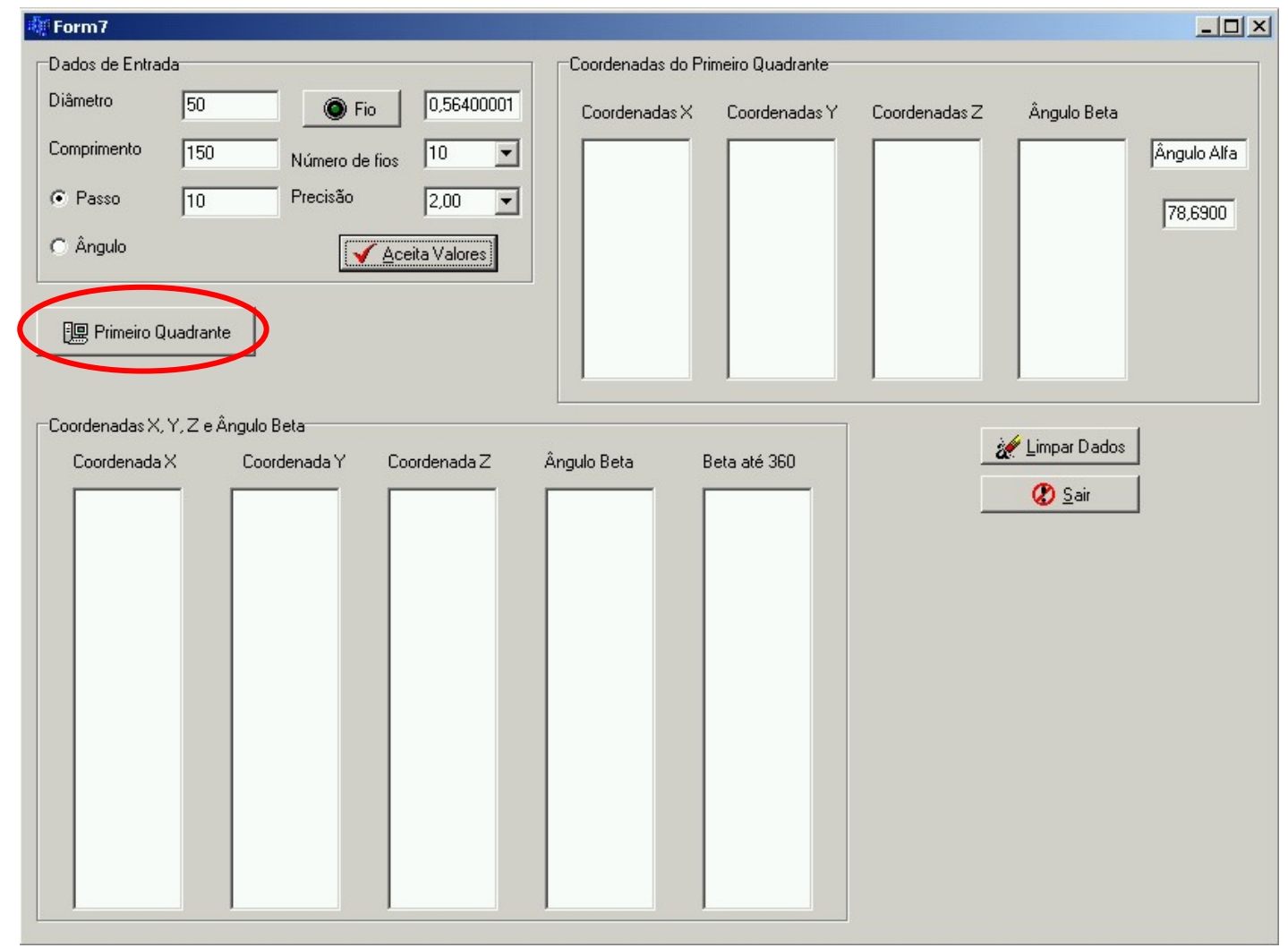

Figura 20 Botão Primeiro Quadrante habilitado.

Acionando o botão de Coordenadas do Primeiro Quadrante, o usuário poderá ver as coordenadas no primeiro quadrante sendo que a precisão que o mesmo escolheu serão os valores para o eixo Y. Em seguida o botão de Coordenadas Finais será habilitado para que o usuário possa ver todas as coordenadas até o final do revestimento. No mesmo painel onde serão mostradas as coordenadas do primeiro quadrante, aparece o ângulo ou o passo calculado pelo programa. Se o usuário forneceu o passo, o programa mostrará o valor do ângulo, se o usuário forneceu o ângulo, o programa mostrará o valor do passo. O valor do Ângulo Beta será mostrado em uma coluna com todos os valores para o primeiro quadrante. 


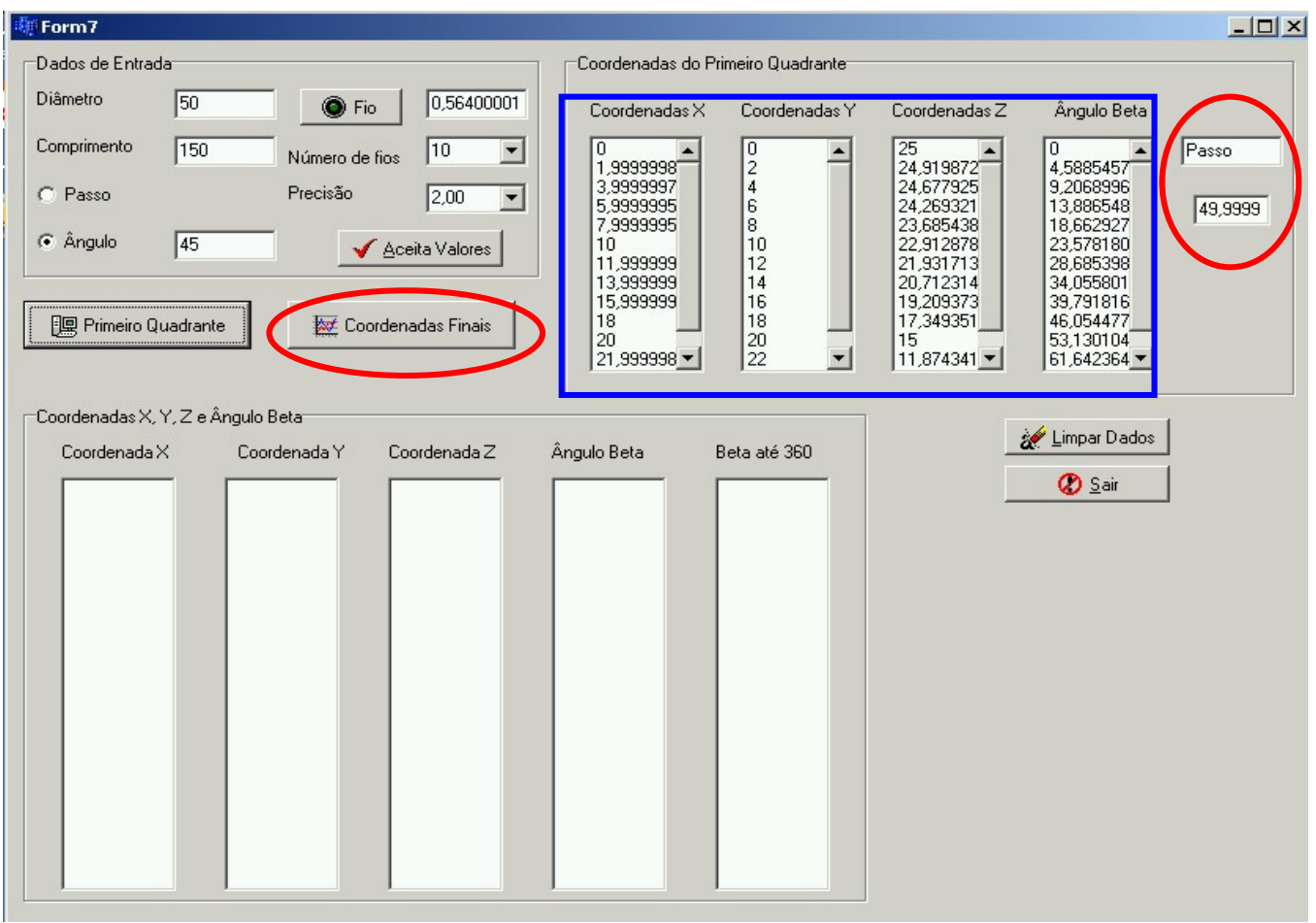

Figura 21 Valores do primeiro quadrante e valor para passo ou ângulo Alfa.

Em seguida o usuário poderá acionar o botão de Coordenadas finais onde serão calculados os valores das coordenadas X, Y, Z e o ângulo beta ao longo do revestimento.

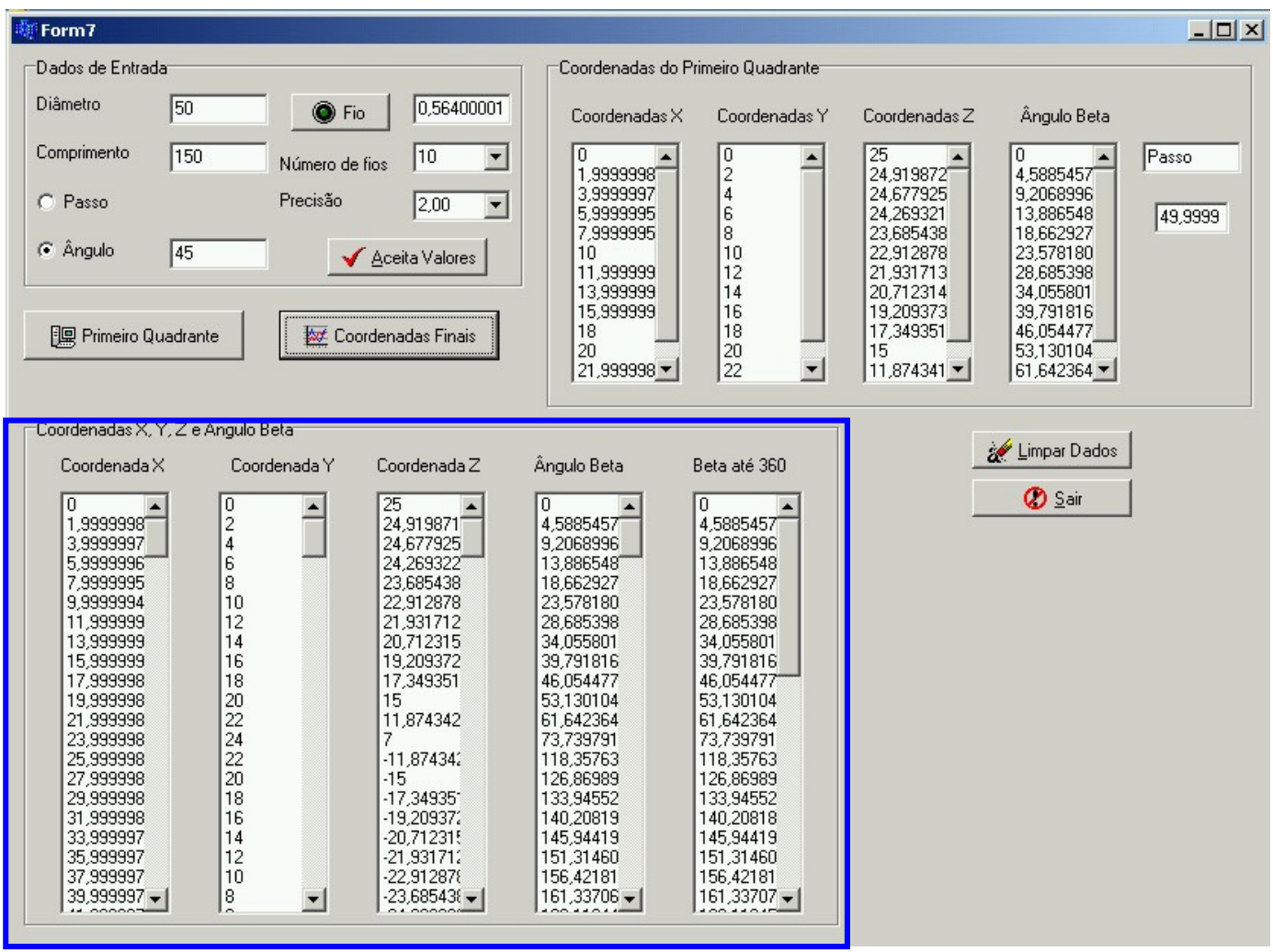

Figura 22Valores dos demais quadrantes para todo o revestimento. 
A intenção desta plataforma é que no futuro, módulos para cálculo das coordenadas com base nos protocolos provenientes de programas CAD (IGES e STL) e peças assimétricas, possam ser executados.

O protocolo IGES traz a descrição para as superfícies nas entidades 126 e 128 do protocolo IGES. O programa também poderá ter seus cálculos realizados no protocolo STL que trata a superfície de um sólido como triângulos, o que poderá acontecer no futuro, assim como um novo protocolo dependendo da necessidade.

O programa trabalhará com módulos ou funções que realizam os cálculos quando são invocados. Estes módulos trabalharão como caixas pretas, ou seja, o usuário não terá acesso aos cálculos que estarão sendo realizados nas funções. Os resultados obtidos por estas funções serão mostrados ao usuário por intermédio da interface do sistema.

O programa também poderá ter alguns módulos para controle dos servos e motores da máquina de “Filament Winding”, cálculo de superfícies assimétricas e visualização gráfica do processo de revestimento.

\subsection{CÁLCULO DA TRAJETÓRIA DA FIBRA}

Cada função no programa tem sua finalidade no resultado final do processo de revestimento ("Filament Winding”), que é a obtenção de uma peça reforçada por fibras de um modo otimizado e de alta resistência. 
Neste trabalho, o enfoque está na plataforma para o desenvolvimento do software que deverá ser concluído no futuro. Nesta fase, somente um módulo será implementado: o cálculo de cilindro simples. No menu do programa é apresentado como peças tubulares como mostrado na figura 14 .

O programa calcula os pontos ao longo da superfície através de cálculos de trigonometria, de maneira que quando estes pontos serem ligados, formarão uma trajetória na superfície do cilindro que a fibra irá percorrer. A figura 20 mostra um desenho feito em CAD de como os pontos calculados pelo programa mostram a trajetória descrita na superfície de um cilindro.
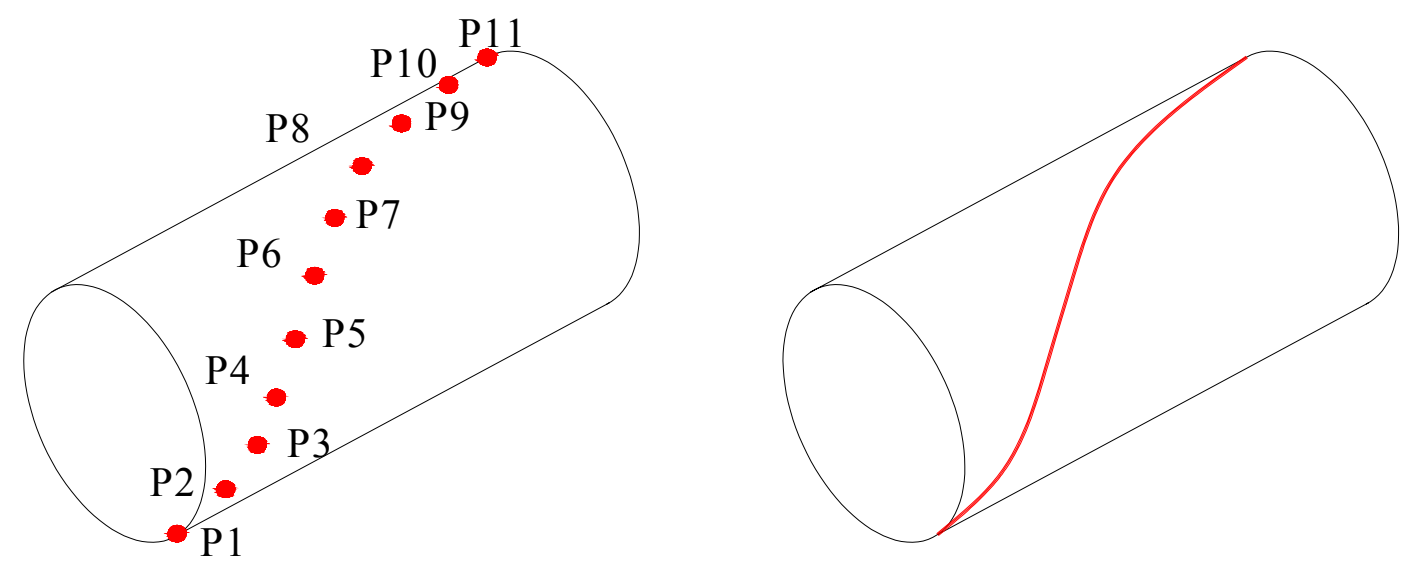

Figura 23 Pontos calculados que formarão uma trajetória para a fibra.

Para entendermos melhor o cálculo da trajetória da fibra, alguns fatores que serviram de fundamento para o desenvolvimento do programa serão apresentados:

- Eixo X é o eixo que forma o eixo de simetria do cilindro;

- Eixo Z é o eixo da horizontal no topo do cilindro;

- Eixo Y é o eixo da vertical no topo do cilindro; 
- Ângulo Alfa é o ângulo formado entre a geratriz do cilindro e a inclinação da trajetória da fibra bobinada no cilindro;

- Ângulo Beta é o ângulo obtido pelo cálculo dos pontos Y e Z. Este ângulo informa o quadrante em que está o processo de cálculo para o programa e o número de revoluções que o cilindro sofreu.

- Topo inicial é o ponto zero ou o início do cilindro de onde a fibra partirá.

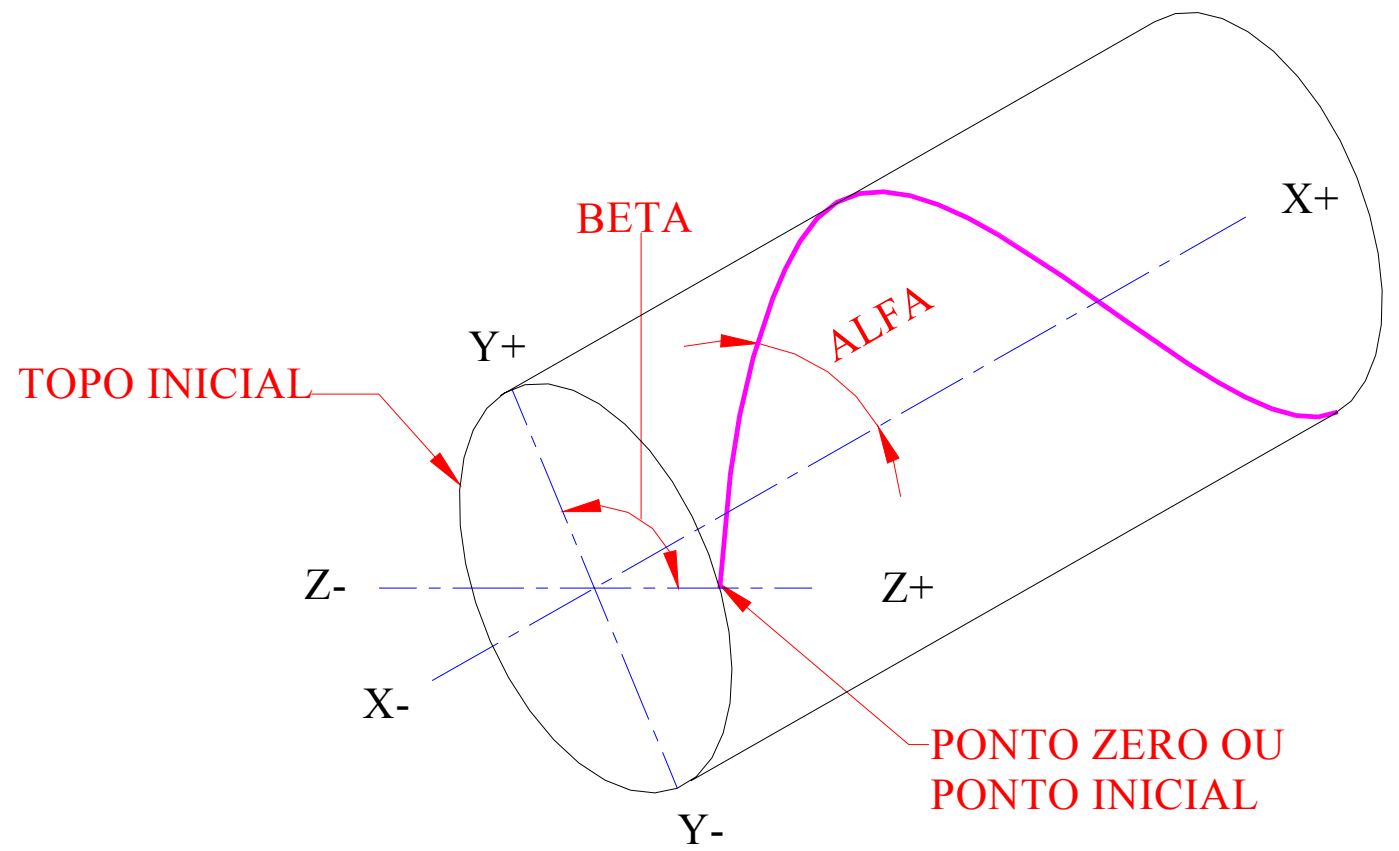

Figura 24 Referência e sentido adotado para os cálculos do programa.

\subsubsection{CÁLCULO DO PRIMEIRO QUADRANTE}

O usuário irá fornecer para o programa o diâmetro e o comprimento do cilindro e o ângulo $\alpha$ ou o passo. Nesta etapa o programa calcula o ângulo alfa ou o passo de acordo com que o usuário forneceu. 
O usuário também deverá escolher a precisão que deseja ter em seu projeto. Esta precisão é a divisão do eixo Y no primeiro quadrante. No programa foram limitados a quatro escalas de precisão: $0,25 \mathrm{~mm}, 0,50 \mathrm{~mm}, 1,00 \mathrm{~mm}$ e $2,00 \mathrm{~mm}$.

A escolha desta precisão dividirá o raio dando o número de pontos em Y no primeiro quadrante. Nesta fase o ângulo Beta estará entre zero e noventa graus.

$$
n Y=\frac{R}{p r}
$$

$\mathrm{O}$ valor de cada ponto do eixo Y é a própria precisão escolhida pelo usuário. A Erro! A origem da referência não foi encontrada. ilustra as divisões do eixo Y que servirá de referência para os cálculos do programa.

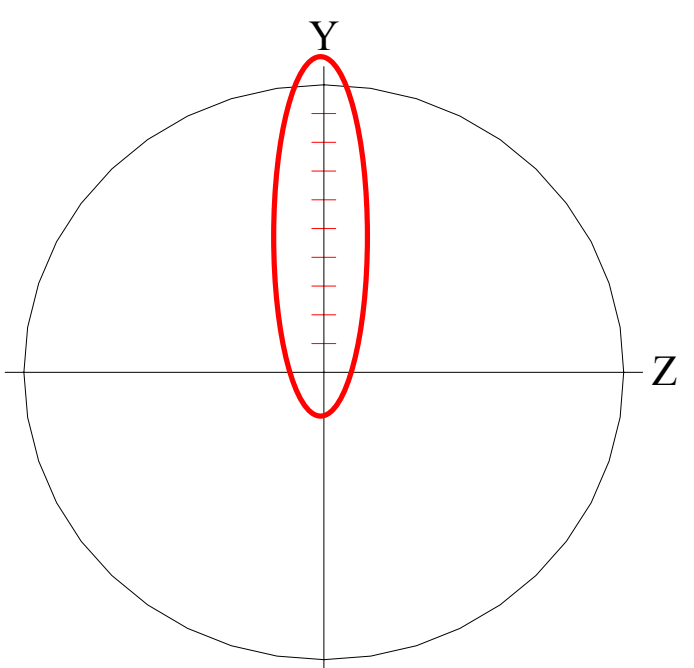

Figura 25 Divisões dos pontos do eixo $Y$.

O valor para cada ponto em $\mathrm{Z}$ é obtido pela relação simples do triângulo retângulo, onde hipotenusa é igual à soma dos catetos ao quadrado. Como o objetivo 
nesta fase é determinar o cateto que será o ponto $\mathrm{Z}$, ele é dado pela raiz quadrada do raio ao quadrado menos o valor do ponto $\mathrm{Y}$ ao quadrado.

$Z=\sqrt{R^{2}-Y^{2}}$

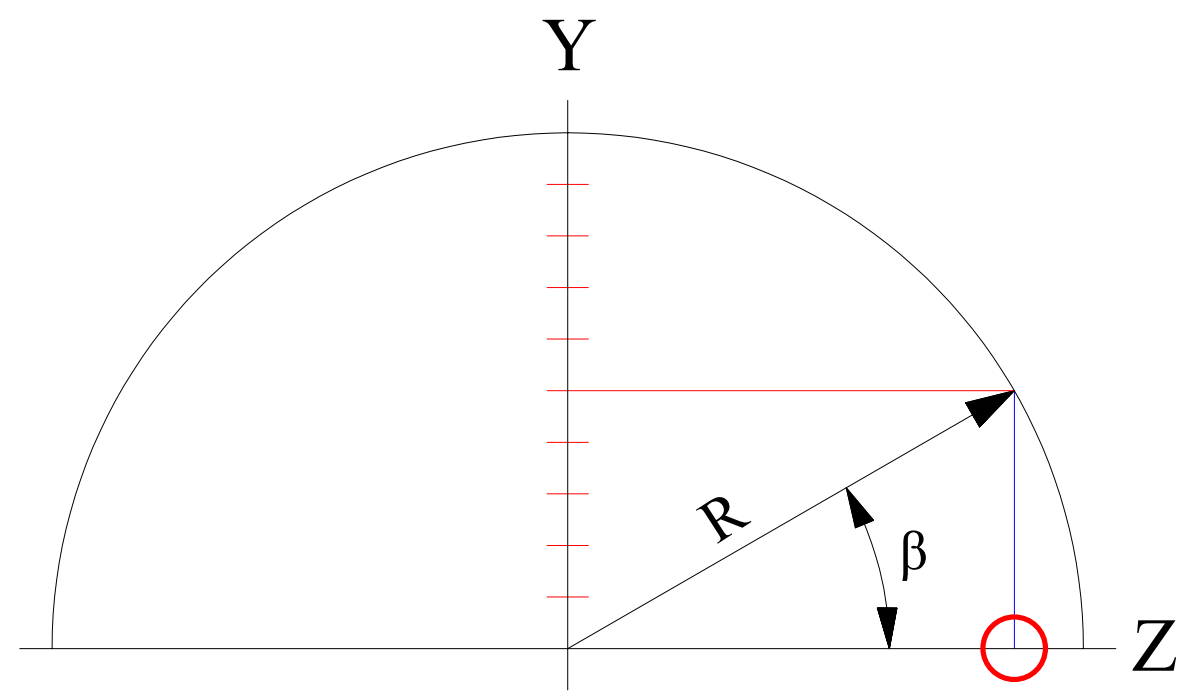

Figura 26 Valor do ponto $\mathrm{Z}$ tendo como base o ponto $\mathrm{Y}$ e o raio.

O ângulo $\beta$ é obtido através dos pontos $\mathrm{Y}$ e Z, representados no topo do cilindro. Com este ângulo é possível determinar quantas revoluções o cilindro sofrerá ao longo do revestimento. Os valores do ângulo Beta são obtidos através do arco co-seno do ponto $\mathrm{Z}$ dividido pelo raio.

$$
\beta=\text { arc } \_ \text {cos }\left(\frac{Z}{\text { raio }}\right)
$$

$\mathrm{O}$ valor dos pontos para o eixo $\mathrm{X}$ é obtido pela relação da tangente de alfa. $\mathrm{O}$ valor para cada ponto $\mathrm{X}$ será o valor do ponto $\mathrm{Y}$ dividido pela tangente de alfa. 


$$
X=\frac{\text { Passo } \times \beta}{360}
$$

Estes dados são mostrados na tela, na janela do primeiro quadrante para que o usuário visualize a descrição da trajetória da fibra no primeiro quadrante.

\subsubsection{CÁlCULO DA TRAJETÓRIA DA FIBRA ATÉ O COMPRIMENTO DO CILINDRO}

As coordenadas para os eixos $\mathrm{X}, \mathrm{Y}, \mathrm{Z}$ e o ângulo beta ao longo do topo do cilindro serão como que um espelho do primeiro quadrante, tendo seus valores negativos ou positivos dependendo do quadrante em que estiverem durante o processo de cálculo do programa.

O responsável em determinar o quadrante no qual o processo de cálculo do programa está, é o ângulo Beta. Uma vez que o ângulo Beta atingiu 360 graus, ele recebe o valor zero e uma variável para contagem de revoluções é incrementada.

No comprimento final do cilindro ou quando o próximo valor para a coordenada $\mathrm{X}$ for maior que o comprimento do cilindro, esta série de cálculos finaliza. Em seguida será efetuada uma série de cálculos para que a trajetória da fibra faça um giro de 180 graus no comprimento final do cilindro.

Nesta etapa os valores para a coordenada $\mathrm{X}$ são mantidos no último valor calculado e os valores para as coordenadas $\mathrm{Z}, \mathrm{Y}$ e Beta são calculados até que a 
trajetória gire 180 graus no comprimento final do cilindro. Para esse giro, utiliza-se a precisão que determinou no início do programa os valores do primeiro quadrante. $\mathrm{O}$ número de valores em que ela resulta é igual a um giro de 90 graus na trajetória da fibra na superfície do cilindro, sendo assim, o dobro dos valores que ela resulta, dará um giro de 180 graus na trajetória da fibra na superfície do cilindro.

O cálculo do giro da trajetória da fibra nos topos do cilindro não é um movimento linear, porém neste primeiro módulo não foi levada em consideração a curva que a trajetória da fibra realiza no momento que ela faz o retorno do olho de um topo ao outro. Sendo assim, o usuário pode optar pela estratégia de colocar pinos ou aumentar o comprimento do cilindro para desprezar esta curva formada pela trajetória.

A estratégia de colocar pinos é recomendada somente no caso onde a fita que revestirá o cilindro seja extremante larga e um número muito pequeno de pinos sejam utilizados. Já no caso do usuário optar por aumentar o comprimento do cilindro, a trajetória da fibra no cilindro desenvolverá a curva nos topos citada acima, porém o comprimento útil para o usuário, ou seja, o comprimento que ele necessita que seja revestido, será revestido sem com que haja pontos na superfície por onde a fibra não seja depositada. 


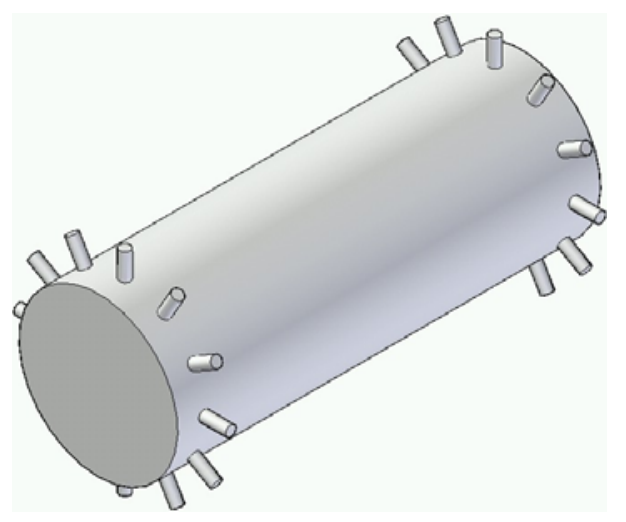

Figura 27 Ilustração de um cilindro com a opção de pinos e com a opção de aumentar o comprimento do cilindro.

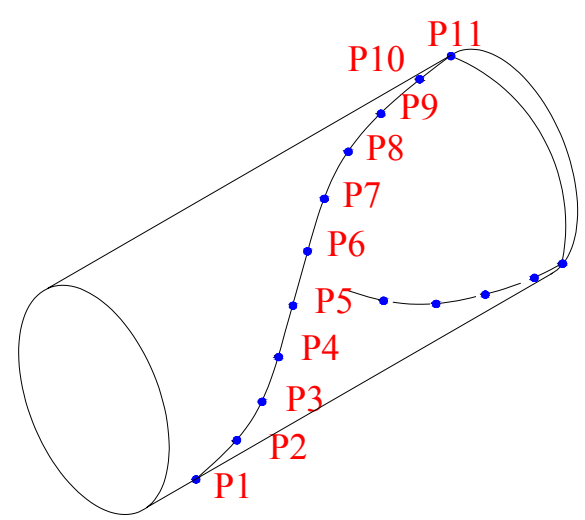

Figura 28 Estratégia do uso de pinos e do aumento do comprimento útil do cilindro.

\subsubsection{CÁlCULO DA TRAJETÓRIA APÓS O GIRO DE 180 GRAUS}

Após o giro de 180 graus, a trajetória da fibra volta ao início do cilindro, porém ela não volta ao ponto de partida onde iniciou o revestimento, ela voltará a 180 graus do ponto de partida para o revestimento mais um incremento que será o próximo passo para o revestimento. 
Os valores dos pontos para o retorno da fibra ao topo inicial do cilindro é um espelho dos pontos calculados para a trajetória da fibra do topo inicial ao comprimento final do cilindro, respeitando-se o quadrante em que se situa o processo de cálculo do programa.

No retorno do olho ao topo inicial do cilindro, a fibra retorna cruzando com a trajetória anterior feita do topo inicial ao comprimento do cilindro.

\subsection{INCREMENTO PARA UM NOVO REVESTIMENTO}

No retorno do olho ao topo do cilindro, um incremento é adicionado ao posicionamento do eixo Y. Este incremento equivale ao número de fios que será utilizado para o revestimento solicitado na tela do programa antes do cálculo de revestimento.

Este incremento determina um novo valor de início de revestimento para o eixo Y de modo que a fita ou o fio que esta revestindo o cilindro fique lado a lado, não sobrepondo nem permitindo superfície sem revestimento.

O valor do incremento é a largura da fita ou o diâmetro do fio no caso de um só fio. O usuário neste caso tem acesso ao diâmetro do fio que está listado na tabela do programa, na janela de Fibras. A largura da fita o programa calcula sendo o diâmetro do fio multiplicado pelo número de fios escolhido pelo usuário. 
O fabricante, no caso aqui utilizado a marca Hexcel ${ }^{\circledR}$, disponibiliza o número de filamentos, o peso em gramas por metro, resistência à tração, rigidez, módulo de deformação, densidade e o diâmetro do filamento. Com estes dados é possível calcular o diâmetro do fio que será utilizado através do cálculo das áreas do mesmo. No programa está sendo utilizados fios de 3000, 6000 e 12000 filamentos.

Filamento é o diâmetro da própria fibra. Uma fita corresponde aos vários filamentos dispostos lado a lado. O programa necessita saber o diâmetro do fio para que possa calcular o valor do incremento que será utilizado nos cálculos da trajetória da fibra ao longo da superfície do cilindro. Logo, conhecendo a fórmula da área e do volume de um cilindro, podemos calcular o diâmetro do fio da fibra que o fabricante fornece.

Para este cálculo, basta multiplicar o diâmetro do filamento pelo número de filamentos que está denominado na fibra $(3000,6000$ ou 12000) e teremos uma área equivalente à de um fio.

$$
s=\sqrt{d f i l^{2} \bullet n_{-} f i l}
$$

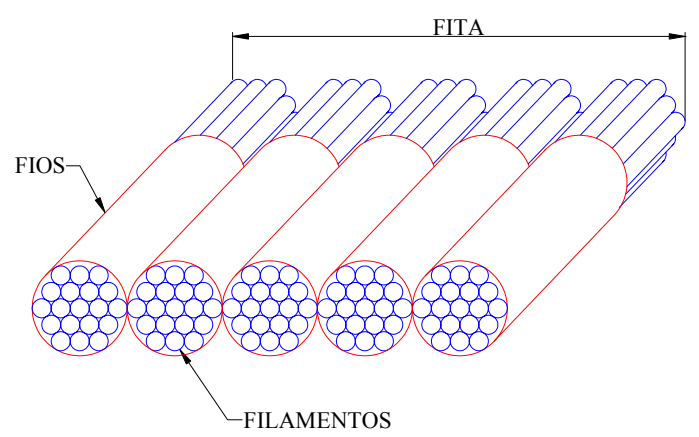

Figura 29 Desenho ilustrativo de uma fita contendo fios e filamentos. 
Para o revestimento de uma camada no cilindro, é necessário que a fibra revista todo o cilindro sem deixar áreas descobertas pela fibra. Um ciclo corresponde a trajetória da fibra que percorreu de um topo ao outro do cilindro ao longo de seu comprimento e retornou ao ponto de onde partiu. Para o revestimento de uma camada, o programa, calcula o número de ciclos que executará, com base na largura da fita e no perímetro circular do cilindro.

O número de ciclos é obtido pela divisão do perímetro por dois, dividindo-se novamente pela largura da fita ou pelo diâmetro de um só fio, se for à escolha do usuário e somando-se mais um para assegurar que a fibra estará revestindo toda a superfície do cilindro.

A fórmula para o número de ciclos será:

$$
N=\frac{P}{L}+1
$$

Para os demais valores de $\mathrm{Y}, \mathrm{Z}$ e Beta, seus valores serão alterados somando-se um incremento para cada um deles. Somente o valor para o eixo X que não terá nenhum incremento por ele representar o comprimento do cilindro.

\subsection{INCREMENTO}

No início do revestimento, os valores para os vetores $\mathrm{X}, \mathrm{Y}, \mathrm{Z}$ e Beta são os próprios valores calculados pelo programa. Após o primeiro ciclo, é adicionado aos valores calculados pelo programa um incremento de valor constante a cada novo ciclo 
que resultará em novos valores para os vetores $\mathrm{X}, \mathrm{Y}, \mathrm{Z}$ e Beta onde será simulado um giro do cilindro durante o revestimento. Para o vetor $\mathrm{Y}$ o valor do incremento é em função da largura da fita, que na superfície do cilindro projeta um valor no eixo Y. Para os vetores $\mathrm{Z}$ e Beta, os valores serão calculados por trigonometria no próprio programa.

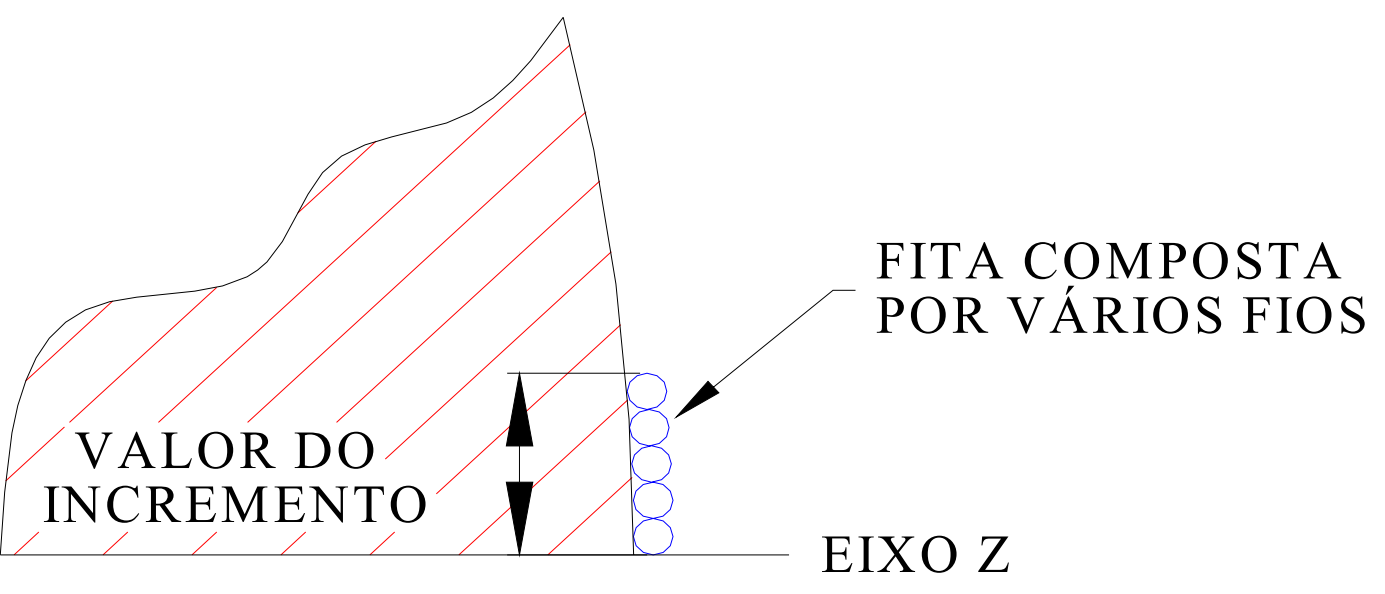

Figura 30 Incremento formado pela largura da fita.

Estes incrementos serão adicionados aos valores dos vetores até o final dos ciclos.

\subsection{NOVA SUPERFÍCIE DE REVESTIMENTO}

A cada fim de revestimento sobre a superfície do cilindro, um novo valor para o diâmetro do cilindro será obtido. Este diâmetro será a soma do diâmetro nominal mais duas vezes a espessura da fita ou diâmetro do fio.

$$
d c=D+2 . d f i l
$$


Neste novo revestimento o ângulo Alfa não necessita ser o mesmo utilizado no revestimento anterior. $\mathrm{O}$ cálculo executado pelo programa será o mesmo cálculo feito anteriormente porém com um novo diâmetro e um ângulo alfa independente, respeitando a escolha deste Alfa como no início do programa.

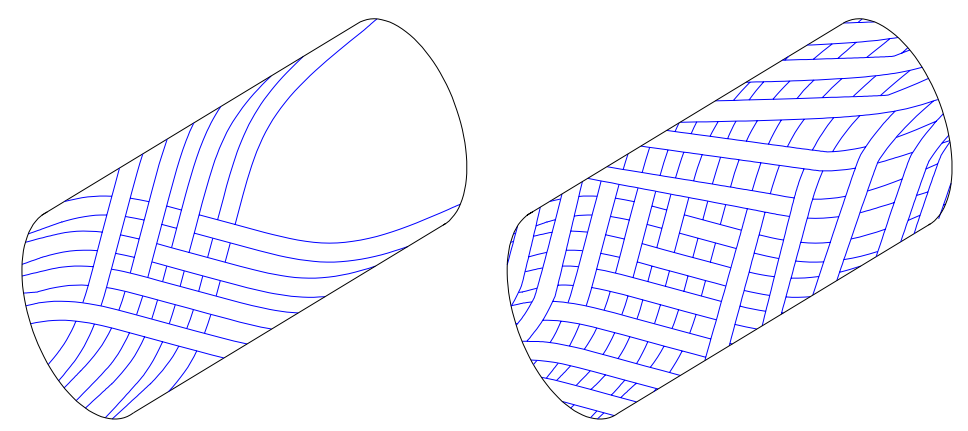

Figura 31 Cilindro revestido com várias camadas de fibra.

\subsection{ARQUIVOS}

O programa salva os valores armazenados nos vetores em um banco de dados do próprio C++ “Builder ${ }^{\circledR}$ ”, o Paradox 7, estes dados estão no formato de três colunas X, Y e Z que são lidas por Access ou Excel. Nesta planilha é possível ser analisada através do programa de CAD “Solid Edge ${ }^{\circledR}$ ”, onde os valores dos vetores são reproduzidos em linhas e podem ser avaliados.

Os valores do vetor Beta são mostrados na planilha, porém estes valores só são interessantes para o programa, para a visualização no "Solid Edge" somente os valores dos vetores $\mathrm{X}$, Y e Z são utilizados. 


\begin{tabular}{|c|c|c|c|}
\hline Coordenadas X & Coordenadas $\mathbf{Y}$ & Coordenadas Z & Ângulo Beta \\
\hline Valores para X & Valores para Y & Valores para Z & Valores para Beta \\
\hline
\end{tabular}

Tabela 4 Disposição dos valores para a planilha.

O programa $\mathrm{C}++$ Builder no qual foi desenvolvido este software, tem por “default”, salvar todos os arquivos na pasta C:/ em arquivos de programas/ Boorland/ Cbuilder6/ Projects, podendo ser alterado na própria fonte do programa, orientado a uma pasta específica ou disponibilizando ao usuário que faça a escolha da pasta que escolher. 


\section{CAPÍTULO 4}

\section{TESTE E COMPARAÇÕES}

\subsection{INTRODUÇÃO}

O programa tem o objetivo calcular as coordenadas $\mathrm{X}, \mathrm{Y}$ e $\mathrm{Z}$ para a trajetória da fibra torno de um cilindro. Esta trajetória sobre a superfície do cilindro é desenvolvida no cilindro através do olho de revestimento de uma máquina para revestimento em materiais compósitos. Essa trajetória possui formato espiral ao longo dos eixos $\mathrm{X}, \mathrm{Y}$ e Z que representam o comprimento, o diâmetro do eixo na vertical e o diâmetro do eixo na horizontal respectivamente. Com os valores para estas três coordenadas calculadas pelo programa é possível construir e visualizar o desenho formado pela trajetória ao longo do cilindro para o revestimento, através de um software CAD.

O programa também calcula o valor para o ângulo nos quadrantes compostos pelos os eixos Y e Z. Este ângulo é chamado de ângulo Beta no programa. Durante o processo de cálculo, os valores são armazenados em vetores que são impressos na tela do usuário para que o mesmo tenha uma visão dos valores no primeiro quadrante e até o 
final do revestimento. Para o programa este ângulo informa o quadrante em que o ponto está na trajetória, conseqüentemente influi no sinal de positivo ou negativo dos valores para os eixos $\mathrm{Y}$ e $\mathrm{Z}$.

Estes valores são salvos em banco de dados Paradox 7 por ser um banco de dados que vem junto com o software $\mathrm{C}++$ Builder. Com estes dados armazenados em um banco de dados, é possível abri-los em uma planilha Excel e através do program CAD “Solid Edge" é possível visualizar a trajetória descrita pelas coordenadas fornecidas pelo programa.

\subsection{METODOLOGIA}

A metodologia utilizada para testes do programa consiste em simular superfícies que serão revestidas no programa e confrontar os valores obtidos pelo mesmo com valores calculados manualmente e obter uma visualização da trajetória da fibra no cilindro, através do software CAD "Solid Edge", bem como conferir se as dimensões formadas pela trajetória estão de acordo com as dimensões do cilindro solicitado no programa. Nesta avaliação serão utilizados dois métodos: computacional e teórica que estão descritas abaixo.

Um Método de Avaliação Teórico foi desenvolvido para conferir os valores resultantes do programa e comparar com os valores obtidos através de cálculos manuais tendo como base três peças de diferentes dimensões e tipo de revestimento. Nesta comparação poderá ser constatada a existência ou não de uma margem de erro com relação aos valores teóricos calculados manualmente. 
O Método de Avaliação Computacional irá avaliar os valores obtidos no espaço tridimensional dentro do CAD. Neste processo serão avaliados dados como o valor do diâmetro, comprimento, passo e ângulo alfa, se estão coerentes com os dados que o usuário forneceu e com que o programa calculou.

O desenho formado no espaço tridimensional será transportado para um desenho bidimensional no próprio programa $\mathrm{CAD}$, onde poderão ser verificadas as dimensões calculadas do programa.

O desenho formado no espaço tridimensional será salvo como extensão par sendo o padrão do modelo sólido do "Solid Edge”. Para a avaliação de dimensões será utilizado o módulo de extensão dft que através do modelo em extensão par cria o desenho do modelo sólido em desenho bidimensional, onde podem ser avaliadas as dimensões do desenho do modelo sólido.

\subsection{SEQÜÊENCIA DE AVALIAÇÃO}

O usuário entrará com os dados externos ao programa que serão: diâmetro externo do cilindro, comprimento útil e ângulo Alfa ou passo. O usuário também escolherá dados internos existentes no programa para o cálculo e validação dos valores para o primeiro quadrante que serão: Tipo de fibra, número de fios e precisão.

Com estes dados o programa calcula os valores do primeiro quadrante. Nesta altura do processo, o programa avalia os valores do ângulo Alfa e do passo. Se o usuário forneceu o passo, o programa calcula o ângulo Alfa e vice-versa. O programa testa o 
valor do passo, se for maior que o comprimento da peça ou menor que a largura da fita, o valor fornecido é reprovado e os campos de ângulo Alfa e Passo tem seus valores apagados e uma mensagem solicita um novo valor para o ângulo Alfa ou passo mostrando qual foi o erro detectado nos cálculos, seja passo acima do comprimento ou menor que a largura da fita.

O ângulo Alfa também obedece a uma regra do programa, o ângulo não deve ser menor que zero e maior que noventa graus. No caso de ângulo de noventa graus o valor do passo será a largura da fita e o valor do ângulo Alfa será calculado, adotando como Alfa teórico noventa, mas para cálculo das coordenadas será mostrado e adotado o ângulo calculado. Obtendo os valores do primeiro quadrante, serão salvos em banco de dados que podem ser lidos por uma planilha de Excel.

Uma tabela com valores para as coordenadas foi criada com base no sistema métrico, na unidade de milímetros. Com os valores desta tabela serão calculados manualmente os valores das coordenadas $\mathrm{X}, \mathrm{Y}$ e $\mathrm{Z}$ e com estes valores será criado um modelo sólido para servir de padrão para os testes.

Os valores obtidos pelo programa serão confrontados com os valores calculados manualmente, se estiverem incoerentes, será checado e alterado o código fonte. Sendo permitido uma margem de erro de 0,01 (um centésimo) para mais ou para menos, sendo o campo de tolerância de 0,02 (dois centésimos). Com estes valores também será criado um modelo sólido e será confrontado com o modelo criado a partir da tabela de valores criada citada acima. A margem de erro será a mesma para ambos os casos e no caso de uma incoerência, será analisado e alterado o código fonte do programa. 
Os valores para o eixo $\mathrm{X}$ ou o comprimento útil da peça, a tolerância tem o seu valor aumentado devido a coordenada $\mathrm{X}$ estar em função dos cálculos no eixo $\mathrm{Y}$, por isso o valor da tolerância para o eixo $\mathrm{X}$ poderá ocorrer da ordem de até 1,0 (um milímetro). 


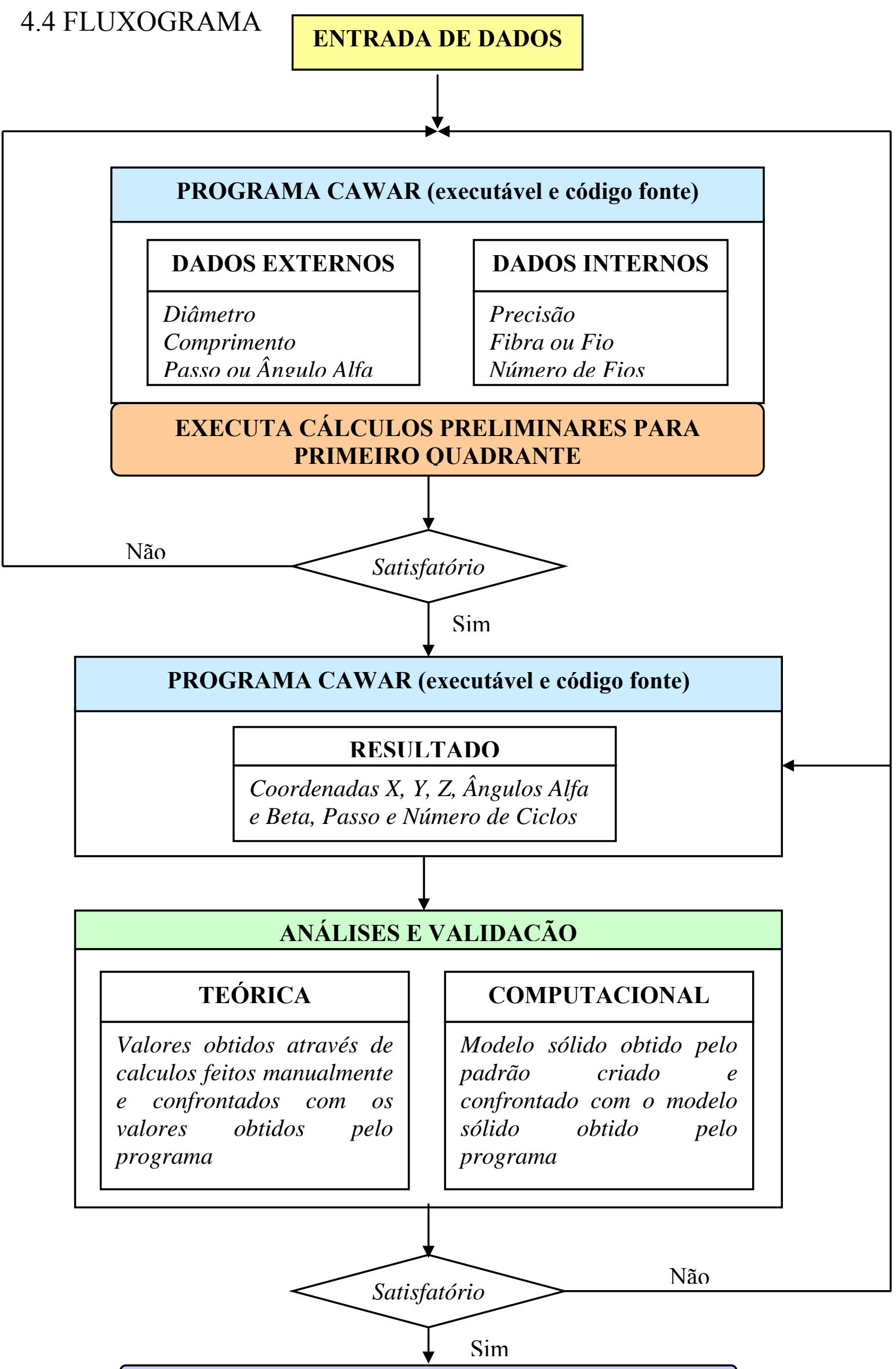




\subsection{PADRÕES DE TESTE}

Os padrões de teste definidos foram cilindros de 20 milímetros de diâmetro por 104 milímetros de comprimento. A fibra escolhida foi a IME 6 de 12000 filamentos com 10 fios. Esta fibra tem um diâmetro de 0,74 milímetros. A largura da fita será de 7,40 milímetros e o ângulo Alfa é de 30 graus.

A motivação da escolha deste cilindro foi devido ao grande número de dados que será gerado pelos cálculos para facilitar a comparação dos mesmos com os dados obtidos pelo programa.

Os valores obtidos foram calculados e auxiliados pelos programadas de CAD AutoCad ${ }^{\circledR}$ e Solid Edge ${ }^{\circledR}$. No software AutoCad ${ }^{\circledR}$ foi simulado em duas dimensões os valores para os eixos Y e Z e os valores para o ângulo Beta. No software Solid Edge foi possível verificar numa visão tridimensional o cilindro com as linhas de revestimento recobrindo toda a superfície do mesmo.

Os valores foram obtidos a partir de cálculos simples de trigonometria. Somente o eixo Y que será calculado com divisão de acordo com a escolha do usuário. As divisões do eixo Y é uma escolha dada ao usuário, ele pode dividir o eixo Y em 0,25, 0,50, 1,00 e 2,00, ficando a critério do mesmo segundo a sua necessidade.

Quanto maior for a precisão, maior será a quantidade de valores para a trajetória da fibra. Numa escolha de 0,25 o eixo Y terá subdivisões de 0,25 mm. Para saber o 
número de pontos gerados pelo programa no primeiro quadrante, ou seja, o número de valores para os eixos $\mathrm{Y}$ e $\mathrm{Z}$ entre os ângulos de zero a noventa graus, basta dividir o valor do raio do cilindro pelo valor da precisão (veja equação número 24). O resultado será o número de pontos do primeiro quadrante e se multiplicarmos por quatro, teremos o número de pontos em uma volta do cilindro, ou seja, os valores para os eixos $\mathrm{Y}$ e $\mathrm{Z}$ em trezentos e sessenta graus.

Se na situação acima o usuário estivesse escolhido uma precisão de dois mm, o número de pontos para o primeiro quadrante cai oito vezes. Por exemplo, num cilindro de $50 \mathrm{~mm}$ de diâmetro, e uma precisão de $0.25 \mathrm{~mm}$, o programa teria 100 pontos no primeiro quadrante. Para um mesmo cilindro, mas com precisão de $0,50 \mathrm{~mm}$ teríamos 50 pontos, para uma precisão de $1,00 \mathrm{~mm}$ teríamos 25 pontos e para uma precisão de 2,00 mm teríamos 12 pontos.

A quantidade de pontos aumenta a precisão da trajetória, porém aumenta na mesma proporção o número de dados resultante dos cálculos.

O cálculo dos valores do eixo Z é obtido pela fórmula de Pitágoras: Hipotenusa ao quadrado é igual à soma dos catetos ao quadrado.

$$
\operatorname{hip}^{2}=\operatorname{cat} 1^{2}+\operatorname{cat} 2^{2}
$$

Os valores para o vetor Z são os valores encontrados para o cateto adjacente ao ângulo Beta para cada valor do vetor Y. Nesta fórmula, os valores do vetor $\mathrm{Y}$ 
desempenham a função do cateto oposto do triângulo retângulo, ao ângulo Beta e o raio do cilindro desempenha a função da hipotenusa. Para os valores do eixo $\mathrm{Z}$ tem se:

$$
Z_{[i]}=\sqrt{R^{2}-Y_{[i]}^{2}}
$$

Os valores para o eixo $\mathrm{X}$ são obtidos pelo cálculo do cateto adjacente do triângulo retângulo onde os valores do vetor Y representam o cateto oposto e o ângulo Alfa dado pelo usuário representa o ângulo par ao cálculo da tangente.

Os valores para o vetor X são obtidos pela fórmula:

$$
X_{[i]}=\frac{P a s s o \times \beta}{360}
$$

Os valores para o ângulo Beta não têm um interesse específico para o usuário como os valores para os eixos $\mathrm{X}, \mathrm{Y}$ e $\mathrm{Z}$, porém são de grande importância para o controle interno do programa e o usuário pode ter uma idéia mais clara de qual quadrante o processo está no momento do cálculo da trajetória. A fórmula para o cálculo dos valores do ângulo Beta segue:

$$
\beta=\arccos \left(\frac{Y_{[i]}}{\text { Raio }}\right)
$$

\subsection{TABELA DE VALORES}

O programa calcula e armazena os valores para o revestimento até que o cilindro revestido esteja por completo revestido em uma camada de fibra. Abaixo são mostrados 
os desenhos gerados pelo software Solid Edge ${ }^{\circledR}$, para ilustrar como ficarão o cilindro e a trajetória da fibra na superfície do mesmo. Os valores são para um ciclo de revestimentos em um cilindro de $20 \mathrm{~mm}$ de diâmetro por 104 de comprimento. A largura da fita que revestirá este cilindro é de 7,54 mm. Este ciclo compreende a um revestimento do topo inicial do cilindro ao final do mesmo, um giro de 180 graus no final, mais um revestimento do final do cilindro ao topo inicial e um giro de 180 graus no topo do cilindro mais um incremento que se refere à largura da fita de revestimento.

O desenho abaixo se refere ao revestimento do topo inicial do cilindro até o final do comprimento do mesmo.
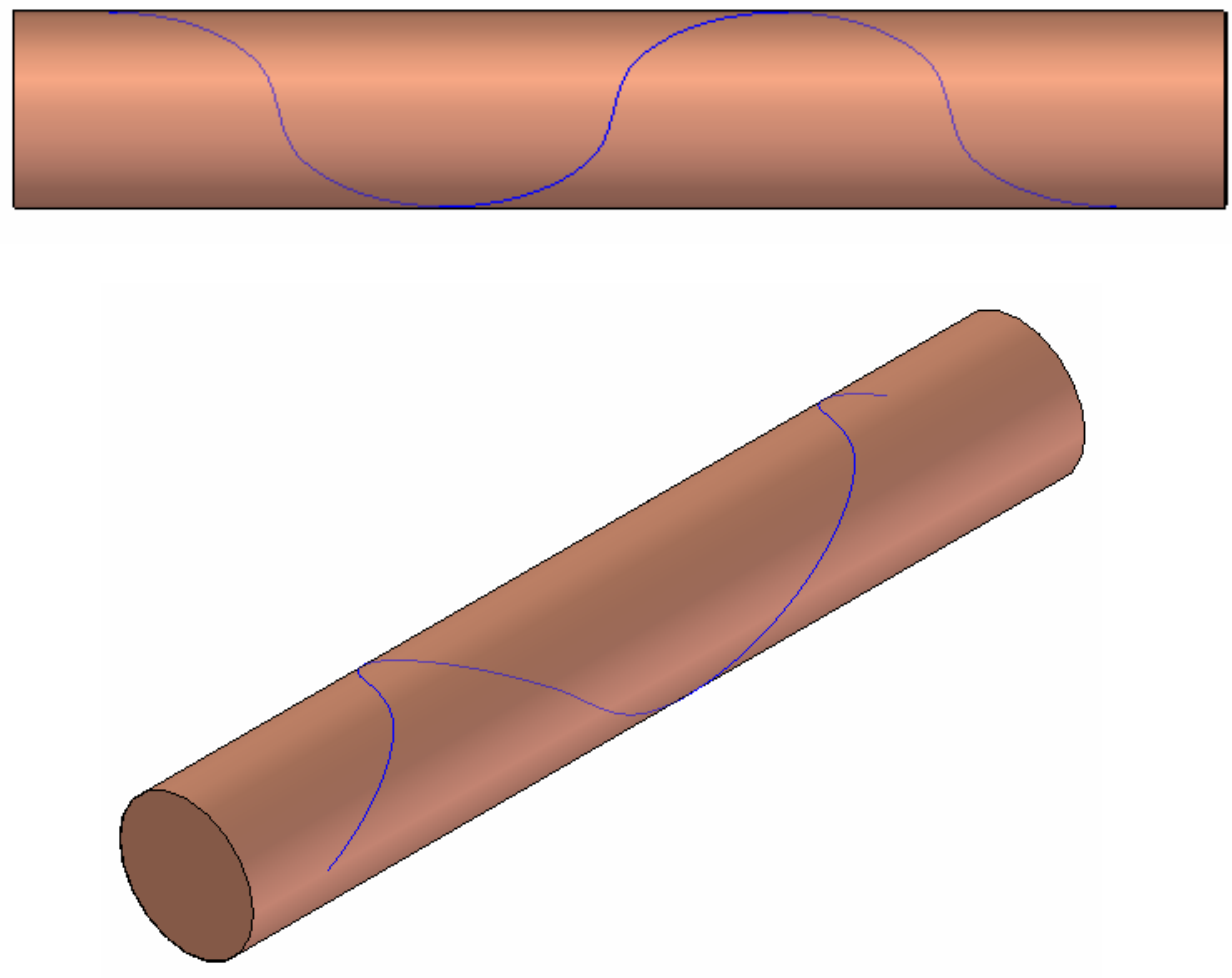

Figura 32 Trajetória da fibra ao longo do cilindro. 
O desenho abaixo ilustra a trajetória descrita pela fibra, destacada em amarelo, no giro de 180 graus no final do cilindro.

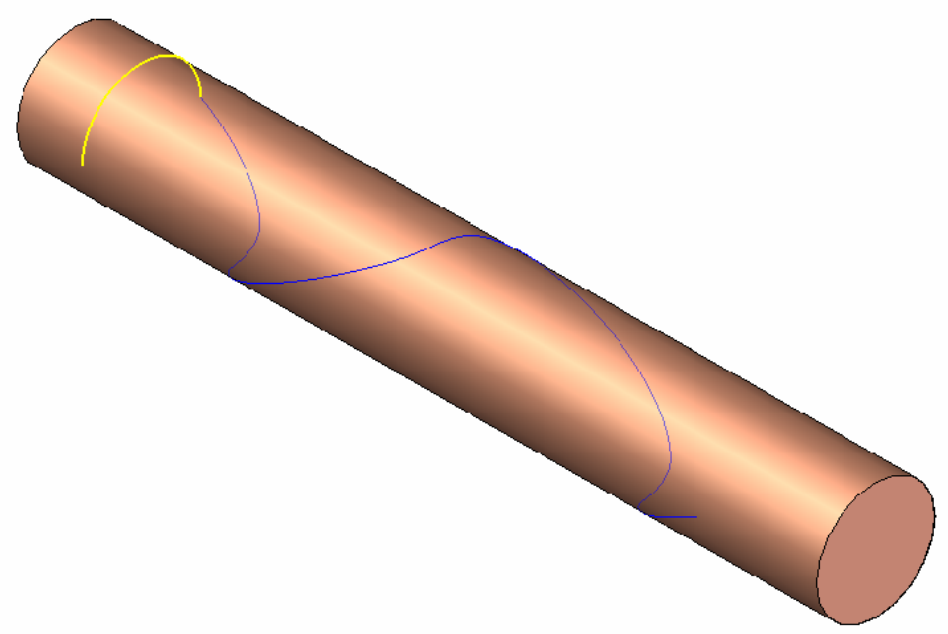

Figura 33 Volta de 180 graus no final do cilindro.

A figura 19 ilustra a trajetória da fibra, destacada em amarelo, do final do comprimento ao topo inicial com as demais trajetórias já calculadas e inseridas no cilindro.
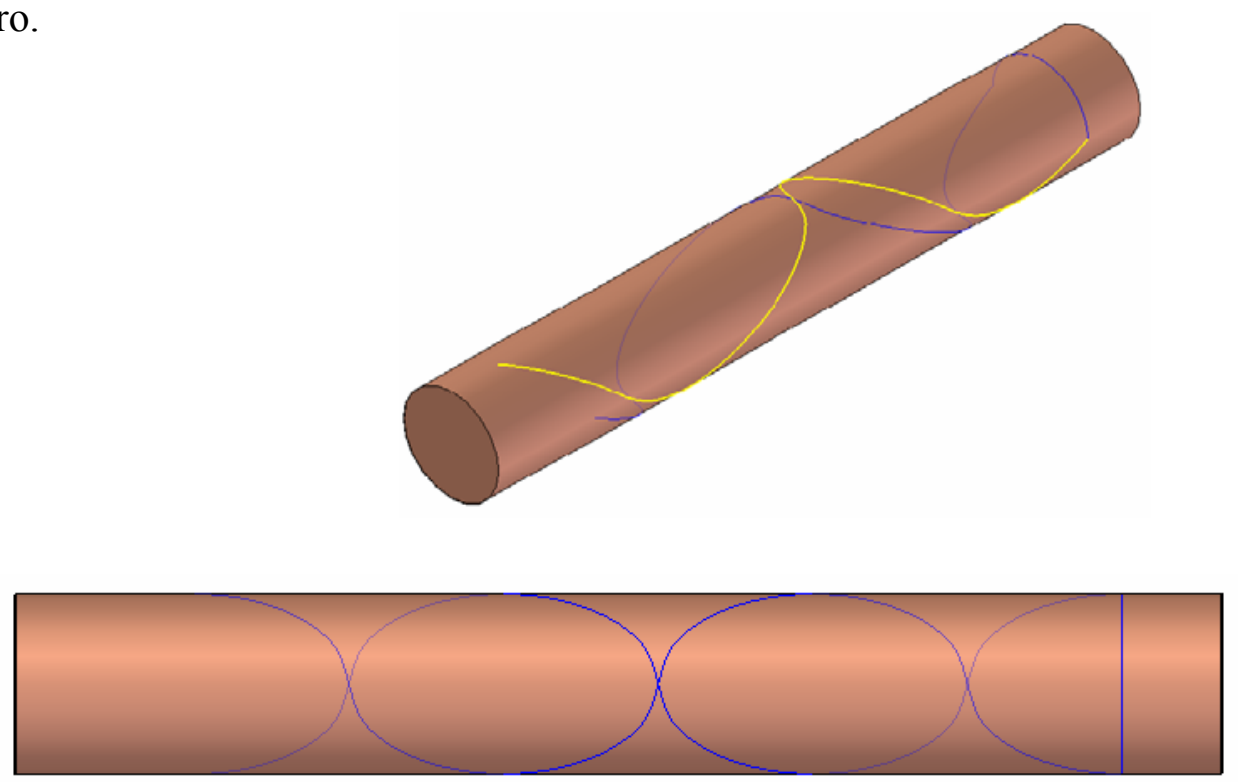

Figura 34 Trajetória da fibra de volta ao topo inicial. 
A Erro! A origem da referência não foi encontrada.0 ilustra o giro de 180 graus no topo inicial do cilindro e mais o incremento para um novo ciclo. Este é o primeiro ciclo de revestimento.

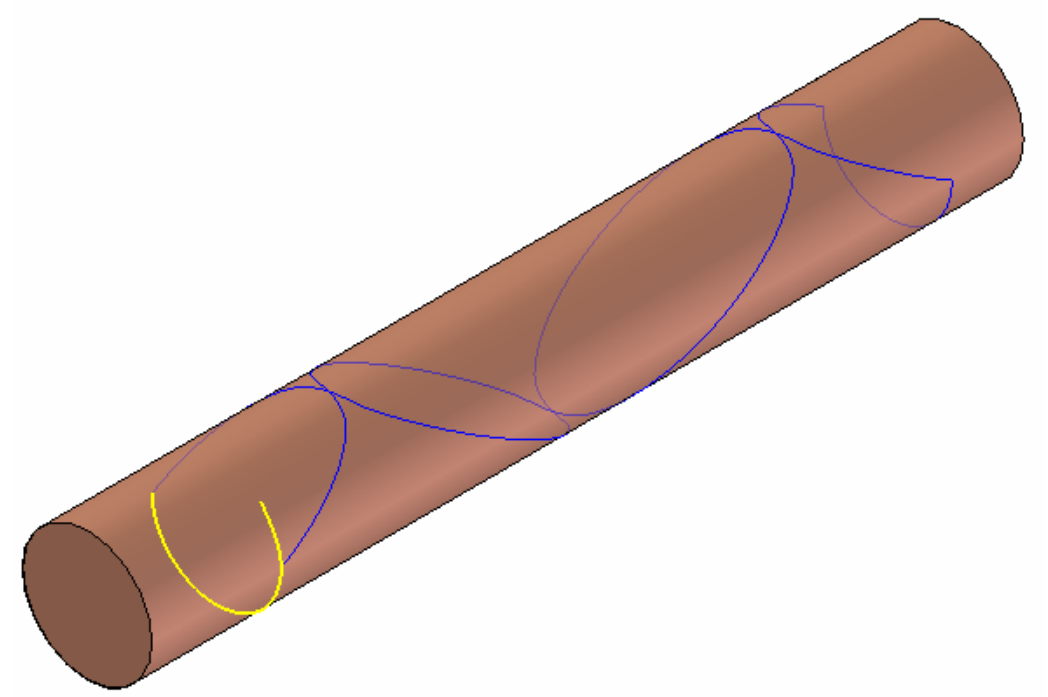

Figura 35 Giro de 180 graus no topo inicial mais incremento. 


\section{CAPÍTULO 5}

\section{RESULTADOS E DISCUSSÕES}

\subsection{ANÁLISE DA TRAJETÓRIA}

CARVALHO (1996) cita que um dos melhores resultados quando se está desenvolvendo um projeto com materiais compósitos é saber como obter o máximo benefício das propriedades inerentes do material. Em geral projetos e técnicas de otimização tem tido bons resultados atualmente. Entretanto, no caso de "Filament Winding”, aspectos restritivos na manufatura, como a precisão das máquinas e equipamentos para desenvolver a trajetória calculada, mostram resultados melhores obtendo-se a melhor trajetória calculada para a fibra dentro dos limites da capacidade da manufatura para executar o processo de “Filament Winding”.

Como já citado anteriormente, neste trabalho foi abordada apenas trajetória geodésica, sendo fornecido pelo usuário valores como diâmetro e comprimento do cilindro, passo ou ângulo para revestimento e a escolha da fibra e largura da fita. 
Os valores resultantes do programa foram os mesmos obtidos através dos cálculos. O gráfico resultado destes valores foram conseqüentemente os mesmos obtidos. O desenho formado pela trajetória mostrou uma linha no formato helicoidal sobre a superfície do cilindro. Sendo assim, o programa apresentou o resultado esperado no que diz respeito aos cálculos.

O desenho e os dados da trajetória variam de acordo com o ângulo ou passo fornecidos pelo usuário, diâmetro do cilindro e o comprimento do mesmo, entretanto o formato de hélices em volta do mesmo é mantido.

\subsection{ARMAZENAGEM DE DADOS EM ARQUIVOS}

Uma das grandes vantagens de se trabalhar com a linguagem $\mathrm{C}++$, quando comparadas as demais linguagens de programação, é seu suporte embutido para arquivos, ela disponibiliza funções específicas para o tratamento de arquivos em disco.

Almeida (2003) cita que ao se trabalhar com grande quantidade de dados, tornase essencial o armazenamento dos mesmos para sua posterior reutilização. Salvar e carregar dados são vitais para a grande maioria dos programas que escrevemos.

É importante também ser determinado um local onde os arquivos serão salvos, tendo a opção de ser mudado pelo usuário quando este julgue necessário.

Os dados gravados em arquivos no programa Cawar têm a sua extensão mudada para *.xls, ou seja, estão no formato de planilhas que podem ser abertas em excel e 
submetidas a análise no Solid Edge. O Solid Edge, quando solicitada leitura de planilhas, não admite que haja intersecção em uma mesma planilha, as coordenadas de uma planilha não podem fazer com que em momento algum tenham uma intersecção no desenho. Para resolver este problema, a análise da trajetória, já que se trata de várias intersecções durante o processo, foi tratada em arquivos para ciclos, sendo que cada ciclo compreende a um revestimento e um giro de 180 graus no cilindro, somente no topo inicial do cilindro que ocorrerá um giro de 180 graus mais o valor do incremento.

Portanto, para um mesmo arquivo, existem várias planilhas de acordo com o número de ciclos para o revestimento. Estes arquivos ficam na mesma pasta e possuem extensão seqüencial para que possam ser mantidos em ordem de reproduzir o desenho da trajetória no Solid Edge.

\subsection{ANÁLISE DOS VALORES DOS DADOS}

Os dados gerados pelo programa foram confrontados com os valores obtidos através de cálculos manuais a fim de validar sua existência. Os valores obtidos pelos cálculos foram colocados em planilha mostrada acima e os dados obtidos pelo programa foram armazenados e confrontados visualmente com os dados calculados. A exatidão se confirmou e o resultado satisfez a expectativa.

Também foram simuladas situações que levariam a erros de cálculos e observado o comportamento do programa. Entrada de dados tais como passo acima do comprimento do cilindro, ângulo que resultaria num passo superior ao comprimento do cilindro. Ângulos maiores que 90 graus, ou seja, um enrolamento no sentido contrário 
do previsto pela máquina de Filament Winding, ângulos compreendidos entre 270 a zero graus, o que resultaria num enrolamento com rotação inversa. Em ambos os casos o programa exibi a mensagem de erro e o problema ocorrido.

Também foi observado que quanto maior for a precisão melhor resultou a qualidade visual do desenho gerado pelos pontos. A escolha da precisão influencia diretamente na qualidade de visualização dos desenhos gerados pelo programa, isto não significa que numa quantidade menor de dados gerados pelo programa devido à escolha da precisão ter sido um valor maior como 1,00 ou 2,00 mm comprometa a trajetória gerada.

Fornecido os dados necessários para o cálculo da trajetória, ela será a mesma independente da escolha da precisão. A precisão afetará única e exclusivamente a qualidade de visualização.

A possibilidade de visualizar o primeiro quadrante deu uma visão clara de como seria o comportamento da trajetória ao longo do comprimento. No primeiro quadrante também é possível visualizar a quantidade de valores para todos os eixos e as variações do ângulo Beta de zero a 90 graus. Foi possível ter uma idéia clara do eixo X, durante o processo no primeiro quadrante, o eixo X mostra suas divisões e percebe-se que quanto maior a precisão e menor o ângulo ou maior o passo, as divisões do eixo $\mathrm{X}$ assumiram valores bem mais altos que os valores do eixo $\mathrm{Y}$ e quanto maior for o ângulo ou menor o passo, bem como menor a precisão, observa-se que o os valores do eixo $\mathrm{X}$ assumiram valores inferiores aos do eixo Y. 
CAPÍTULO 6

\section{CONCLUSÕES E SUGESTÕES}

\subsection{CONCLUSÕES}

Os objetivos deste trabalho foram alcançados com resultados satisfatórios. A metodologia previa um teste de validação simples, porém eficiente para validar o programa e analisar os dados obtidos. A linguagem de programação foi à mesma utilizada por Johan e Carvalho quando desenvolveram seus trabalhos na Bélgica, isto também mostra que apesar da linguagem $\mathrm{C}$ ter sofrido atualizações ao longo dos anos, continua sendo uma linguagem confiável e que atende as necessidades tanto acadêmicas como comerciais da atualidade.

A visualização gráfica atendeu a necessidade deste trabalho entendendo que este é o primeiro passo para um programa que tem seu código fonte aberto e que com certeza será aperfeiçoado, modificado e estendido a outras funções e módulos como o controle de servos e motores para Filament Winding. 
Sendo assim o programa Cawar está apto a calcular trajetória para cilindros geodésicos conhecendo-se o diâmetro externo, comprimento, passo ou ângulo Alfa, o tipo de fibra e a largura da fita ou número de fios.

\subsection{SUJESTÕES PARA TRABALHOS FUTUROS}

- Desenvolver um algoritmo que calcule a trajetória da fibra através de Splines, esta técnica de aproximação suaviza as curvas da trajetória.

- Desenvolver um algoritmo que calcule a trajetória através dos protocolos IGES e STL sem com que o usuário tenha de fornecer os dados, mas através do próprio desenho da peça o programa calcule e desenvolva a trajetória.

- Desenvolver um algoritmo que permita o cálculo de peças não geodésicas.

- Desenvolver um algoritmo que controle os motores e servos de uma máquina de Filament Winding.

- Desenvolver interface gráfica de modo que o usuário consiga visualizar o desenho da trajetória e a superfície sem a necessidade de um programa CAD. 


\section{REFERÊNCIAS BIBLIOGRÁFICAS}

CARVALHO, J. (1996). Computer Integrated Desing Optimisation and Manufacturing of Filament Wound Parts. V1, p5-198.

LOSSIE, M. (1994) Computer Integrated Desing Optimization and Manufacturing of Filament Wound Parts, p. 50.

MATHEWS, F.L.; RAWLINGS, R.D. (1994). Composite Materials: engineering and science. London, Chapman \& Hall.

BEAUMONT, P.W.R. (1989). The failure of fiber composites: an overview. Journal of Strain Analysis. V.24, n4, p. 189 - 205.

CALLISTER W. D. (1994). Materials Science and Engineering: An introduction, third edition. P.521-531. New York, John Wiley \& Sons, Inc.

HULL D. (1981). An introduction to composite materials. London, Cambridge University Press.

HAISHENG LI, YOUNDONG LIANG and HUJUN BAO (2005). CAM system for filament winding on elbows. Journal of Materials Processing Technology. v. 161 p. 491-496.

CHEOL-UNG KIM, JI-HO KANG, CHANG-SUN HONG and CHUN-GON KIM (2005). Optimal design of filament wound structures under internal pressure based on the semi-geodesic path algorithm. Composite Structures v.67 p. 443-452.

W. POLINI AND L. SORRENTINO (2005). Influence of winding speed and winding trajectory on tension in robotized filament winding of full section parts. Composite Science and Technology. Artigo em impressão.

HEATHER L. GIACOLETTO (2002). The art of filament winding. Reinforced Plastics. v.46 p. $30-31$. 
HEATHER L. GIACOLETTO (1998). Automation sets filament winding on the right path. Reinforced Plastics. v. 42 p. 48-50.

B. S. Johansen, Aa. Lystrup and M. T. Jensen (1998). CADPATH: a complete program for the CAD-, CAE- and CAM-winding of advanced fibre composites. Journal of Materials Processing Technology v.77 p. 194-200.

SCHOLLIERS JOHAN (1992). Filament Winding: a Manufacturing Technique for Composites. v. 1 p. $5-59$.

FILHO, GERALDO DANTAS S. (2001). Comportamento Mecânico do Poliuretano Derivado de Óleo de Mamona Reforçado por Fibra de Carbono: Contribuição para o Projeto de Hastes de Implante de Quadril. v. 1

SMITH, BREADFORD; RINAUTDOT, GAYLEN R.; REED, KENT A. e WRIGHT, THOMAS (1998). Initial Graphics Exchange Specification (IGES). v. 4 p. 118 - 121. MAIA, LUIZ PAULO e MORELLI, EDUARDO (2003). Programação Orientada a Objetos.

ALMEIDA, WALDIR MARTINS DE (1996). Conhecendo o C++ Builder CONSTATINE, LARRY L.(2000). Fundamentos do Desenho Orientado a Objeto com UML.

CadFil - site: $\underline{\text { http://www.crescon.fsnet.co.uk/cadfil_axsym_program.htm }}$

Fiber Grafix - site: $\underline{\text { http://www.entec.com/fgx.shtml }}$

Pattern Máster - site: http://www.material.be/products/cadwind.html

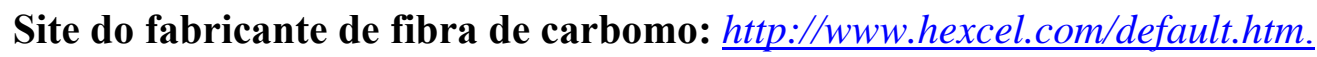

